\title{
The 1986 Kalamata (South Peloponnesus) Earthquake: Detailed Study of a Normal Fault, Evidences for East-West Extension in the Hellenic Arc
}

\author{
H. Lyon-CAEn, ${ }^{1}$ R. ARmijo, ${ }^{2}$ J. Drakopoulos, ${ }^{3,4}$ J. Baskoutass, ${ }^{4}$ \\ N. Delibassis, ${ }^{3}$ R. GaUlon, ${ }^{1}$ V. Kouskouna, ${ }^{3}$ J. LatousSaKis, ${ }^{4}$ \\ K. Makropoulos ${ }^{3}$ P. Papadimitriou, ${ }^{1}$ D. Papanastassiou, ${ }^{4}$ and G. Pedott ${ }^{5}$
}

\begin{abstract}
Tectonic and seismological data collected in the field following the September 13, 1986, Kalamata earthquake (south Peloponnesus) are presented and analyzed to discuss the earthquake rupture process and the regional tectonics. The event occurred on the Kalamata normal fault whose trace was mapped with SPOT images and topographic and field observations. This fault is part of an approximately NNW-SSE en échelon system cutting through the Hellenic nappes. The fault striking $\mathrm{N}^{\circ} 5^{\circ} \mathrm{E}$ on the average, with a dip of about $50^{\circ}$, has a minimum cumulated Quaternary throw of the order of $1 \mathrm{~km}$. The measured coseismic slip is $6-18 \mathrm{~cm}$ over a length of 6 $\mathrm{km}$. The main shock focal mechanism obtained from long-period waveform modeling (strike $=201^{\circ}$ $\left(+10^{\circ},-20^{\circ}\right)$, dip $=45^{\circ} \pm 5^{\circ}$, rake $\left.=283^{\circ}\left(+10^{\circ},-25^{\circ}\right)\right)$ represents almost pure east-west extension and is in good agreement with tectonic observations. The centroid depth is constrained to $5 \pm 3$ $\mathrm{km}$ and the seismic moment to $7.0 \pm 2.5 \times 10^{17} \mathrm{~N} \mathrm{~m}$. Over 700 aftershocks, located by a 16-station network installed after the earthquake for a period of 2 weeks, define two clusters separated by a "gap" of aftershock activity, from the surface to a depth of about $10 \mathrm{~km}$. The main cluster, to the south, defines a $45^{\circ}$ west dipping plane which lies on the downward extension of the fault mapped at the surface. Focal mechanisms of aftershocks on this fault plane are homogeneous and represent $\mathrm{E}-\mathrm{W}$ extension as the main shock. In contrast, the majority of focal mechanisms in the uppermost part of the footwall show more or less E-W compression, probably corresponding to postseismic stress release. The northern cluster of aftershocks is very dense and located away from the surface rupture, within a relay zone between the Kalamata and the next en échelon faults to the NW, the Thouria faults. There focal mechanisms represent extension from about $\mathrm{N} 15^{\circ}$ to ${\mathrm{N} 70^{\circ}}^{\circ}$ and $\mathrm{N} 20^{\circ}$, corresponding mostly to fault reactivation in an area where nonrigid deformations prevail. The main shock probably initiated in this relay zone 3-4 s before the rupture front reached the main fault plane and released most of the energy there, the rupture presumably propagating southward. The focal mechanism of the Kalamata earthquake and that of the April 27, 1965, earthquake located to the northwest of Crete, as well as the regional active normal fault pattern, imply that $\mathrm{E}-\mathrm{W}$ extension oblique to the Hellenic arc is presently the dominant tectonic regime. E-W stretching occurs partly on reactivated NW-SE faults parallel to the Hellenic structures but mostly on newly formed N-S normal faults across those structures. The latter faults are responsible for the apparent segmentation of the Hellenic belt from southern Peloponnesus to Crete. The existence of active $\mathrm{E}-\mathrm{W}$ extension in this region implies a recent change in the tectonic regime and consequently a change in boundary conditions at the subduction zone, probably in response to the incoming margin of Africa.
\end{abstract}

\section{INTRODUCTION}

The September 13, 1986, earthquake ( $M_{L}=5.5$ (Athens), $M_{s}=5.8$ (National Earthquake Information Service, NEIS)) that destroyed a large part of the city of Kalamata in southwestern Peloponnesus (maximum intensity $X$ ) is the first shallow event in the overriding continental crust of the Aegean between Corinth and Crete to be well recorded teleseismically and to have produced clear surface faulting.

\footnotetext{
${ }^{1}$ Laboratoire de Sismologie, Institut de Physique du Globe, Paris, France.

2 Laboratoire de Tectonique, Institut de Physique du Globe, Paris, France. Greece.

Division of Geophysico-Geothermy, University of Athens,

4 Seismological Institut, National Observatory of Athens, Greece.

5 IRIGM, Observatoire de Grenoble, France

Copyright 1988 by the American Geophysical Union.

Paper number 88JB03484.

$0148-0227 / 88 / 88 \mathrm{JB}-03484 \$ 05.00$
}

Because of the low level of seismicity compared with that of areas nearby like the gulf of Corinth or Thessaloniki and the apparently long recurrence time of medium- or largesize earthquakes, the tectonic activity in this area has been somewhat overlooked up to now. In particular, no focal mechanisms were available for this region. The detailed study of the Kalamata earthquake presented here bears both on the seismotectonics of the Aegean and on earthquake rupture processes.

The Aegean area has long been recognized as a region of intense and widespread continental extension, but the mechanisme of this extension are atill a matter of debate [e.g., McKenzie, 1978; Le Pichon and Angelier, 1979; Mercier et al., 1979a; Jackson and McKenzie, 1983]. The direction of active extension is approximately north-south in Thessaloniki [Soufleris and Stewart, 1981; Mercier et al., 1979b; Hatzfeld et al., 1987], in the gulf of Corinth [Jackson et al., 1982; Sebrier, 1977] and probably also in the Cyclades, the northern Aegean, and western Anatolia [Angelier et al., 1982]. Such north-south extension, despite small episodic or local fluctuations, appears to be the dominant tectonic regime since the Pliocene [Mercier et al., 1979a; Angelier et al., 


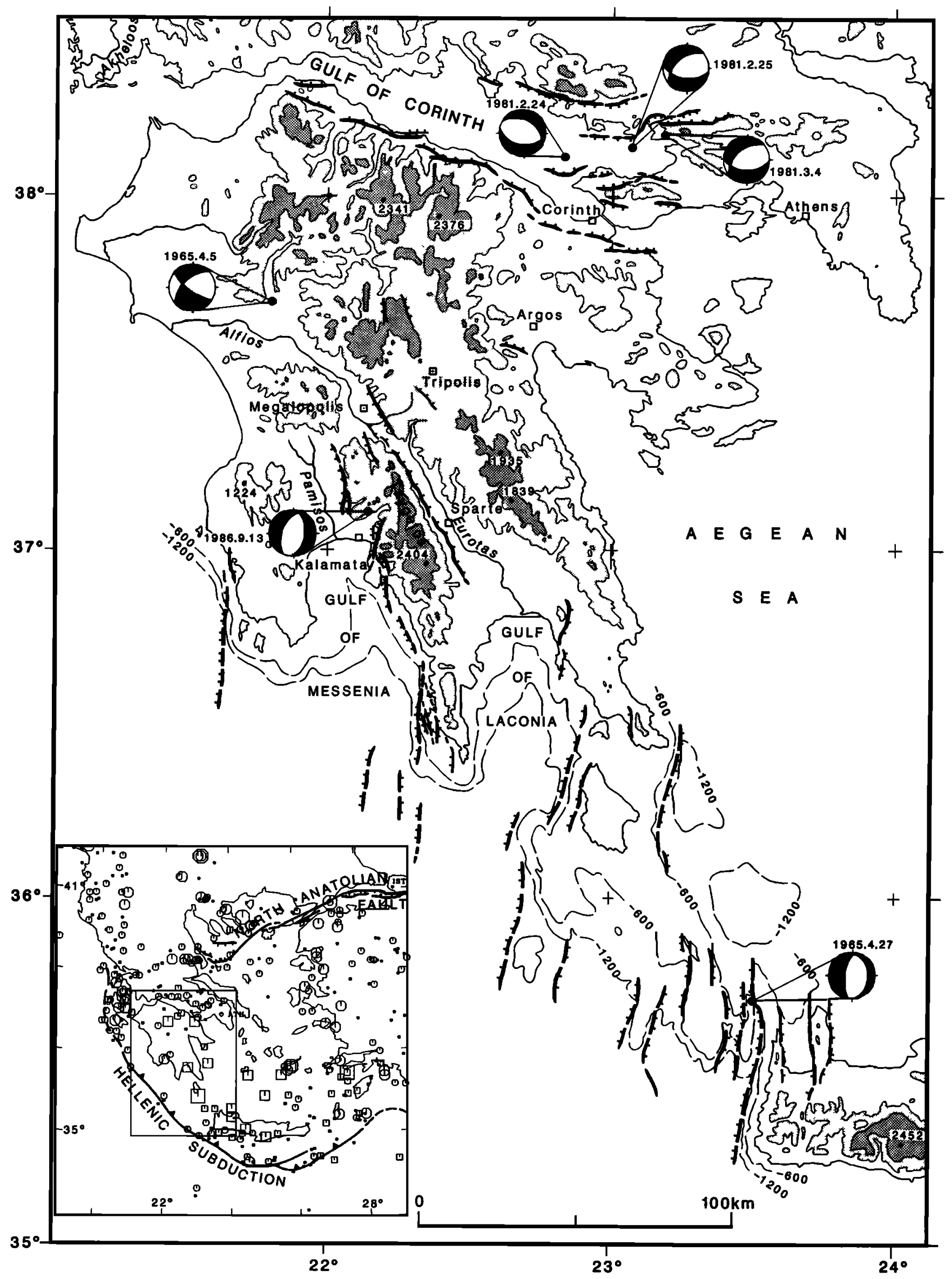


1982; Lyberis, 1984]. In contrast with this apparent uniformity in most of the Aegean and western Anatolia, the active and Quaternary tectonics just to the north of the Hellenic trench, from southern Peloponnesus to Crete and Rhodes, is more complex: both north-south and east-west extension has been observed [Angelier et al., 1982]. However, local microtectonic measurements [Angelier, 1979] and Landsat image interpretation [Armijo et al., 1986] (Figure 1) suggest that the most recent movements are being accommodated by north-south normal faulting and east-west extension.

In this paper we present both tectonic and seismological data collected in the field following the September 13, 1986, earthquake in Kalamata. We mapped the Kalamata fault and other active faults in the area with the aid of air photographs, topographic maps, and high-resolution SPOT images. We evaluated both the long-term (structural and morphological) offsets and the 1986 coseismic slip. We conetrain the focal mechanism and the centroid depth of the main shock using waveform modeling and present an analysis of the locations and individual focal mechanisms of aftershocks recorded by a portable network of 16 stations for a period of 10 days. Papazachos et al. [1988] already described the main shock focal mechanism from first motion readings and the results of a 3-day aftershocks study with a network of five portable stations. The quality and large amount of data enable us to constrain precisely the geometry of the afterahock zone. We then combine seismological and tectonic observations for a discussion of both the rupture process of this earthquake and the regional east-west extensional tectonics.

\section{Tectonic OBSERvations}

\section{Quaternary Tectonic Setting}

The structure and topography of southern Peloponnesus is marked by a series of three high (1200-2400 m), long (50$100 \mathrm{~km}$ ), approximately NNW-SSE ranges, separated by the two parallel depressions of the Pamisos and Eurotas rivers (Figure 1). Those ranges and basins extend southward into the Aegean Sea by pronounced peninsulas separated by the gulfs of Messenia and Laconia. The bulk of this internal relief ( $\geq 3500 \mathrm{~m}$ ) postdates the Miocene Hellenic nappe emplacement, apparently as a consequence of both

Fig. 1. (opposite) Seismotectonic map of the Peloponnesus and adjacent areas. Topography and bathymetry (in meters) are from the International Bathymetry Chart of the Mediterranean [UNESCO, 1981] at 1:1, 000, 000 scale. Contours are at 600 and $1200 \mathrm{~m}$. Active faults are modified from Jackson et al. [1982] and Lyberis et al. [1982] and from Landsat image interpretation [Armijo et al., 1986]. Inferred faults are shown segmented. All faults are mainly normal and the tics point to the downdropped compartment. Fault plane solutions of shallow events are from McKenzie [1972] for the April 5, 1965 event, from Jackson et al. [1982] for the 1981 events, from this study for the April 27, 1965 (Figure A1) and the September 13, 1986, (Figure 9a) events. Inset shows the tectonic framework and earthquakes with magnitude larger than 5.0 in the Aegean region from 1900-1986. Circles are for events less than $40 \mathrm{~km}$ deep; squares are for events more than $40 \mathrm{~km}$ deep. Earthquakes are classified in four groups of magnitude $(M<5.5,5.5<M<6.5,6.5<M<7.5$, $7.5<M<8.5)$ corresponding to the different sizes of symbols. late Hellenic compression (late Miocene-Pliocene?) and subsequent Pliocene-Quaternary extension. Compression may have initiated the formation of internal relief by large-scale, gentle NW-SE folding of the nappe structure. This led to updoming of ranges at anticlinoria and downwarping of basins at synclinoria [Institute of Geology and Mineral Exploration (IGME), 1986]. Extension apparently amplified this smooth, "compressional" relief by large, often en échelon normal faults oriented approximately N-S which roughly broke at the boundaries between ranges and basins and produced more localized uplift and downdrop on them. Particularly large Quaternary and active normal faults are clearly visible on satellite images along the two edges of the Taygetos range (Figure 1) [Armijo et al., 1986] but have not been described in detail so far. The September 13, 1986, earthquake broke along one of those normal faults whose trace runs along the western mountain front of the Taygetos massif, only about $4 \mathrm{~km}$ east of Kalamata (Kalamata fault, Plate 1 and Figures 2, 3, and 4) (Plate 1 is shown here in black and white. The color version can be found in the separate color section in this issue). No surface disruption or earthquake had been observed and associated to this Quaternary fault before the 1986 event.

\section{Surface Faulting of the September 19, 1986, Earthquake}

Small but sharp surface faulting occurred along the trace of the Kalamata fault during the earthquake. This was immediately noticed by the inhabitants because the main fault break crossed the road to Eleochori (site 5 in Figure 2b). We were able to follow the breaks almost continuously in the field for about $4.5 \mathrm{~km}$ between sites 1 and 6 . The breaks, however, extend with some discontinuities up to site 8 (Figure 2b), reaching a total length of $6 \mathrm{~km}$. They usually produce a fissure and a normal fault step in colluvium or terraced olive orchards which lie against bedrock outcrops on the mountain front (Figure $5 a$ ). The coseismic fissure and step are generally very steep $\left(70^{\circ}-90^{\circ}\right)$, about $6-18 \mathrm{~cm}$ high and 2-6 $\mathrm{cm}$ wide on the average (Figure 5). They are typically located a few to several tens of centimeters west of large normal fault slickensides in the bedrock (Figure $5 d$ ). The step merges with those slickensides locally along strike (Figures $5 b$ and $5 d$ ) and also certainly at depth $(\simeq 1 \mathrm{~m})$. Thus the seismic break branches off the master fault near the surface where the reduction of soil cohesion facilitates the rupture propagation along steeper planes (Figure 6).

The normal fault slickensides lie at the main slope break at the base of the front of Mount Kalathio which is the uplifted footwall visible in Figure 4. Most of the mountain front is composed of crystalline Mesozoic-Eocene limestones of the Ionian platform (plattenkalk) which has been exhumed from below the Tripolis nappe by normal faulting with a total throw of the order of 1-2 km (Figures $2 a$ and $3 a$ ). With regard to the geology and the morphology the total throw on the Kalamata fault reaches its maximum at Mount Kalathio. North of Mount Kalathio the total throw diminishes rather abruptly and vanishes south of Renta Rachi (Figures 2 and 4). The large dimension of steep, young triangular facets on Mount Kalathio front ( $\simeq 30^{\circ}$, up to $250 \mathrm{~m}$ high) and the observation that they derive from still larger facets which form the overall, trapezoid-shaped mountain front (700 m high on the average, Figures 4 and $2 b$ ) imply that much of the total throw across the Kalamata fault is of Quaternary age. 


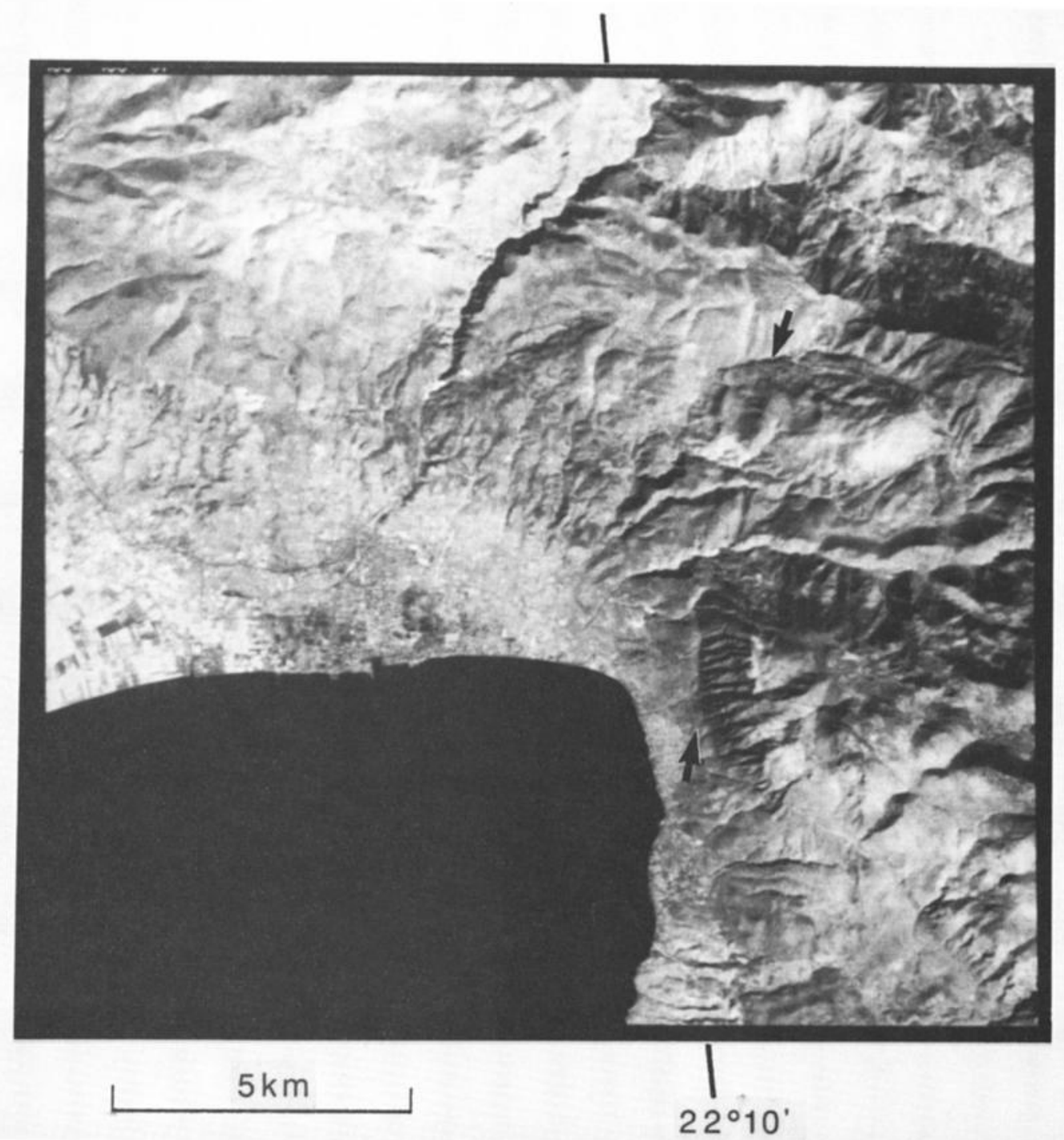

Plate 1. SPOT image of the Kalamata area. XS channel 2 (0.61-0.068 $\mu \mathrm{m}$ ). (The color version and a complete description of this figure can be found in the separate color section in this issue.)

The coseismic movement corresponds systematically to normal faulting with downdrop of the western block, although soil deformation may locally yield hanging wall collapse against footwall salients and an apparent reverse faulting geometry (Figure $5 c$ ). The net coseismic slip is directly measured on the master fault plane at places where the steep step in the soil merges with that plane (Figures $5 b$ and $5 d$ ). Although surface faulting was very clear at site 6 west of Eleochori (Figures $2 b, 7 a$ and $7 b$ ) and a small step was still visible at site 8 (Figures $2 b$ and $7 c$ ), no localized surface disruption was found between these two sites. There the fault trace is marked by footwall faceted spurs cut in the uppermost Pindos nappe (Figures $2 a$ and $2 b$ ). The water discharge in springs located on that trace at Perivolakia (site 7, Figure 26) is reported by the inhabitants to have had large fluctuations after the earthquake. We conclude that between sites 6 and 8 , the rupture was more diffuse than south of site 6 or that it nearly failed to reach the surface.

South of site 1 (Figure $2 b$ ) there was no surface break although en échelon Quaternary normal faulting appears, on the SPOT image, to extend southeastward into the gulf of Messenia (Plate 1 and Figure 2). In particular, the road to Verga was not cut by fault reactivation during the earthquake. Similarly, north of site 8 (Figure $2 b$ ), there is no evidence of coseismic surface faulting. In contrast with the southern end of the rupture at site 1 , however, no Quaternary fault trace extends northeastward beyond site 8 and across the WNW-ESE limestone range of Renta Rachi, which therefore marks the northernmost end of both the seismic rupture and the quaternary basin of Kalamata (Figures $2 b$ and $7 a$ ). The next major normal fault system bounding the Pamisos plain is found to be offset about $25 \mathrm{~km}$ to the WNW from the Kalamata fault trace, on the western border of the nearly unfaulted Goupata Rachi plateau (Thouria fault, Plate 1 and Figures $2 a$ and $3 b$ ).

The average strike of the Kalamata master fault is $\mathrm{N} 20^{\circ} \mathrm{E}$, and it is formed of two fault sub segments: a N10 ${ }^{\circ} \mathrm{E}$ striking segment south of the bend at site 3 and a N $30^{\circ} \mathrm{E}$ striking segment north of that bend (Figure 26). The dip measured on metric slickensides along the master fault trace is $60^{\circ}$. $70^{\circ} \mathrm{W}$ (see Figure $5 d$ ). This contrasts with the shallower dips of about $50^{\circ} \mathrm{W}$ obtained by detailed mapping of the 


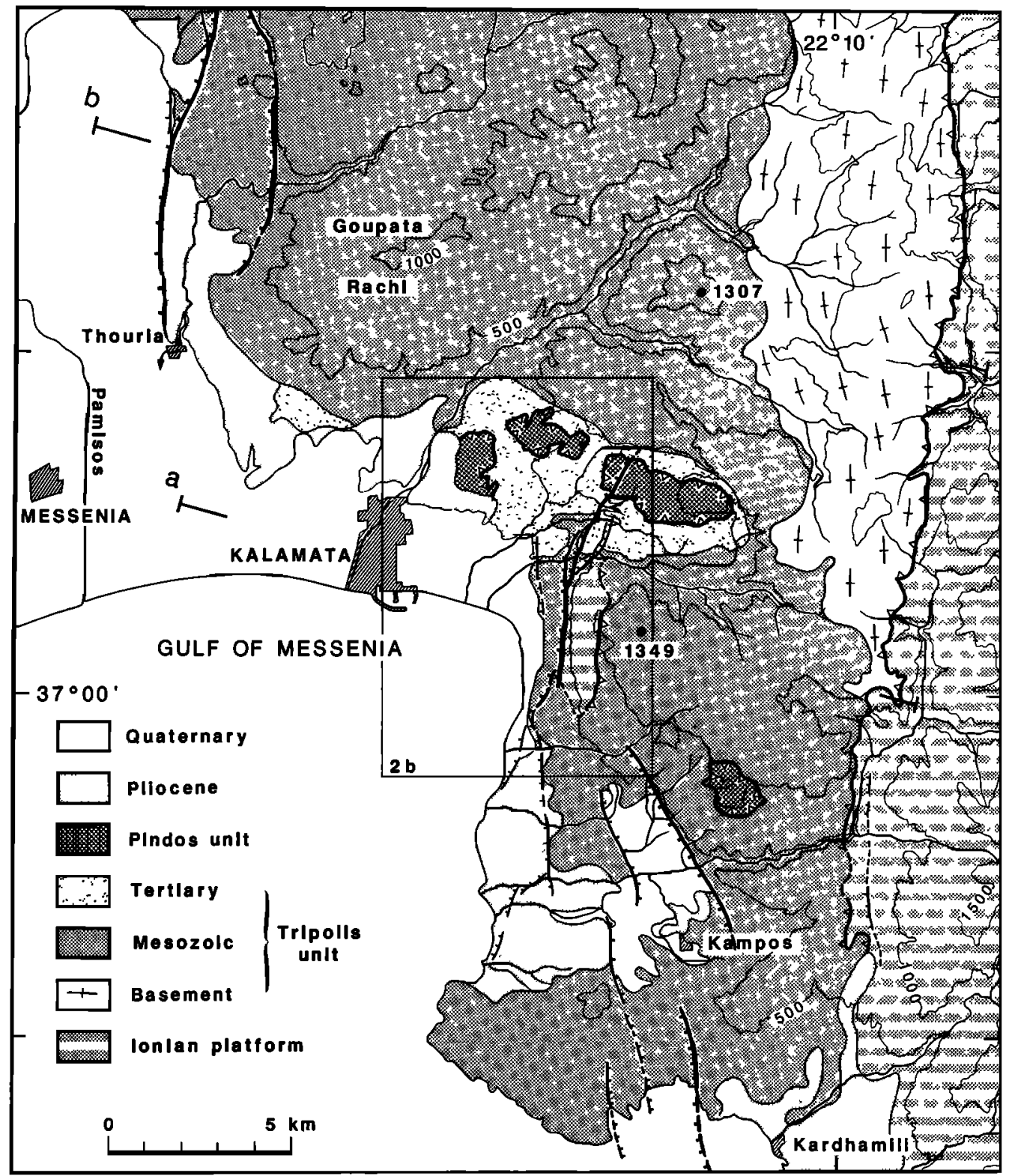

Fig. 2a. Map of active faults near Kalamata. Topography (in meters) and geology are simplified from the IGME, Athens, 1:50, 000 scale maps. Faults are compiled from the SPOT image in Plate 1, aerial photographs, and field observations. Major faulte are in bold. Nappe contacts are shown with triangles pointing toward the upthrust unit. The box corresponds to Figure $2 b$. Sections a and $b$ are shown on Figures $3 a$ and $3 b$.

fault trace across the rough topography ( $\simeq 200 \mathrm{~m}$ relief in canyons) (Figure $2 b$ and 6). Coseismic slip at the surface was observed to be mainly normal with very small amounts of either right- or left-lateral component of slip. Such undecided lateral components probably have little tectonic significance and may only reflect local influence of steep slopes in transverse canyons, as in the vicinity of the road to Eleochori (site 5, Figure 2b). By contrast, the lateral component of slip in the slickensides observed at the base of the mountain front is small (rake $\geq 75^{\circ}$ ) and consistently dextral (Figure $5 d$ ). Those slickensides are probably of Quaternary age, have formed within the bedrock/bedrock master fault contact at depth, and have been exhumed since their formation by continuing uplift of the footwall (Figure 6).

Coseismic movements of 1986 on the Kalamata fault imply that it ruptured completely up to its northern extremity (site 8) but that the break did not propagate along the whole length of the fault system, southward of site 1 (Figure 2b). Except for local, small breaks on the road to Eleochori about $300 \mathrm{~m}$ west of site 5 and unclear but probable reactivation of faults in the small graben south of Eleochori, none of the secondary faults mapped in Figure $2 b$ was reactivated at the surface. All other surface disruptions found in the area [Papazachos et al., 1988] appeared to us to be gravitational slides with doubtful relation to active faults. 


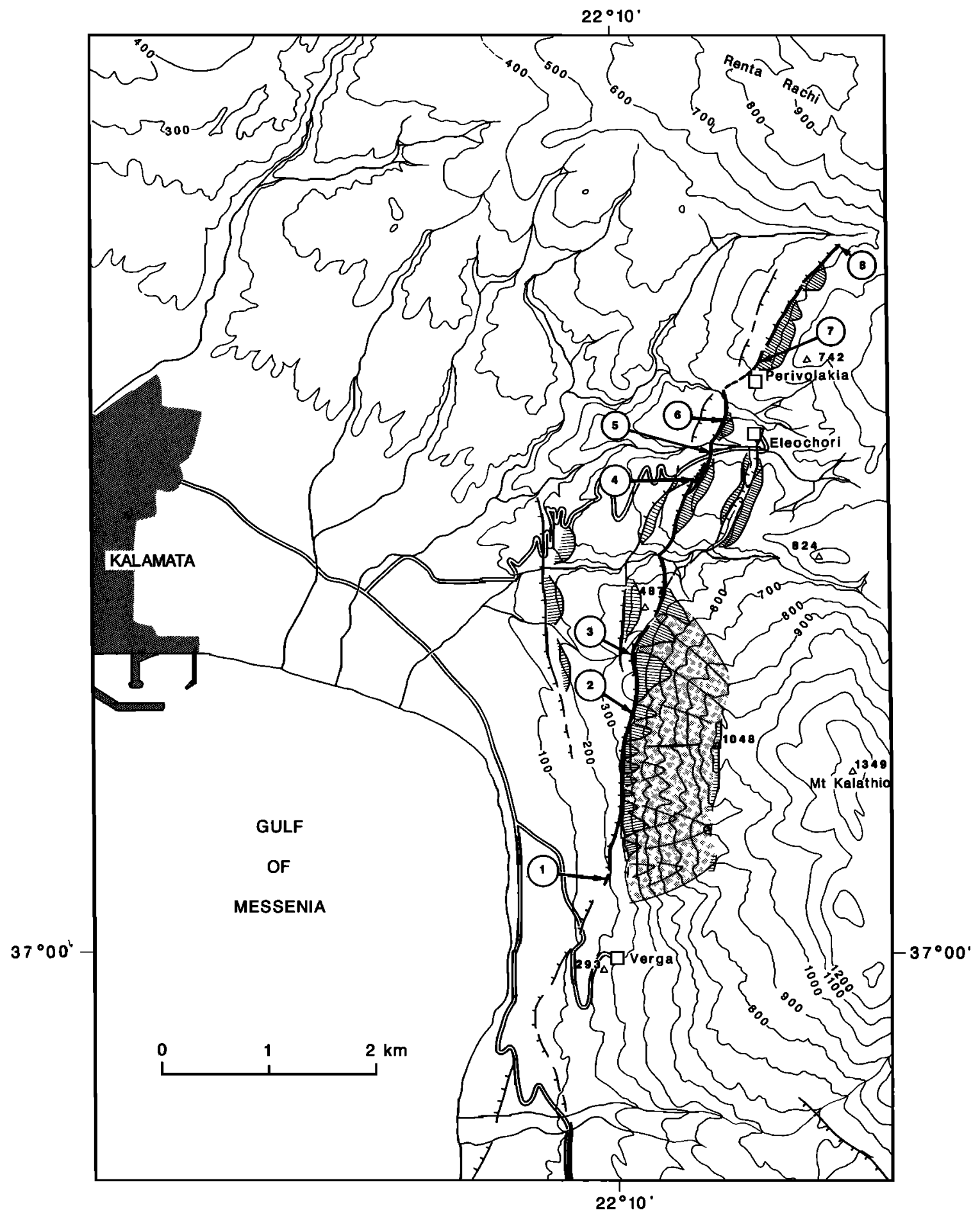

Fig. $2 b$. Detailed map of surface breaks of the September 13, 1986, earthquake. Circled numbers are observation spots on the main rupture (heavy line). Large morphological scarps ( $\simeq 100 \mathrm{~m}$ high) and triangular facets are hatched, Mount Kalathio front is in light grey. Surface breaks were not continuous between sites 7 and 8 . Other faults did not break during the earthquake.

The Kalamata fault is part of a larger fault system formed by en échelon, west dipping normal faults at the border between the Taygetos range and the Pamisos plain (Figures 1 and $2 a$ ). South of the Kalamata fault the system is complicated by an oblique, NW-SE trending graben at Kampos and extends probably into the gulf of Messenia by a large offehore fault west of Kardhamili (Figures 1 and 2a).
North of the Kalamata fault the offset with the Thouria fault coincides with a $\mathrm{N} 10^{\circ} \mathrm{E}$ deflection of the late Hellenic folds in Pindos units, which usually strike $N 150^{\circ} \mathrm{E}$, parallel to the general trend of the Taygetos range (Figure $2 a$ ). This fault offset and fold deflection are probably located along a zone of lateral ramp in the Ionian unit and the overlying Tripolis nappe (Figures $2 a$ and 3). It is thus very likely that the 


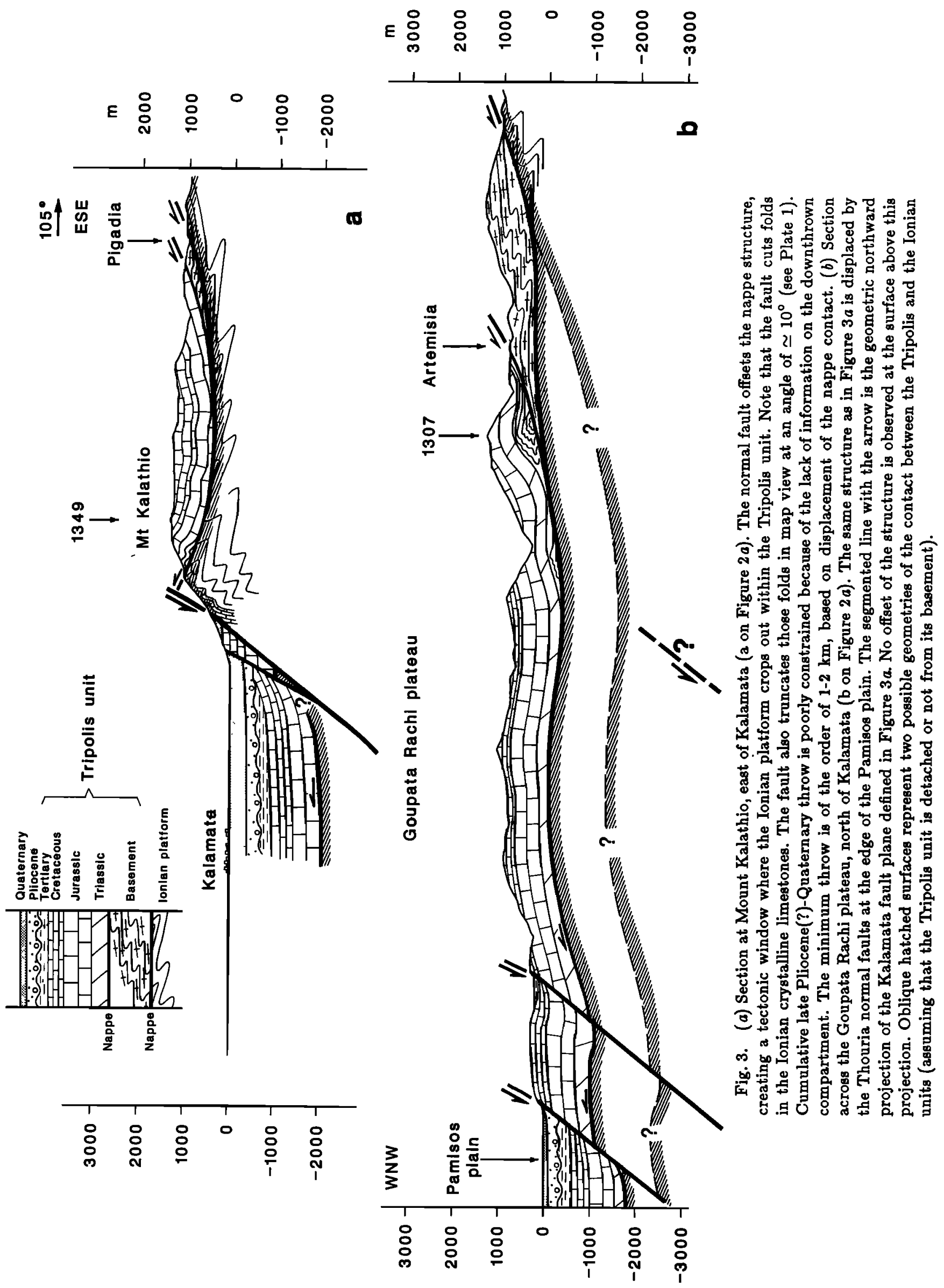




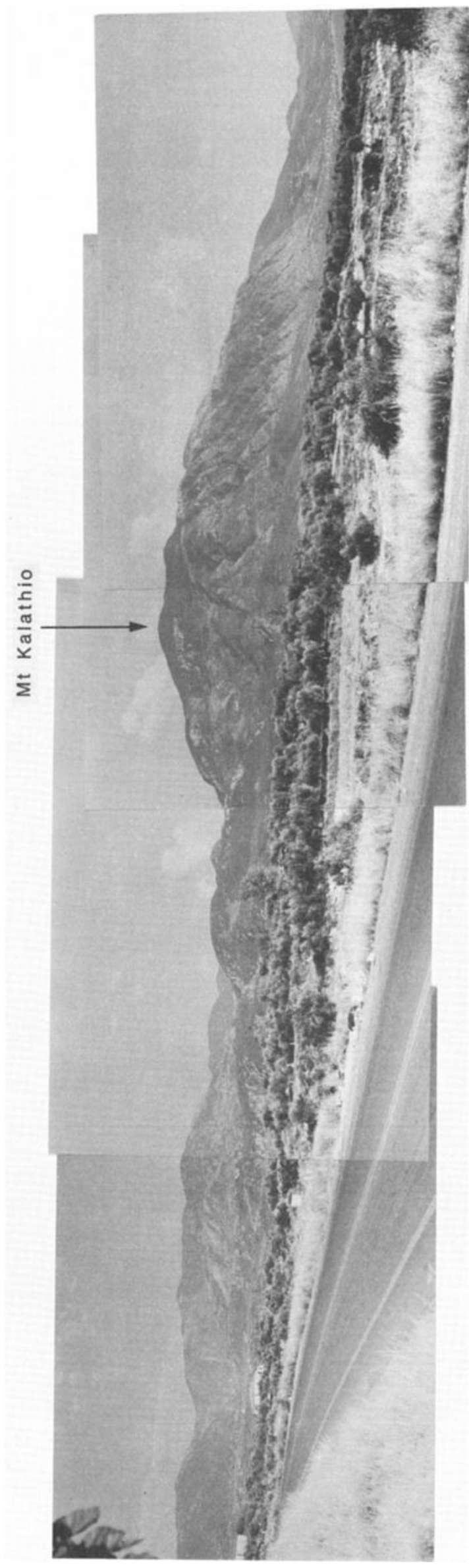

offeet between the Kalamata and Thouria faults is located along an older zone of transverse fractures which do not exhibit traces of surface reactivation during the Quaternary.

\section{MaIN SHOCK}

\section{Location}

Locations of the main shock (September 13, 1986, at 1724 GMT) given by the European Seismological Center (CSEM) and the National Observatory of Athens (NOA) almost coincide and are situated at the northeastern extremity of the aftershock zone found in this study (Table 1 and Figure $8 b$ ). The, largest aftershock ( $M_{L}=4.8$, Athens) occurred on September 15 at $1141 \mathrm{GMT}$ (followed by an $M_{L}=3.6$ aftershock on September 15 at 1247 GMT). Both aftershocks are located to the south of the main shock, nearer to Kalamata city, by CSEM and NOA (Table 1). For the main shock and the largest aftershock, a single three-component strong motion instrument (SMA-1 type) from the town of Kalamata was in operation, and the record shows a time difference of $1.9 \mathrm{~s}$ between the $S$ arrival and the triggering time for the main shock, and of $1.4 \mathrm{~s}$ for the aftershock. These data imply that the main shock and the aftershock epicenters cannot be much closer to Kalamata city than about 10 and $5.5 \mathrm{~km}$, respectively, assuming a mean $P$ velocity larger than $5 \mathrm{~km} / \mathrm{s}$, a $V_{p} / V_{a}$ ratio of 1.73 and depths of events of $5 \mathrm{~km}$ or more. Qualitatively, these results are in agreement with locations given by NOA, CSEM and Papazachos et al. [1988], although they differ from each other by few kilometers (Table 1 and Figure 86 ). These calculated distances would be about $25 \%$ smaller (7.5 and $4.5 \mathrm{~km}$, respectively) if one assumes a 2 km-thick sedimentary layer, with $P$ and $S$ velocities of 3.0 and $1.66 \mathrm{~km} / \mathrm{s}$, beneath the plain of Kalamata. We attempted to relocate the same two events with respect to locally well-located aftershocks, but the data did not provide stable relocations. One reason for this lack of resolution, at least for the main shock, may be the apparent complexity of the initial rupture. On teleseismic World-Wide Standard Seirmograph Network (WWSSN) short-period records and on short-period records at Global Digital Seismograph Network (GDSN) stations, this complexity is expressed as a small arrival (equivalent to a magnitude 4.5 or 5 event) about 3.5 8 before the main event, suggesting that the rupture propagation was not smooth. The combined interpretation of these short-period records and strong motion will be important to better constrain the initiation and propagation of the rupture on the fault (M. Besnard et al., manuscript in preparation, 1989). Based on the data discussed above, we think that the relative location of the main shock and of its largest aftershock with respect to the aftershock zone is not very well constrained, but the main shock most likely initiated within the northern half of the aftershock zone and the September 15 aftershock within the central or southern part.

It is interesting to note also that the centroid calculated by Driewonski et al. $[1987]\left(36.8^{\circ} \mathrm{N}, 22.64^{\circ} \mathrm{E}\right)$ is shifted almost $50 \mathrm{~km}$ to the east. Mislocations of about $50 \mathrm{~km}$ to the northeast also occurred for the 1981 Corinth earthquakes [Driewonsti and Woodhouse, 1983] and for the 1983 Kephallinia earthquake. In contrast, centroid locations of earthquakes in the western Mediteranean like El Asnam, 1980 (Algeria) [Ouyed et al., 1983] or Constantine, 1985 (Algeria) [Bounif et al., 1987] are precise to about $10 \mathrm{~km}$. It is likely that these mislocations reflect lateral heterogeneities in the 


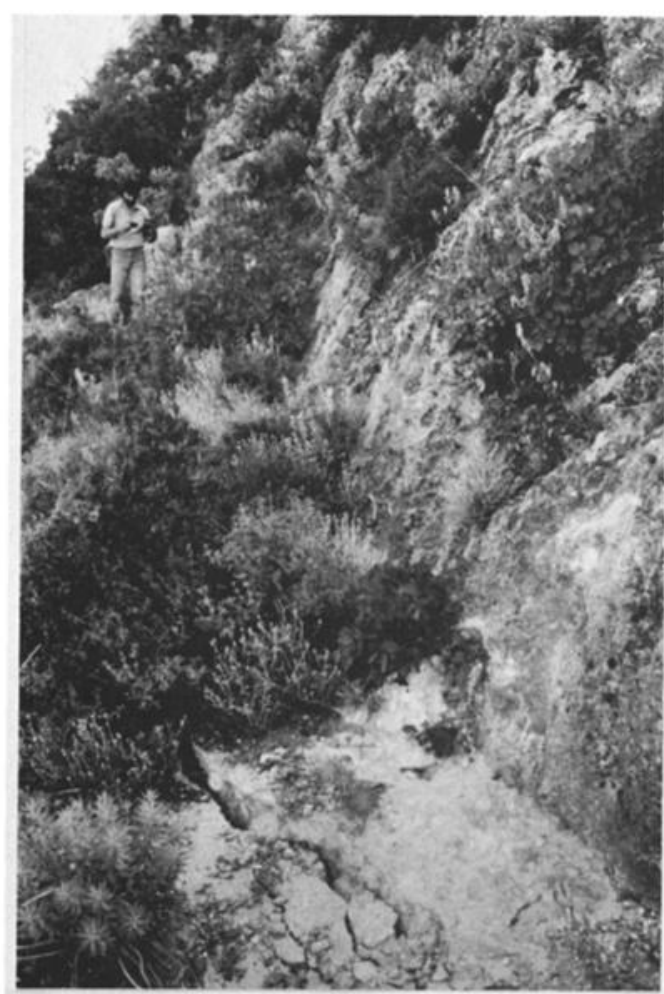

a
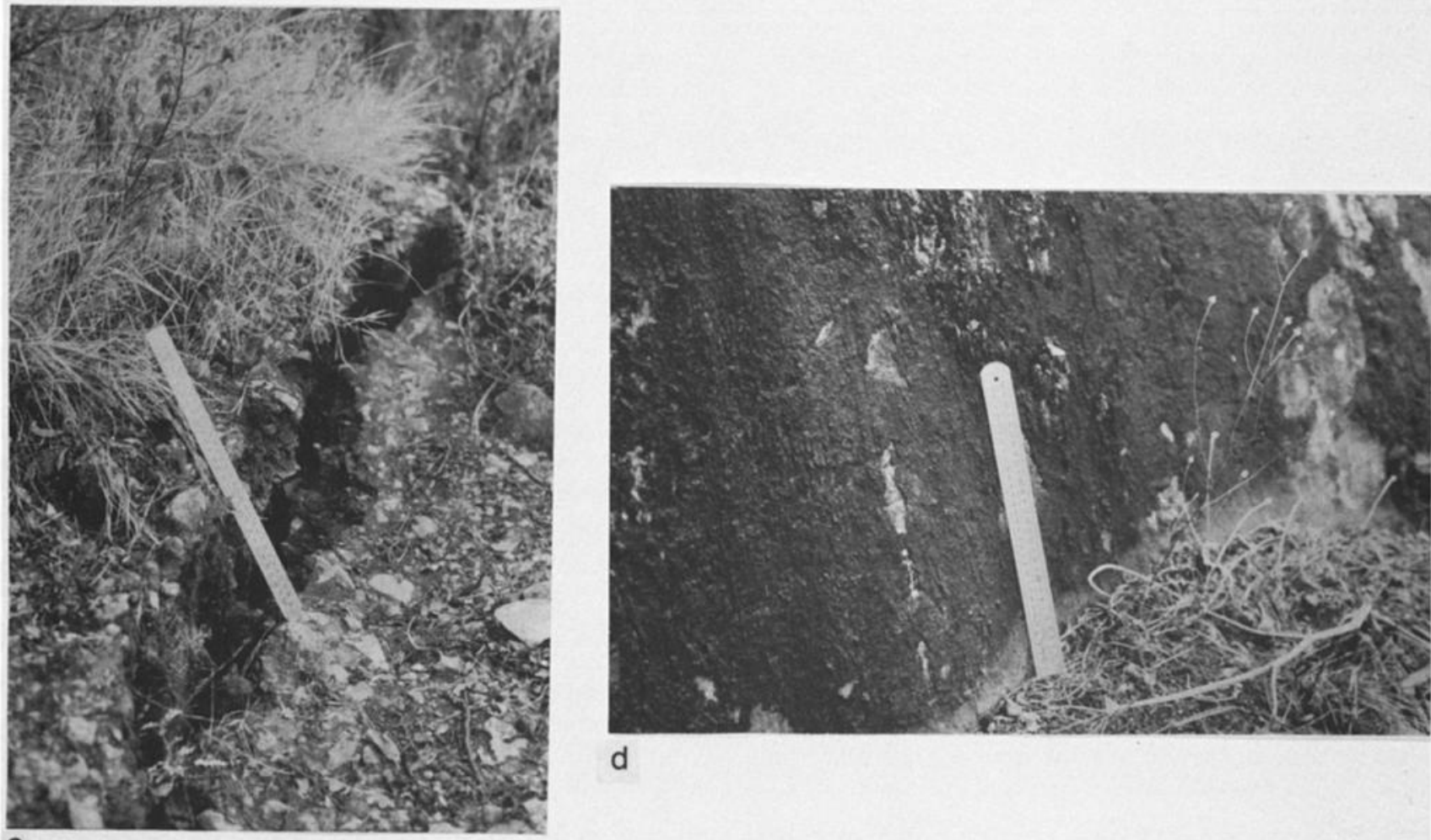

d

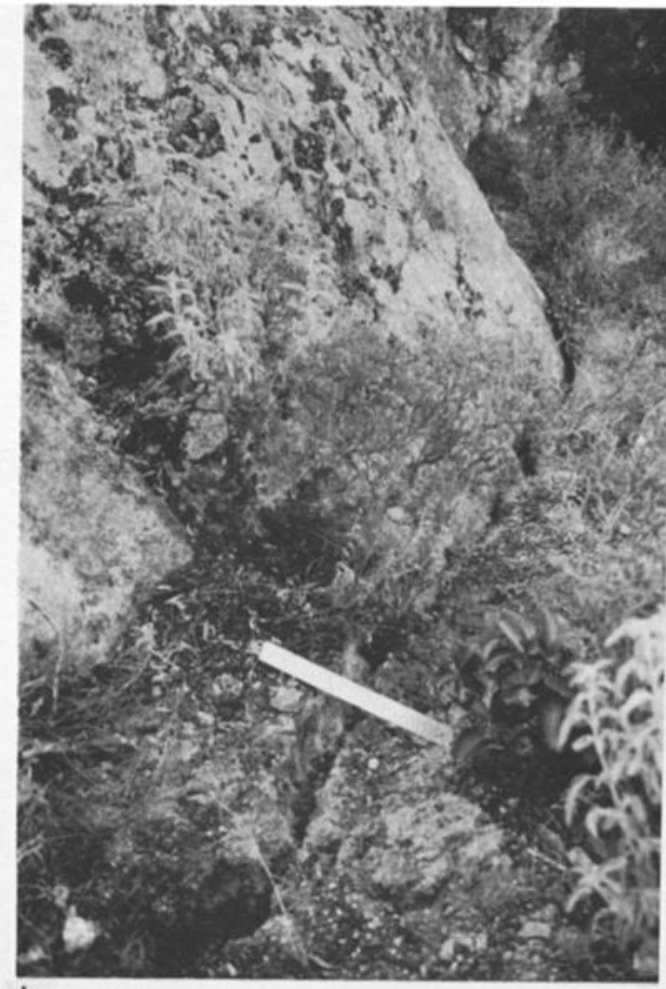

b

Fig. 5. Details of the fault break south of Eleochori road (site 5 on Figure 2b). Figures $5 a, 5 b$ and $5 c$ are at site 4; Figure $5 d$ is at site 2 (see Figure 2b). (a) Continuous, 3-cm-wide fissure makes 10- to 12-cm-high step in soil, less than $1 \mathrm{~m}$ away from the $N 45^{\circ} \mathrm{E}$ striking and $60^{\circ} \mathrm{W}$ dipping fault plane in bedrock (see Figure 6). (b) As step in soil merges with bedrock/soil fault plane, the net resolved dip component of slip is $10 \mathrm{~cm}$. (c) A 13-cm-high step-and-fissure $3 \mathrm{~m}$ away from the bedrock fault. Because of the collapse of the hanging wall, the apparent slip may be reverse. (d) Slickensides and grooves rake $82^{\circ} \mathrm{N}$ on a $\mathrm{N}^{\circ} \mathrm{E}$ striking and $70^{\circ} \mathrm{W}$ dipping plane. Only 6- to $7-\mathrm{cm}$-wide bare stripe at the base of the plane was exhumed by the downdrop of grass-covered sediments during the earthquake. Note that the smallest break is observed just at the foot of Mount Kalathio where the long-term displacement reaches a maximum. 


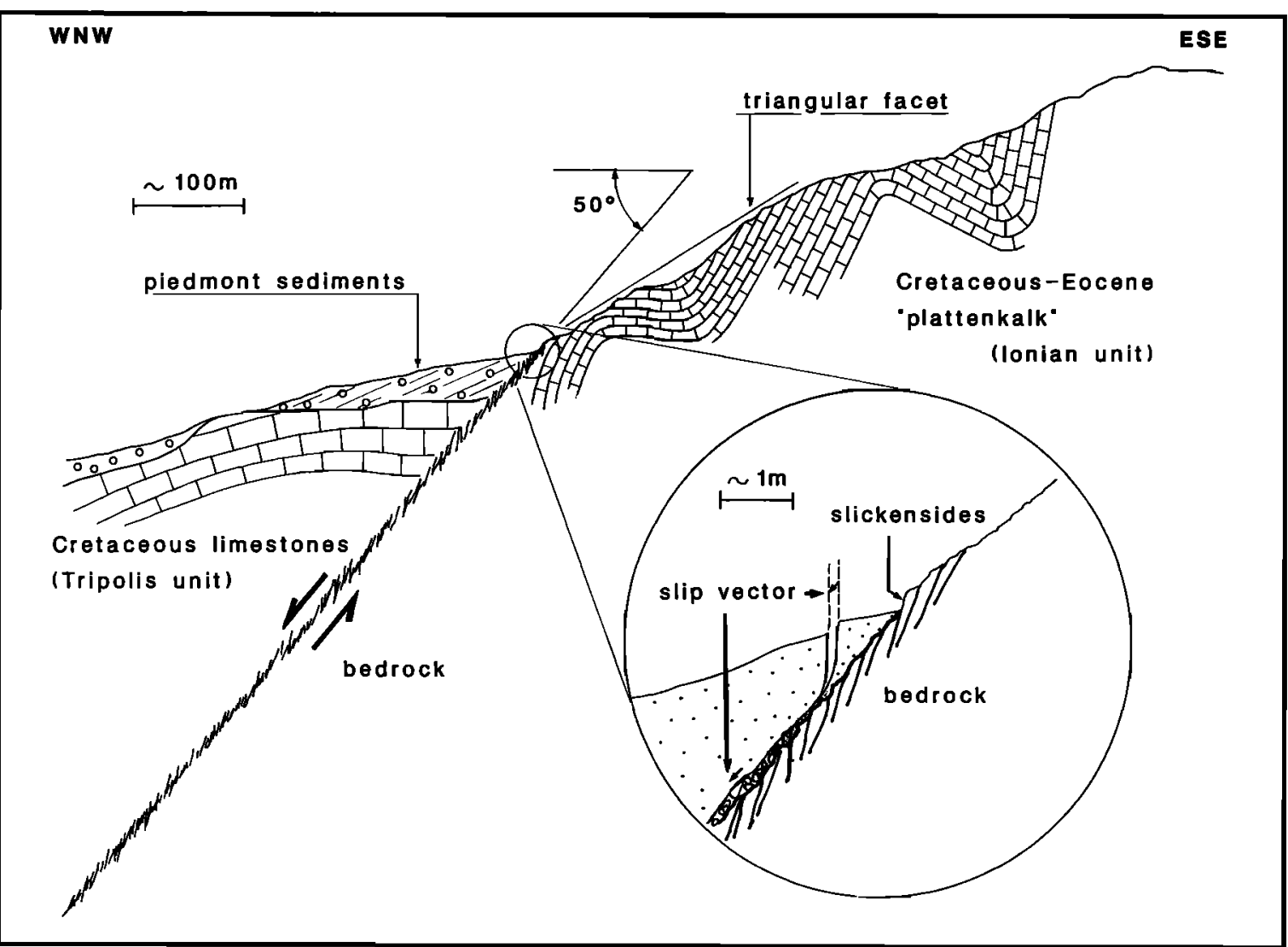

Fig. 6. Schematic cross section of the Kalamata fault near site 2 (Figure 2b). Circle blows up the surface break geometry. Master fault dips about $50^{\circ}$ near the surface, slickensides about dip $60^{\circ}$, and fissures in soil with low cohesion are still steeper $\left(\geq 80^{\circ}\right)$.

velocity structure not taken into account by the preliminary reference Earth model (PREM) [Dzievonski and Anderson, 1981] used in centroid determinations. Instead they may result from either a high-velocity zone associated to the subducting plate beneath the Aegean or a low-velocity zone related to the widespread extension and high heat flow in the Aegean or a combination of both.

\section{Waveform Analysis}

In order to constrain the depth and focal mechanism of the main shock, we inverted available $P$ and $S H$ waveforms of long-period WWSSN seismograms [Nábelek, 1984; McCaffrey and Nábelek, 1987] for focal mechanism parameters (strike, dip, and rake), centroid depth, seismic moment, and source time function. The inversion algorithm minimizes the difference between observed and calculated seismogramms in a least squares sense. However, it is very important to explore the range of acceptable values for focal mechanism parameters and depth because the standard errors provided by the algorithm do not represent the true uncertainties on these parameters [e.g. McCaffrey and Nábllek, 1987]. Sets of calculations were performed in a half-space with a mean $P$ wave velocity varying from 5.4 to $6.0 \mathrm{~km} / \mathrm{s}$, which corresponds to the acceptable range deduced from the analysis of the rms of a hundred of selected aftershocks (see below concerning aftershocks locations). The inversion algorithm yields a strike of $201^{\circ}$, a dip of $45^{\circ}$, and a rake of $283^{\circ}$ (Figure $9 a$ ) and these three parameters are quite inde- pendent of the assumed mean velocity and of the depth and source duration.

By fixing one of the focal mechanism parameter and inverting for the remaining ones, we explored the uncertainties on each parameter. The dip was always very stable. The strike can vary between $185^{\circ}$ and $220^{\circ}$ (see rows 2-3 on Figure 9b) and the rake between $290^{\circ}$ and $260^{\circ}$ without significantly deteriorating the fit of waveforms (rows 4-5 on Figure 96). The centroid depth is moderatly well resolved, as expected for such a small and shallow event, because of the trade-off between source time function duration and depth. However, SH waveforms allow constraining the depth to be less than $8 \mathrm{~km}$. At larger depth, the $s S$ phase starts to appear as a separated arrival (at station NAI and KBS in particular, see row 6 on Figure 9b). A very good overall fit of waveforms and amplitudes is obtained for a depth of $5 \mathrm{~km}$ and a source duration of $4 \mathrm{~s}$ (Figure $9 \mathrm{a}$ ), yielding a seismic moment of $7.9 \times 10^{17} \mathrm{~N} \mathrm{~m}$. Thus for a fixed depth the seismic moment is well constrained. However, good fits can also be obtajned for a depth of $3 \mathrm{~km}$ with a 5 s-long time function and a seismic moment $9.1 \times 10^{17} \mathrm{~N}$ m or for a depth of $7 \mathrm{~km}$ with a 2 s-long time function and a seismic moment of $4.5 \times 10^{17}$ $\mathrm{N} \mathrm{m}$. We conclude that the depth is constrained to $5 \pm 3 \mathrm{~km}$ and the seismic moment to $7.0 \pm 2.5 \times 10^{17} \mathrm{~N} \mathrm{~m}$.

The nodal plane striking $201^{\circ}$ and dipping $45^{\circ}$ to the north west is in excellent agreement with the observed geometry of surface faulting described in the previous section and with the fault geometry outlined at depth by the af- 


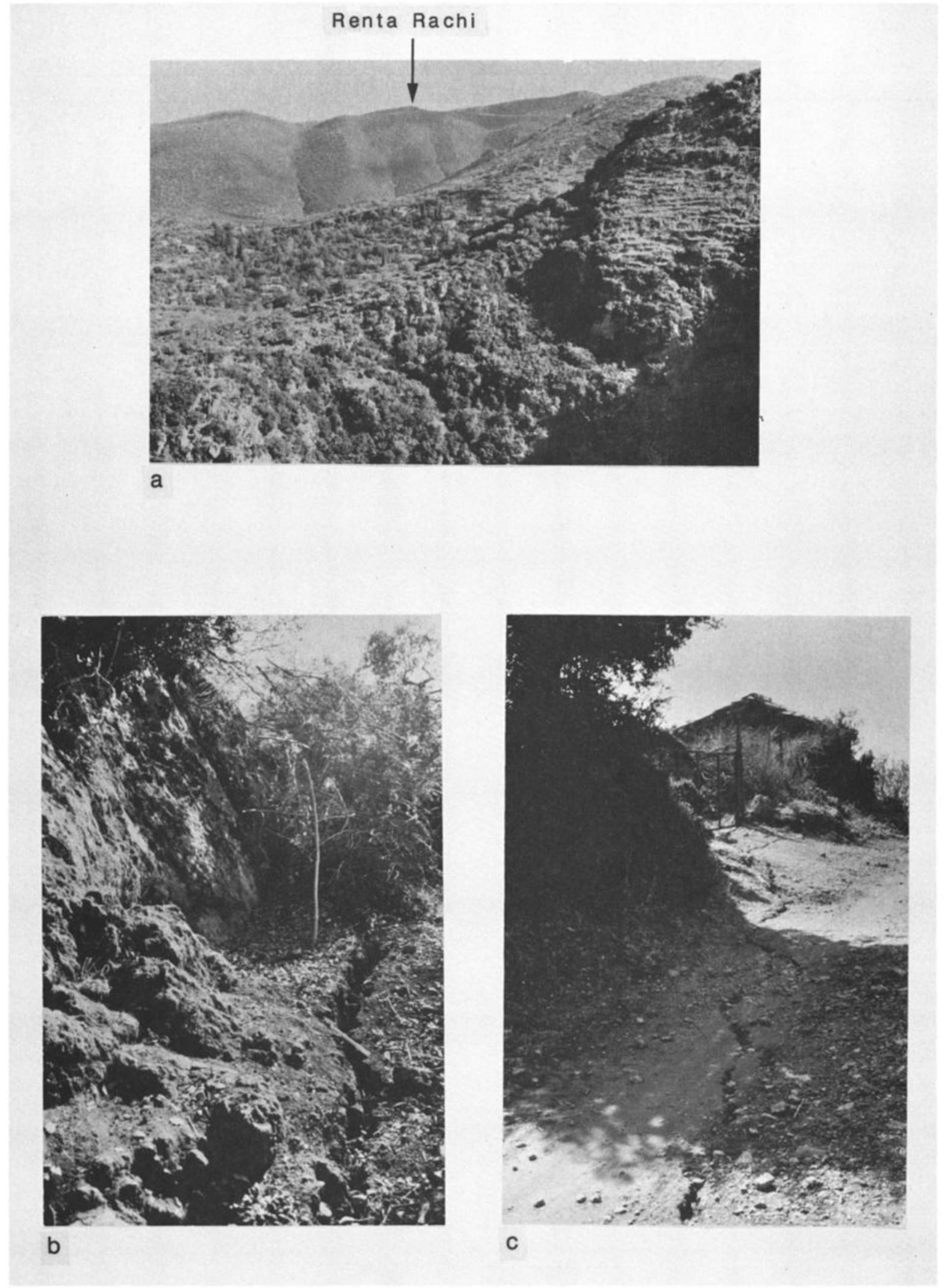

Fig. 7. (a) View to the northeast of the northern segment of the fault from Eleochori road (site 5 on Figure 26). The limestone hill with the triangular facet in the foreground to the right marks the uplifted footwall. The ruins of Eleochori village lie on top of that hill. Note the unfaulted transverse range in the background. (b) Break at site 6 (see Figure 2b). View to the southwest. The scale is given by the pencil. (c) Cracks across a dirt road at the northern tip of the rupture zone (site 8 on Figure $2 b$ ). The vertical component of slip is $2 \mathrm{~cm}$ down-to-the northwest (to the right of the picture). 
TABLE 1. Hypocentral Parameters

\begin{tabular}{|c|c|c|c|c|c|c|}
\hline & Latitude & Longitude & Depth, km & $M_{L}$ & $M_{s}$ & $m_{b}$ \\
\hline \multicolumn{7}{|c|}{ Main Shock September 1s, 1986, 1724 GMT } \\
\hline $\begin{array}{l}\text { Athens (NOA) } \\
\text { CSEM } \\
\text { Thessaloniki* } \\
\text { NEIS }\end{array}$ & \begin{tabular}{cc|}
$37^{\circ}$ & $6.0^{\prime}$ \\
$37^{\circ}$ & $7.8^{\prime}$ \\
$37^{\circ}$ & $6.6^{\prime}$ \\
$37^{\circ}$ & $6.0^{\prime}$
\end{tabular} & $\begin{array}{l}22^{\circ} 11.4 ' \\
22^{\circ} 12.0^{\prime} \\
22^{\circ} 08.4 ' \\
22^{\circ} 11.6^{\prime}\end{array}$ & $\begin{array}{r}1.0 \\
41.0 \\
8.0 \\
11.0\end{array}$ & 5.5 & $\begin{array}{l}6.4 \\
\\
5.8 \\
5.8\end{array}$ & 6.0 \\
\hline \multicolumn{7}{|c|}{ Aftershock September 15, 1986, 1141 GMT } \\
\hline $\begin{array}{l}\text { Athens (NOA) } \\
\text { CSEM } \\
\text { Thessaloniki* } \\
\text { NEIS }\end{array}$ & $\begin{array}{ll}37^{\circ} & 4.8^{\prime} \\
37^{\circ} & 2.4^{\prime} \\
37^{\circ} & 2.4^{\prime} \\
36^{\circ} & 55.8^{\prime}\end{array}$ & $\begin{array}{l}22^{\circ} 04.2^{\prime} \\
22^{\circ} 10.2^{\prime} \\
22^{\circ} 07.8^{\prime} \\
22^{\circ} 10.8^{\prime}\end{array}$ & $\begin{array}{r}1.0 \\
37.0 \\
8.0 \\
10.0\end{array}$ & 4.8 & $\begin{array}{l}5.3 \\
\\
5.4 \\
4.8\end{array}$ & 4.9 \\
\hline
\end{tabular}

* Paparachos et al. [1988].

tershocks. The fault mechanism obtained here differs from that obtained by Papazachos et al. [1988] from first motion readings (strike $=204^{\circ}$, dip $=51^{\circ}$, rake $=303^{\circ}$ ) and that of Dziewonski et al. $\left[1987\right.$ ] (strike $=211^{\circ}, \operatorname{dip}=56^{\circ}$, rake $=304^{\circ}$ ) essentialy by having a smaller component of left-lateral slip. Figure $9 b$ (row 7) shows a comparaison of observed and synthetic seismograms for the solution of Papazachos et al. $S H$ waves at BUL, KBS, and KEV are almost nodal for this solution which disagrees with observations. Moreover, polarities read on long-period WWSSN records at stations STU and IST which are compressional constrain the solution and were misplotted by Papazachos et al. [1988]. At these stations the first arrival is a $P n$ phase and assuming an upper mantle velocity of $8 \mathrm{~km} / \mathrm{s}$ and a lower crust velocity of $6.5 \mathrm{~km} / \mathrm{s}$, the incidence angle is about $54^{\circ}$ instead of $48^{\circ}$ as shown by Papazachos et al. [1988]. Thus the solution obtained agrees with the first polarities read on long-period records (Figure 9a).

\section{ReCORding AND ANalysis of AFtershocks}

A few days after the main shock, a team from the Observatory of Athens and from Athens University installed a portable network of seven smoked paper instruments. This network was complemented by nine stations from the Institut de Physique du Globe of Paris and from the Observatoire de Grenoble. Thus, for a period of 10 days from September 18 through September 27, 16 smoked paper instruments (Sprengnether MEQ 800) equipped with $1-\mathrm{Hz}$ vertical geophones were deployed. They provided a good coverage of the aftershock area (Figure 8) and allowed both for wellresolved hypocenters and reliable individual focal mechanism determination. Station coordinates are listed in Table 2. All the instruments recorded at $120 \mathrm{~mm} / \mathrm{min}$, yielding a time reading precision of $0.05 \mathrm{~s}$ for $P$ waves, except for some far away stations like PET or KVAS that were recording at $60 \mathrm{~mm} / \mathrm{min}$. In this case the reading precision is only $0.1 \mathrm{~s}$. $S$ wave arrival times were also read on vertical components. Often, at the close stations, $S$ waves were impulsive, and only in this case were they taken into account and always weighted down with a factor of 2 or more compared to $P$ waves. For $S$ waves, the estimated reading error is 0.28 . Every day (or every 2 days for those stations recording at $60 \mathrm{~mm} / \mathrm{min}$ ) the internal clock of the recorder was checked against a radio signal in order to control the drift of the internal clock which was usually between 0 and $0.1 \mathrm{~s}$ and always less than $0.2 \mathrm{~s} / \mathrm{d}$.
Over a hundred of aftershocks per day were recorded, and 740 were located on the basis of having at least five readings of $P$ arrivals (Figure 8b). Below, we first discuss the choice of a velocity model and the precision on the locations as well as the procedure used for focal mechanisms determination. We then discuss the aftershocks distribution and focal mechanisms based on the most reliable locations and on individual focal mechanism solutions.

\section{Velocity Model and Location Uncertainties}

No detailed information on the velocity structure of the area is available. Thus, in order to find a reliable velocity model we selected 100 well-recorded aftershocks (with more than six $P$ and two $S$ readings) that would be a representative sample of all the aftershocks, both in location and depth and first located these events in a half-space with a $P$ velocity between 5.0 and $6.2 \mathrm{~km} / \mathrm{s}$, the $V_{p} / V_{s}$ ratio being kept constant and equal to 1.73. There is a clear minimum in the mean rms of the 100 events for a $P$ velocity between 5.5 and $5.4 \mathrm{~km} / \mathrm{s}$ (Figure 10). Moreover, looking at the mean rms by depth range, the minimum occurs at a $P$ velocity around 5.3-5.4 km/s for earthquakes shallower than $5 \mathrm{~km}$. In contrast, for earthquakes deeper than $5 \mathrm{~km}$ the minimum occurs at a $P$ velocity close to $5.7 \mathrm{~km} / \mathrm{s}$ and for earthquakes deeper than $7 \mathrm{~km}$ at a $P$ velocity close to $5.8 \mathrm{~km} / \mathrm{s}$ (Figure

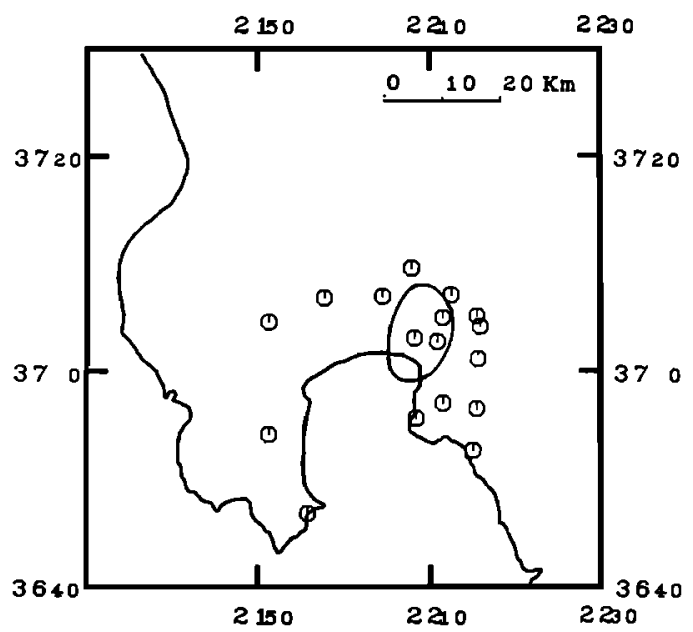

Fig. 8a. Network geometry and outline of the aftershock area. 


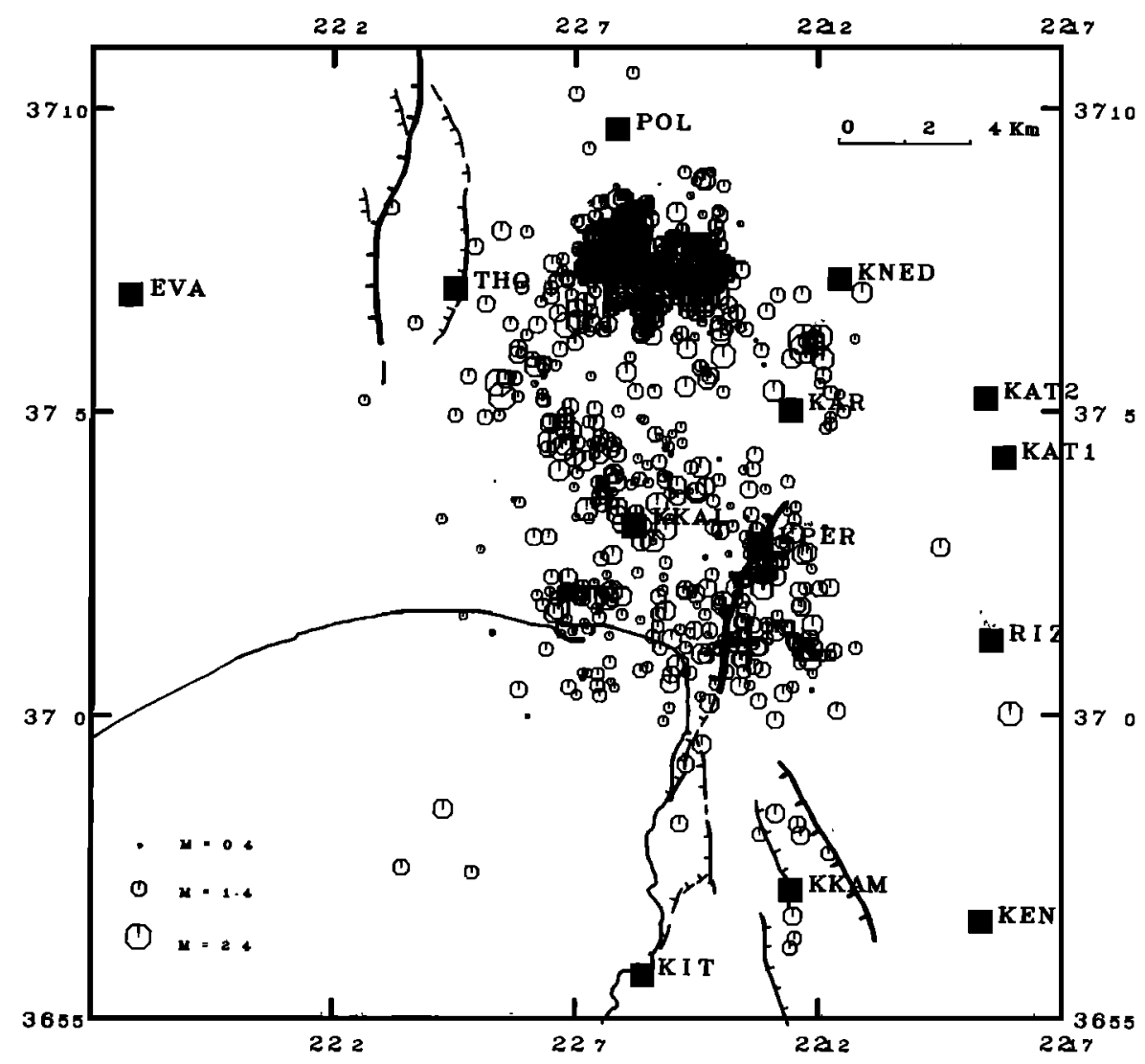

Fig. 8b. Detail of the aftershock distribution with $\mathbf{7 4 0}$ located events. Faults are from Figure $2 a$ and the heavy line is the observed surface rupture on the Kalamata fault. Solid squares are station locations, the solid circle is the location of the strong motion instrument.

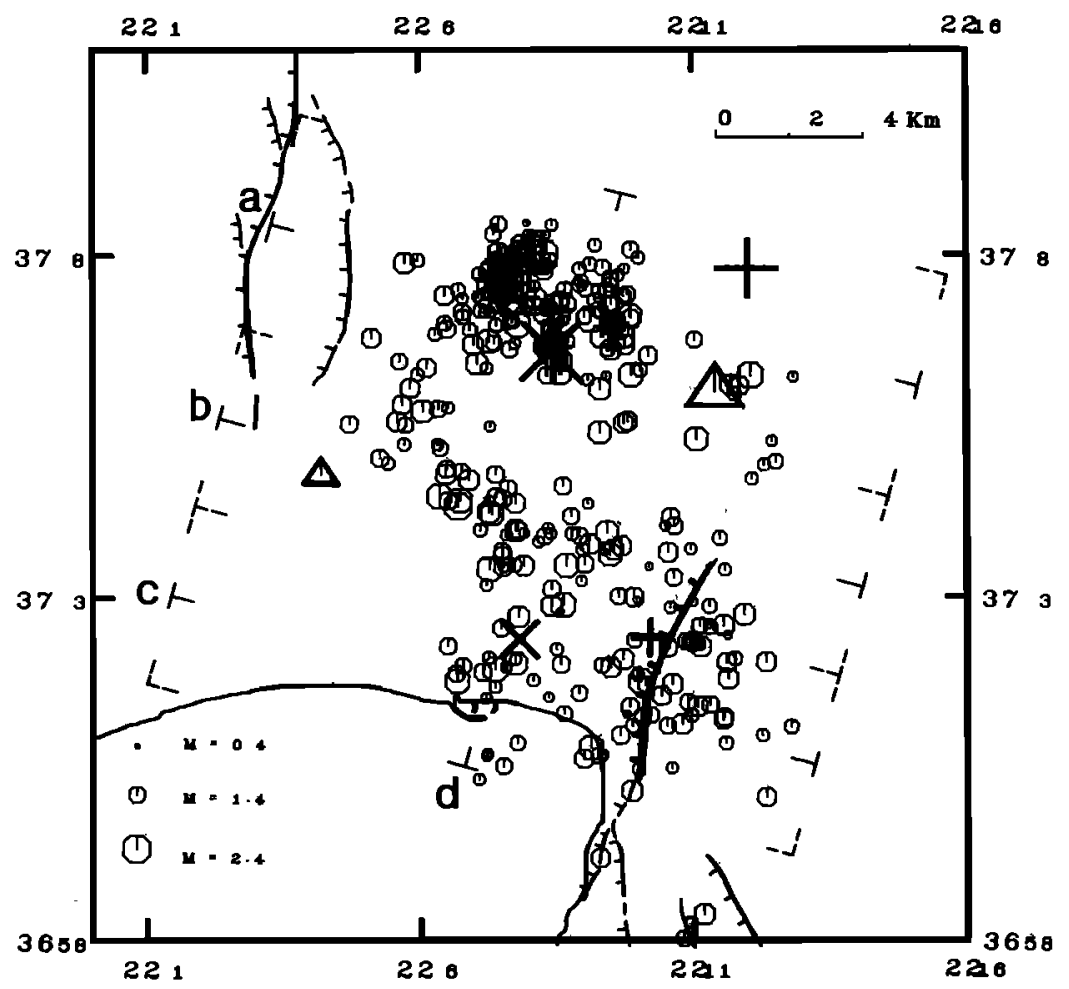

Fig. 8c. Map view of the 344 best located aftershocks (see text for the selection criteria). a, b, $c$ and d are locations of cross sections in Figures 14 and 13. Large and small bold symbols indicate locations of the September 13 mainshock and of the September 15 largest aftershock, respectively, given by the CSEM (pluses), NOA (triangles) and Papazachos et al. [1987] (crosses) (Table 1). Faults and aftershock locations shown as in Figure $8 b$. 


\section{KALAMATA 1986.09 .13}

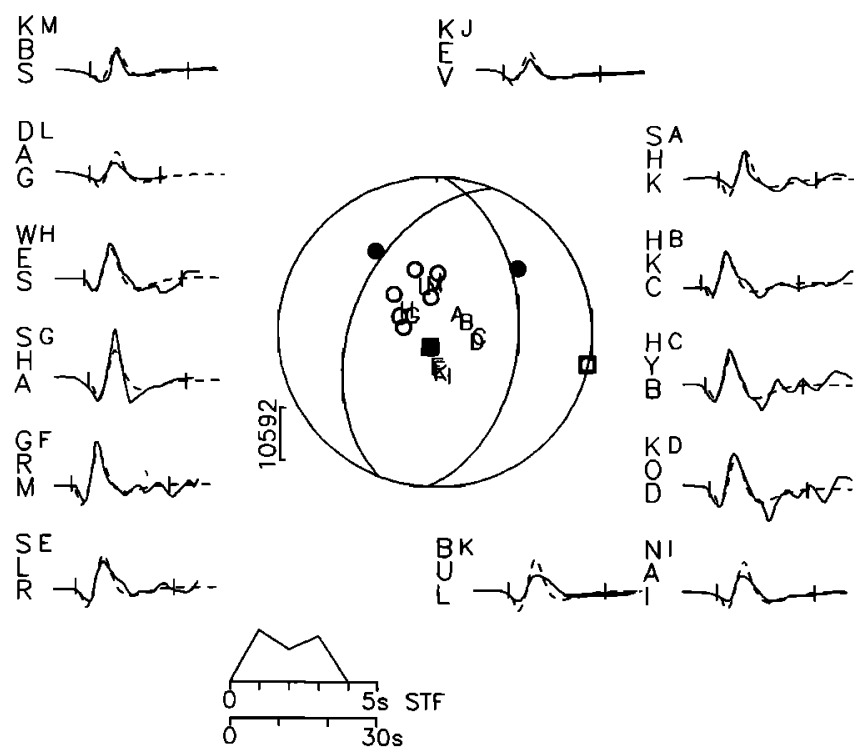

$\stackrel{K E}{S}+$ H $\quad \stackrel{K I}{V}+\Omega=$

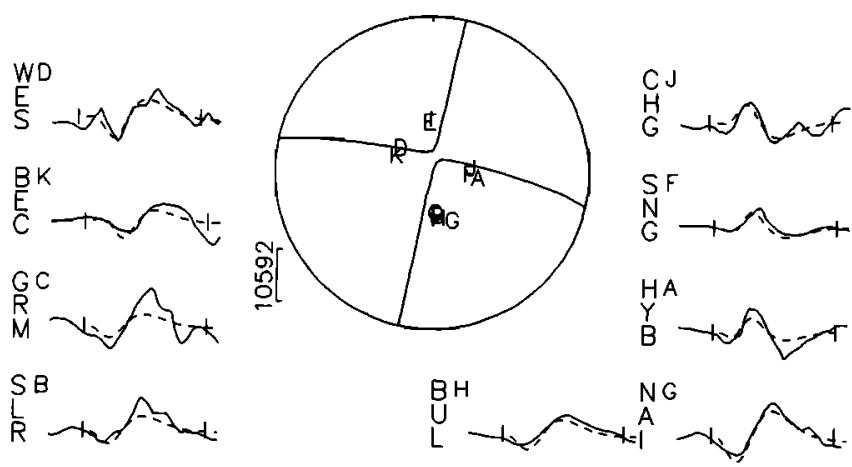

Fig. 9a. Main shock focal mechanism obtained by simultaneous inversion of $\boldsymbol{P}$ (top) and $\boldsymbol{S H}$ (bottom) long-period WWSSN waveforms. Observed (solid curve) and synthetic (dashed curve) seismograms are plotted scaled to the seismic moment. STF is the source time function; the amplitude scale is in microns. Parameters used are listed in Table 4. Each seismogram is represented by a letter on the focal sphere. Open circles show additional $P$ wave dilatational first motions read on long-period records. Solid circles (compressional first motion) are stations STU and IST discussed in the text. Open square is $T$ axis, black square is $P$ axis.

10). Thus there is apparently a strong velocity gradient in the upper $7 \mathrm{~km}$ of the crust. This result is in agreement with the interpretation of a refraction profile passing through the plain of Kalamata (Kampos-Kalamata-Kyparissia; about 5 $\mathrm{km}$ southwest of the network [Delibassis et al., 1987]) that shows a 5-km-thick layer with a $5.2 \mathrm{~km} / \mathrm{s} P$ velocity over a layer with a $6 \mathrm{~km} / \mathrm{s} P$ velocity. In doing the same exercise to study the influence of the $V_{p} / V$, ratio we found that it had almost no effect on the mean rms at any $P$ velocity. Thus a $V_{p} / V_{\text {s }}$ ratio of 1.73 was chosen. We then tried to find a layered velocity structure that would account for the features described above. Because of the apparent strong velocity gradient in the upper $5 \mathrm{~km}$ of the crust and in order to avoid too large velocity contrasts between layers for which we did not find evidences and that would create problems, especially when computing incidence angles for focal mechanisms, we used a three-layer instead of a simpler twolayer velocity structure. The final velocity structure chosen (Table 2) yields at all depths a smaller mean rms than any of the half-space model (Figure 10). This is probably in part due to the larger number of parameters involved but also reflects the better adequacy of such a velocity structure at locating shallow events in particular than just a half-space structure.

Aftershocks were selected on the basis of the quality of their location. The events were located using the HYPO71 computer program [Lee and Lahr, 1975], which gives standard errors ERZ, ERX, ERY for depth, latitude, and longitude respectively. It is well known that those errors underestimate the true errors on absolute location [e.g., Hatzfeld et al., 1987] but still are useful in estimating the quality of a location. The following criteria were used: $\mathrm{rms}<0.15 \mathrm{~s}, \mathrm{ERZ}<1.2 \mathrm{~km}, \mathrm{ERX}<0.6 \mathrm{~km}, \mathrm{ERY}<0.6 \mathrm{~km}$ in addition to requiring at least five $P$ and one $S$ readings and that the distance to the closest station be smaller or equal to the depth of the event for events deeper than $3 \mathrm{~km}$. For shallower events the last two conditions were changed to requiring at least two $S$ readings and that the closest station be at a distance less than twice the depth of the event. This choice was made to combine the needs for precise location and homogeneity in the aftershock distribution. Among events that are selected this way, very few have a rms larger than $0.1 \mathrm{~s}$.

Because the network is dense and covers the aftershock area quite well, the locations are rather insensitive to the velocity structure. For all the models tested (i.e., halfspace with velocity from 5 to $6 \mathrm{~km} / \mathrm{s}$, two or three layers) the variation in locations given by the different models is less than $200 \mathrm{~m}$ for events within the network (i.e., almost all events that passed the selection criterion). The variation in depth is in most cases not larger than $1 \mathrm{~km}$ except for events shallower than $3 \mathrm{~km}$. Those are clearly better located with a mean $P$ velocity between 5.4 and $5.0 \mathrm{~km} / \mathrm{s}$ than 5.6 or more, but the precise depth depends strongly upon the velocity of the upper layer and the calculated depth could vary from 0.5 to $2.5 \mathrm{~km}$ quite easily. However, from these tests it is clear that events with a computed depth less than about $3 \mathrm{~km}$ and that meet the selection criteria defined above (e.g. have $2 S$ readings and the distance to the closest station is smaller than twice the depth of the event) are really shallower than 3km. These tests also indicate that the errors (ERZ, ERX, ERY) are realistic estimates of relative locations errors of the events one with respect to another, except for the error on the depth of events shallower than $3 \mathrm{~km}$ which could be $2 \mathrm{~km}$ or so.

We present the location of the 344 selected aftershocks in map view (Figure 8), in cross section parallel to the fault trace (Figure 13) and in cross sections perpendicular to the fault trace (Figure 14). 
KEV P HYB P SLR P CHG SH BUL SH BEC SH KBS SH

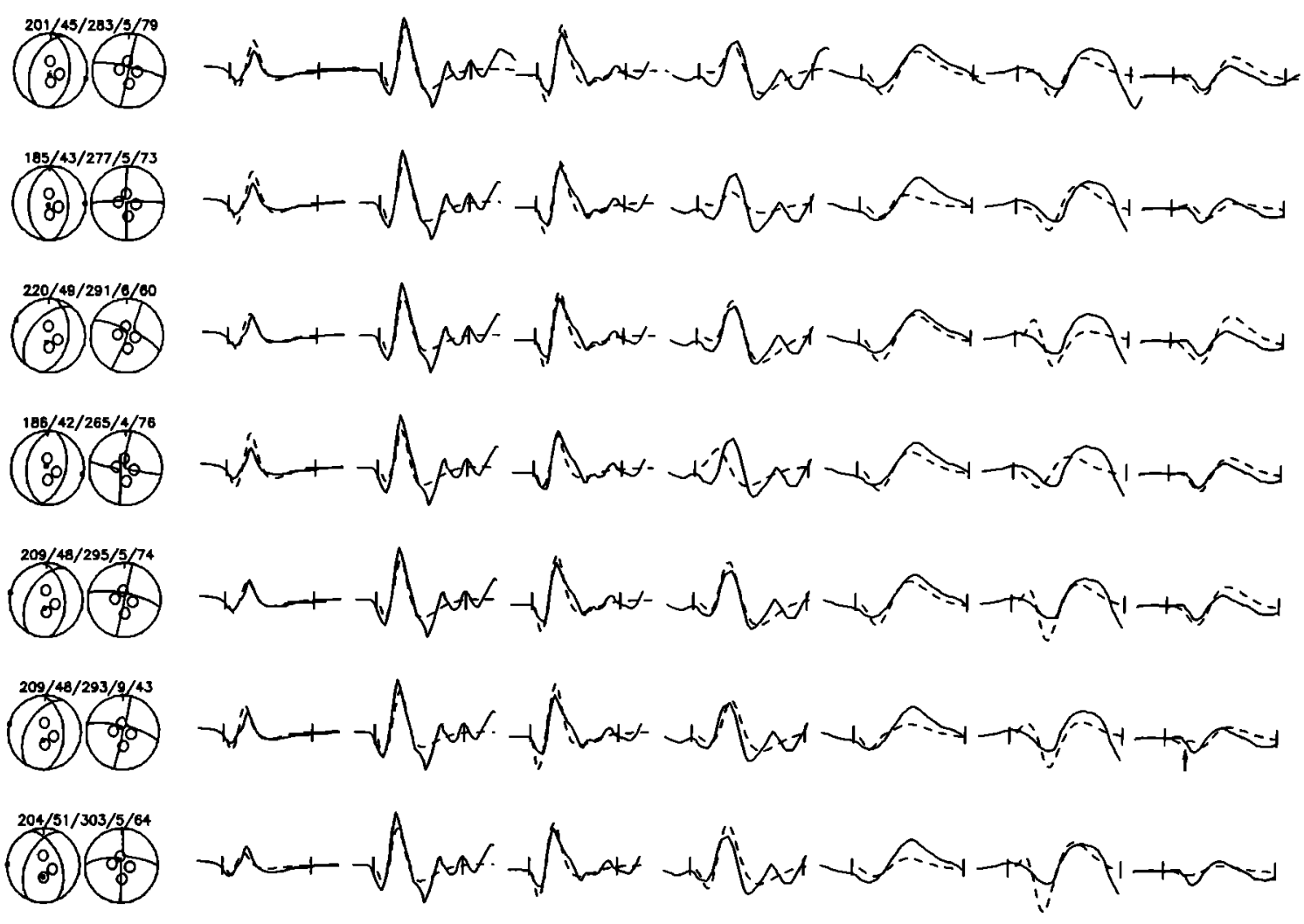

Fig. $9 b$. Sensitivity of waveforms to variations in strike, rake and depth at seven selected stations. Row 1 is the solution in Figure 9a. Row 2-6, one parameter was fixed (strike in rows 2 and 3, rake in rows 4 and 5, depth in row 6) and waveforms were inverted for the remaining ones. The arrow on row 6 at KBS indicates arrival of $s S$ phase. Row 7 is Papazachos et al's [1988] solution. Numbers on top of each focal sphere areinstrike/dip/rake/depth/moment $\times 10^{16}$.

\section{Focal Mechanisms}

Station polarities for the events selected above and that had more than six readings were plotted on a focal sphere using incidence angles given by HYPO71. From these plots, only the events for which nodal planes could be drawn without too much uncertainty were kept and will be discussed in this study. As pointed out before [e.g., Ouyed et al., 1983], the assumed velocity structure does not have much influence on the determination of the nodal planes for the deeper events. The main problem is with focal solutions that involve refracted rays. This occurs for events located above a velocity discontinuity (here 2 and $5 \mathrm{~km}$ ). For those rays the projection on the focal sphere may strongly depend upon the assumed velocity structure. We choose to show only the solutions for which the orientation and nature of the focal solution remain roughly unchanged if no velocity discontinuity was present. Often the solutions have only one well-constrained nodal plane. In this case we choose to show the solution that minimizes the strike slip component of the mechanism.

We calculated 133 focal solutions and show their polarity readings in Figure 11. All parameters for these solutions are listed in Table 3 . We also present map views of the distribution of focal mechanisms by depth range (Figure 12)

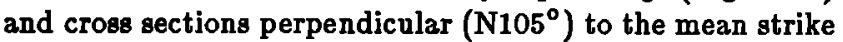
of the surface fault trace (Figure 14).
TABLE 2. Station Coordinates and Velocity Structure

\begin{tabular}{|c|c|c|}
\hline Code & Latitude & Longitude \\
\hline $\begin{array}{l}\text { EVA } \\
\text { KAR } \\
\text { KAT1 } \\
\text { KAT2 } \\
\text { KDIO } \\
\text { KEN } \\
\text { KIT } \\
\text { KKAL } \\
\text { KKAM } \\
\text { KNED } \\
\text { KPER } \\
\text { KPRO } \\
\text { KVAS } \\
\text { PET } \\
\text { POL } \\
\text { RIZ } \\
\text { THO }\end{array}$ & 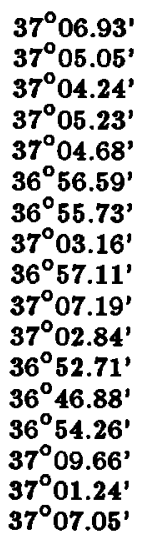 & $\begin{array}{l}21^{\circ} 57.82^{\prime} \\
22^{\circ} 11.45^{\prime} \\
22^{\circ} 15.84^{\prime} \\
22^{\circ} 15.47^{\prime} \\
21^{\circ} \mathbf{5 1 . 3 9} \\
22^{\circ} 15.37^{\prime} \\
22^{\circ} 09.05^{\prime} \\
22^{\circ} 08.24^{\prime} \\
22^{\circ} 11.48^{\prime} \\
22^{\circ} 12.47^{\prime} \\
22^{\circ} 10.85^{\prime} \\
22^{\circ} 14.93^{\prime} \\
21^{\circ} 55.83^{\prime} \\
21^{\circ} 51.31^{\prime} \\
22^{\circ} 07.87^{\prime} \\
22^{\circ} 15.577^{\prime} \\
{ }^{\circ} 04.5{ }^{\prime}\end{array}$ \\
\hline \multicolumn{2}{|c|}{$P$ Velocity, km/s } & Depth, km \\
\hline \multicolumn{2}{|c|}{$\begin{array}{l}5.4 \\
6.0\end{array}$} & $\begin{array}{l}0.0 \\
2.0 \\
5.0\end{array}$ \\
\hline
\end{tabular}

Poisson's ratio is 0.25 


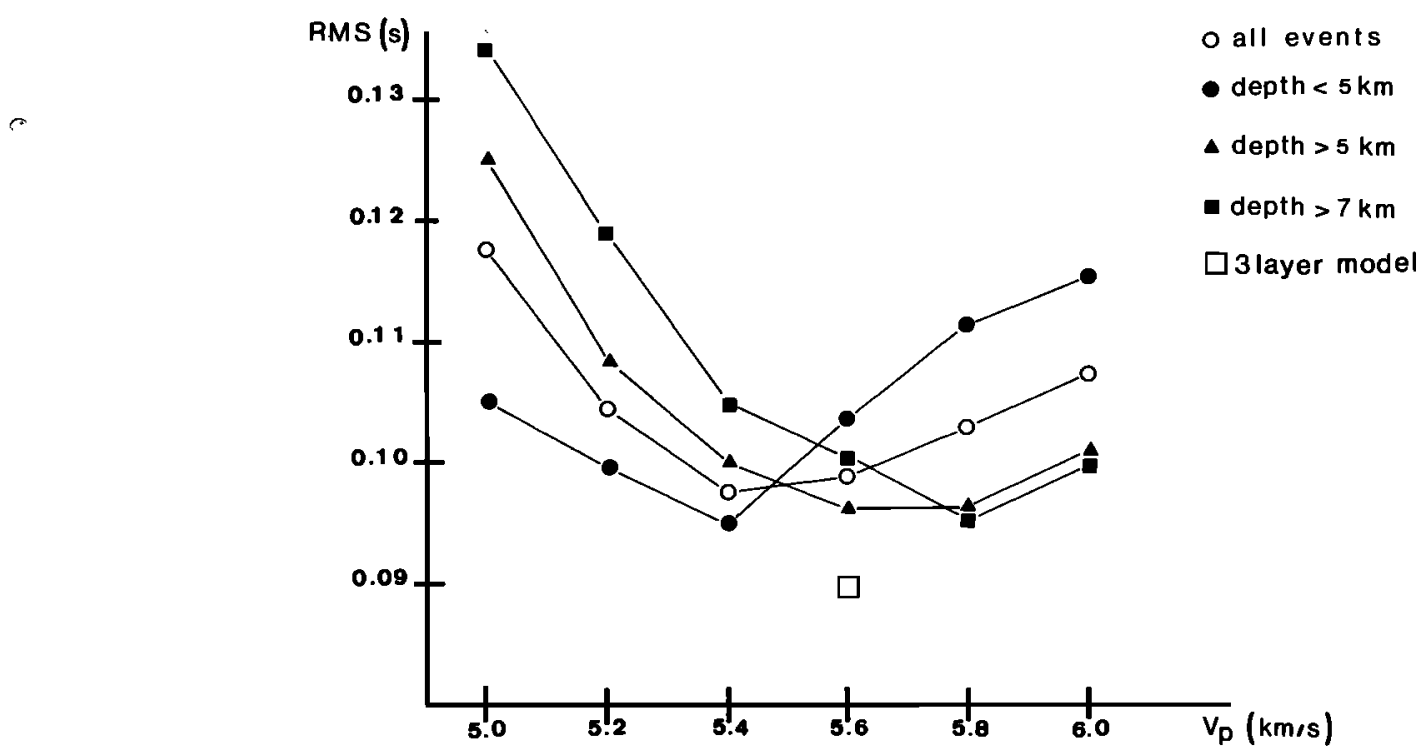

Fig. 10. Plot of mean rms given by HYPO71 of 100 selected aftershocks versus the assumed half-space $P$ velocity. Note that the velocity at which the minimum rms occurs depends upon the depth of events considered. The three layer velocity model chosen is listed in Table 2.

\section{Aftershocks Distribution AND FOCAL MECHANISMS}

The aftershocks cover an area of about 15 by $10 \mathrm{~km}$ and can be separated into two clusters in map view (Figure 8). The main cluster located to the south can clearly be associated with the observed surface rupture and will be called below the Kalamata fault cluster. Farther north, the second cluster is located away from the surface rupture, within the relay zone north of the Kalamata fault zone, between the Thouria and Kalamata faults (Figures $2 a$ and $8 b$ ). Between the two clusters there is a well-defined "gap" of aftershock activity over a width of $2 \mathrm{~km}$ and down to a depth of about $8 \mathrm{~km}$ (Figures 8 and 13). These two separated zones of seismicity seem to join at a depth of 9-10 km (Figure 13). No events deeper than $12 \mathrm{~km}$ were located, most of them being confined to the 10 first kilometers of the crust.

\section{Kalamata Fault Cluster}

On cross sections $b$ and $c$ perpendicular to the fault trace (Figures $14 b$ and 14c) the cluster appears clearly as a northwestward dipping zone, although in its southernmost part (Figure 14c) the seismicity seems to be more diffuse than in its northern part (Figure 14b). On Figure $14 b$ we show the observed surface geometry with the fault plane dipping about $50^{\circ}$ as well as its downward extension, dipping $45^{\circ}$, in agreement with the main shock focal mechanism solution (i.e., the "average" fault plane shown with a dashed line on Figure 146, Table 4). The two parallel lines bound a sone labeled $\mathrm{F}$ within which all hypocenters are at a distance less than $0.85 \mathrm{~km}$ from that "average" fault plane. This distance corresponds to a variation in depth of $\pm 2 \mathrm{~km}$, which represents the depth location uncertainty. Thus all hypocenters enclosed in zone $F$ can be considered, within location uncertainties, to lie on the master fault plane defined both by surface and deep data. Clearly, the great majority of events in the northern part of the cluster (Figure 14b) lie within zone $F$, and the activity is continuous from about 2 to $10 \mathrm{~km}$. The remaining events occur below F, in the footwall.

The seismicity in the southern part of the cluster (Figure $14 c$ ) is more diffuser and seems to occur mostly in the footwall as defined by the extension of zone $F$ to the south. Such deformation in the footwall may be related to the fault bend in the vicinity of the cross section (Figure 8) where the surface fault strike changes from about $\mathrm{N} 30^{\circ} \mathrm{E}$ in the north to $\mathrm{N} 10^{\circ} \mathrm{E}$ in the south. Alternatively, the fault plane may be steeper $\left(\simeq 55^{\circ}-60^{\circ}\right)$ there than farther north (which would not be surprising in view of the topography and morphology of the two areas).

Almost all focal mechanisms within zone $F$ (both in the northern and southern part of the cluster; Figures 12, 14b, and 14c) show normal faulting consistent with the main shock mechanism, continuously from a depth of 10 to $4 \mathrm{~km}$. However, the dip of the individual fault planes of aftershocks mechanism are steeper $\left(55^{\circ}\right.$ or $\left.60^{\circ}\right)$ than that defined by both the aftershocks distribution and the main shock focal mechanism $\left(45^{\circ}\right)$. For these events (e.g., 1, 5, 8, 35, 44, 50, $75,119,121)$ the dip of the fault plane is usually constrained by the polarity reading at KPER. In most cases a clear compression was observed at this station which lies just on the fault trace. Without a very reliable velocity model it is not easy to evaluate the significance of such an observation. Variations of about $10^{\circ}$ of the incidence angle can probably occur by perturbing the velocity structure (i.e., by introducing velocity gradients) or because of inhomogeneities in the vicinity of the fault plane. Thus the discrepancy between the fault plane dip of aftershocks and that of the main shock could be a consequence of the simple structure used. However, if this discrepancy is real, it can be compared to the steep en échelon fault planes observed at the surface $\left(\simeq 60^{\circ}\right.$ $\left.70^{\circ}\right)$ as opposed to a less steep average fault plane deduced from detailed mapping ( $\simeq 50^{\circ}$ ) (see Figure 6). Such an en échelon geometry of faulting has often been observed at various scales and within different rock types [e.g., Tchalenko, 

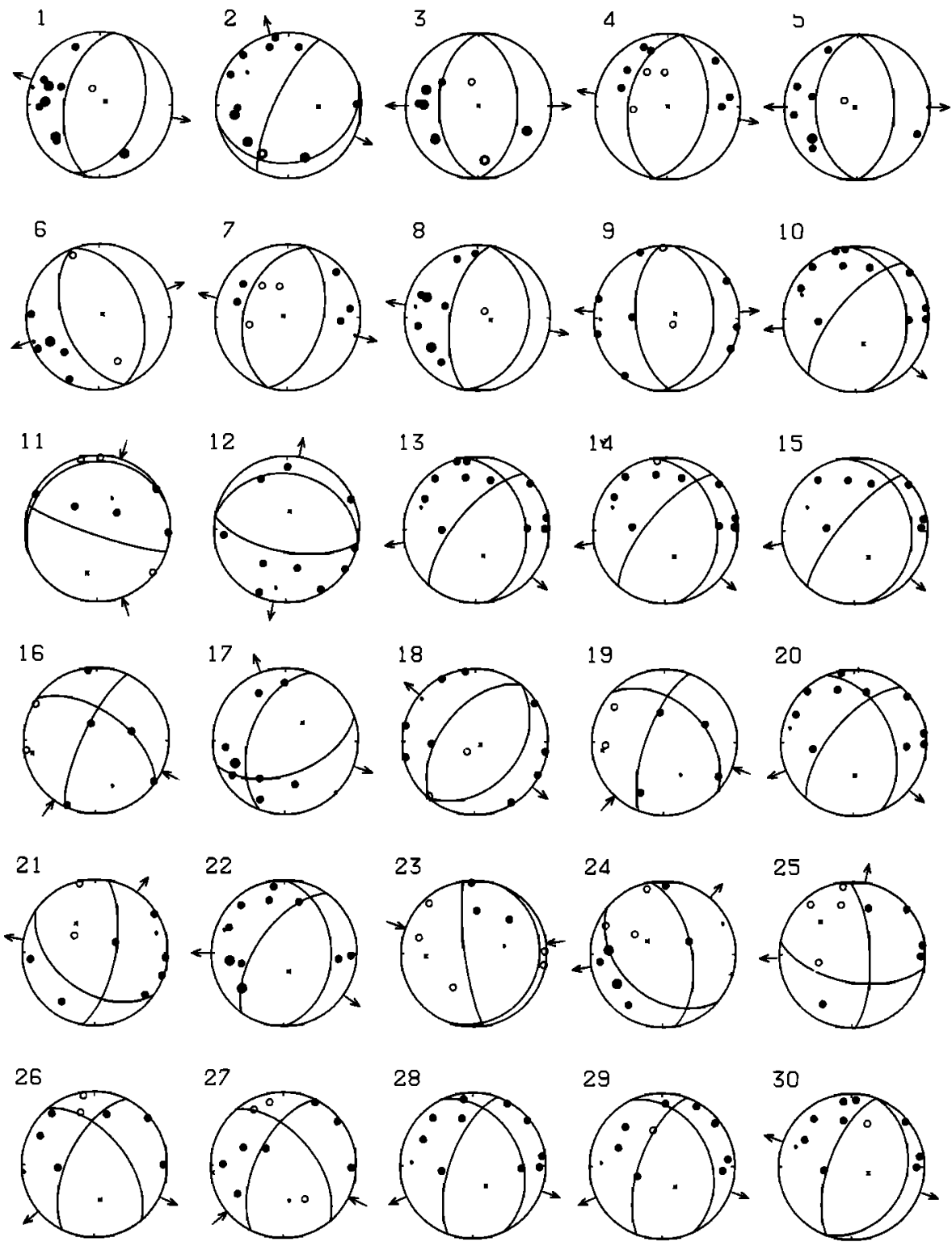

30
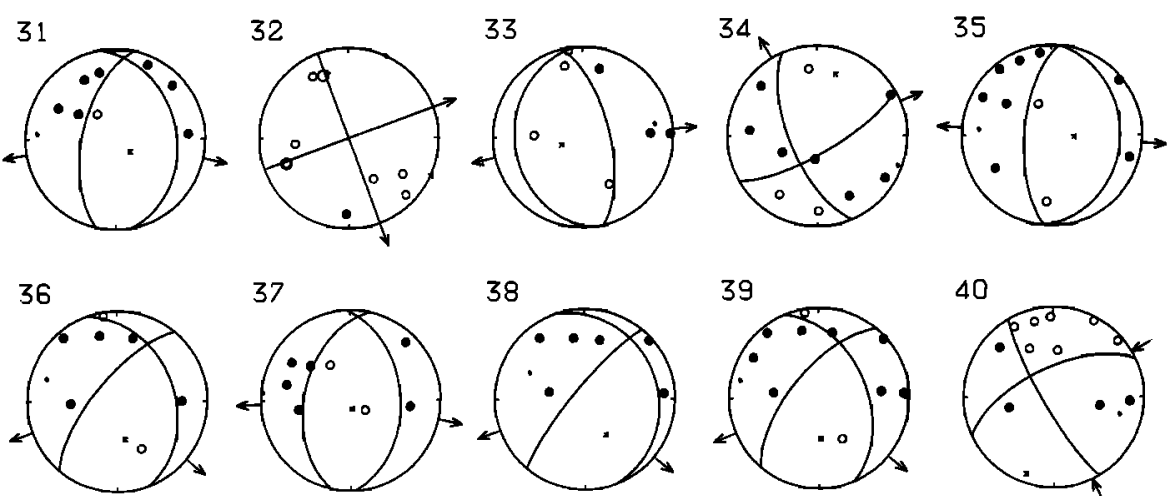

38
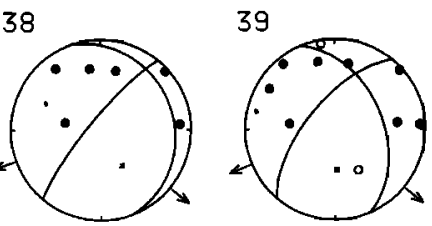

40
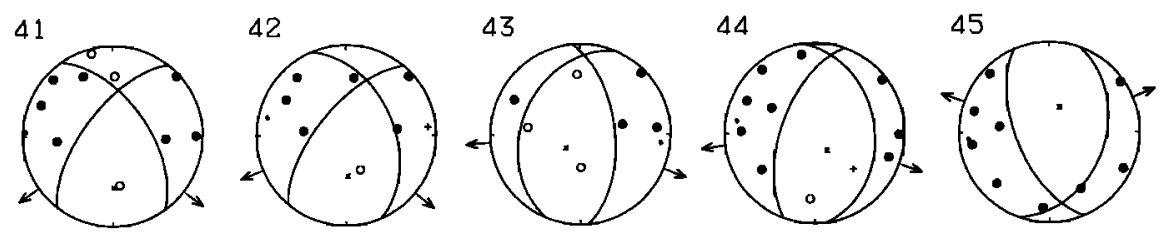

Fig. 11. Focal mechanisms of 133 aftershocks plotted on the lower hemisphere. Solid circles are compressions; open circles are dilatations. Refracted arrivals are indicated with larger circles. $P$ and $T$ axis are also indicated in addition to the slip direction on each of the nodal planes. Earthquake and focal solution parameters are listed in Table 3. 

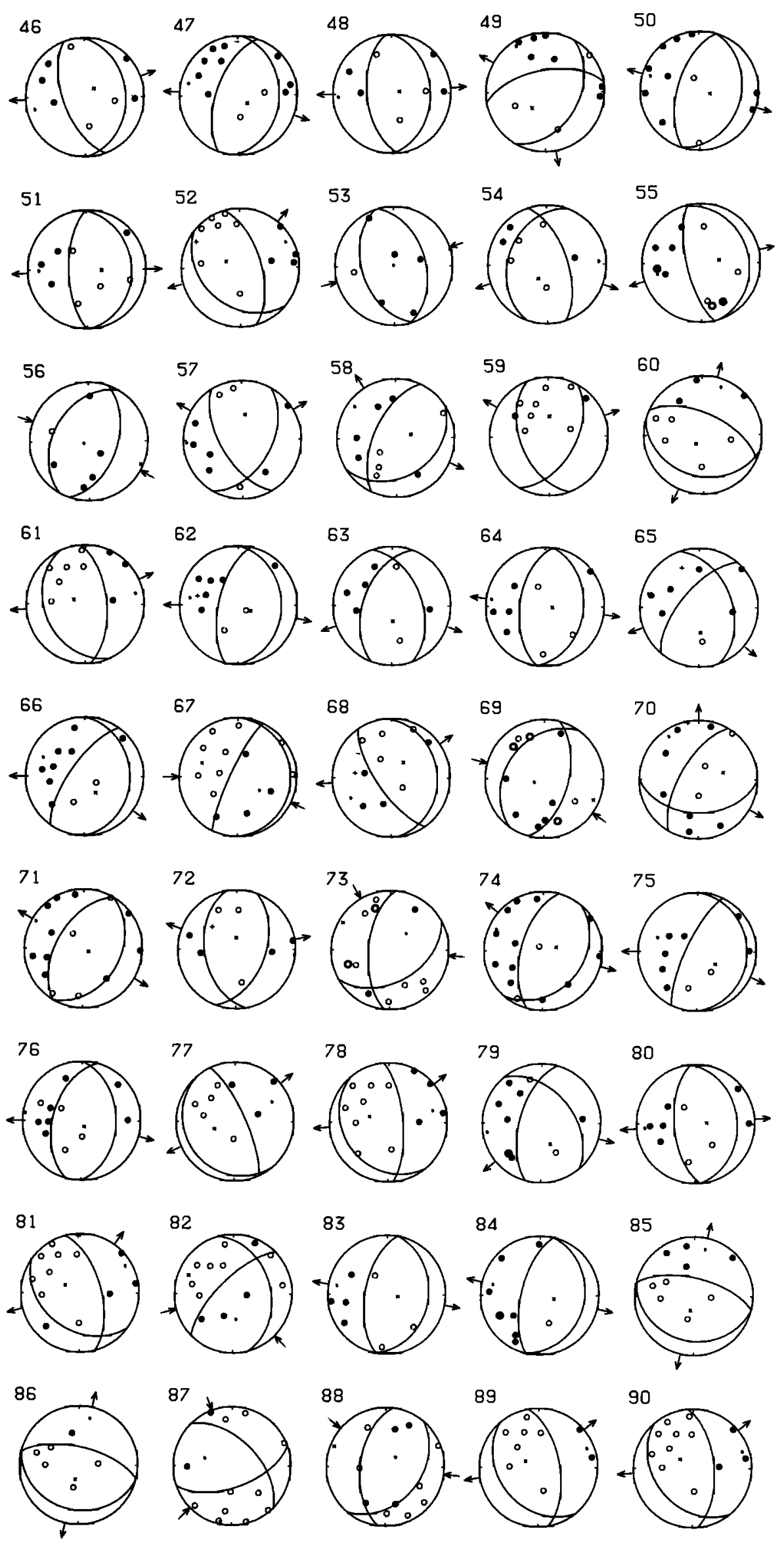

Fig. 11. (continued) 

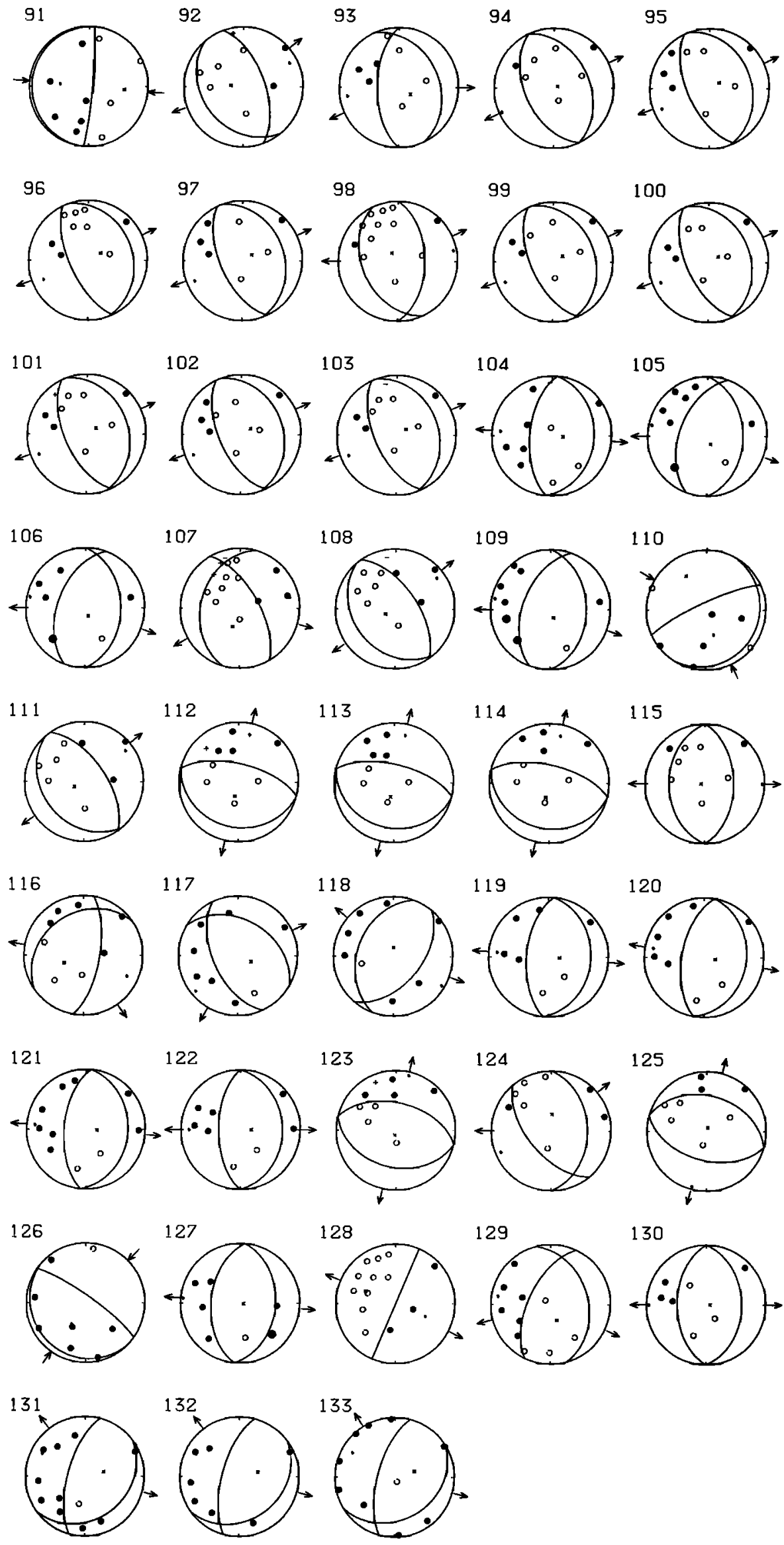

Fig. 11. (continued) 
TABLE 3. List of Location Parameters for the 133 Aftershocks Shown With their Focal Mechanisms in Figure 11

\begin{tabular}{|c|c|c|c|c|c|c|c|c|c|c|c|c|c|}
\hline Event & $\begin{array}{c}\text { Day } \\
\text { Sep.1986 }\end{array}$ & $\begin{array}{l}\text { Time } \\
\text { GMT }\end{array}$ & $\begin{array}{c}\text { Latitude } \\
\mathbf{3 7}^{\circ}\end{array}$ & $\begin{array}{c}\text { Longitude } \\
2^{\circ}\end{array}$ & $\begin{array}{c}\text { Depth, } \\
\text { km }\end{array}$ & $\begin{array}{l}\text { Mag- } \\
\text { nitude }\end{array}$ & $\begin{array}{c}\text { rms, } \\
\mathbf{8}\end{array}$ & $\begin{array}{c}\text { ERX, } \\
\text { km }\end{array}$ & $\begin{array}{c}\text { ERY, } \\
\text { km }\end{array}$ & $\begin{array}{c}\text { ERZ, } \\
\text { km }\end{array}$ & $\begin{array}{l}\text { Strike, } \\
\text { deg }\end{array}$ & $\begin{array}{l}\text { Dip, } \\
\text { deg }\end{array}$ & $\begin{array}{c}\text { Rake, } \\
\text { deg }\end{array}$ \\
\hline 1 & 18 & $1452: 23.5$ & 3.98 & 7.76 & 4.73 & 1.84 & 0.12 & 0.4 & 0.4 & 0.6 & 190. & 50. & -97 \\
\hline 2 & 18 & $1527: 01.4$ & 7.06 & 9.13 & 3.39 & 2.23 & 0.14 & 0.4 & 0.5 & 1.1 & 205. & 75. & -107 \\
\hline 3 & 18 & $1614: 55.2$ & 4.46 & 7.76 & 4.85 & 1.42 & 0.15 & 0.6 & 0.5 & 0.5 & 180. & 45. & -90. \\
\hline 4 & 19 & $0146: 30.3$ & 6.86 & 7.82 & 9.43 & 2.40 & 0.04 & 0.2 & 0.2 & 0.5 & 190. & 45. & -90. \\
\hline 5 & 19 & 0229:32.3 & 3.45 & 7.53 & 4.14 & 0.89 & 0.07 & 0.6 & 0.3 & 0.5 & 180. & 42. & -90. \\
\hline 6 & 19 & 0309:47.9 & 1.44 & 9.14 & 2.72 & 0.99 & 0.07 & 0.4 & 0.3 & 0.9 & 158. & 60. & -91 \\
\hline 7 & 19 & 0414:06.4 & 6.35 & 7.24 & 9.15 & 0.99 & 0.07 & 0.4 & 0.6 & 1.0 & 193. & 45. & -92 \\
\hline 8 & 19 & 0743:00.2 & 3.47 & 8.67 & 4.40 & 2.07 & 0.07 & 0.3 & 0.2 & 0.3 & 190. & 60. & -90. \\
\hline 9 & 19 & 0824:06.8 & 2.89 & 8.61 & 5.00 & 2.14 & 0.04 & 0.1 & 0.1 & 0.2 & 175. & 55. & -96 \\
\hline 10 & 19 & 0942:18.3 & 7.01 & 9.55 & 5.73 & 2.02 & 0.07 & 0.2 & 0.3 & 0.6 & 220. & 68. & -68. \\
\hline 11 & 19 & $1007: 02.8$ & 3.95 & 9.42 & 5.00 & 1.97 & 0.10 & 0.4 & 0.4 & 0.5 & 108. & 82. & 96. \\
\hline 12 & 19 & 1053:13.3 & 0.81 & 9.11 & 5.44 & 2.06 & 0.08 & 0.3 & 0.2 & 0.6 & 100. & 70. & -90. \\
\hline 13 & 19 & $1207: 25.6$ & 7.17 & 9.67 & 6.12 & 2.17 & 0.06 & 0.2 & 0.2 & 0.5 & 220. & 68. & -66 \\
\hline 14 & 19 & 1208:17.5 & 7.40 & 9.85 & 5.88 & 1.89 & 0.04 & 0.1 & 0.2 & 0.4 & 220. & 70. & -68. \\
\hline 15 & 19 & 1211:37.3 & 7.41 & 10.04 & 6.70 & 1.85 & 0.04 & 0.2 & 0.2 & 0.3 & 220. & 75. & -73 \\
\hline 16 & 19 & $1404: 50.2$ & 3.66 & 10.53 & 5.00 & 1.67 & 0.07 & 0.3 & 0.3 & 0.5 & 205. & 75. & 145. \\
\hline 17 & 19 & $1411: 36.0$ & 0.65 & 8.98 & 4.18 & 1.59 & 0.08 & 0.4 & 0.2 & 1.0 & 199. & 50. & -127 \\
\hline 18 & 19 & $1449: 43.6$ & 2.72 & 7.81 & 5.00 & 1.81 & 0.08 & 0.2 & 0.3 & 0.4 & 218. & 52. & -91. \\
\hline 19 & 19 & $1732: 28.8$ & 4.04 & 10.64 & 3.52 & 1.43 & 0.04 & 0.2 & 0.2 & 0.4 & 200. & 70. & 129. \\
\hline 20 & 19 & $2056: 49.3$ & 6.81 & 9.34 & 5.55 & 1.98 & 0.05 & 0.1 & 0.2 & 0.4 & 220. & 65. & -51 \\
\hline 21 & 19 & 2322:34.9 & 3.70 & 9.53 & 5.22 & 1.71 & 0.09 & 0.2 & 0.3 & 0.6 & 125. & 46. & -146 \\
\hline 22 & 20 & $0006: 18.6$ & 6.62 & 9.50 & 4.10 & 1.77 & 0.07 & 0.2 & 0.3 & 0.6 & 215. & 60. & -71 \\
\hline 23 & 20 & $0006: 39.5$ & 5.31 & 11.05 & 5.20 & 2.04 & 0.10 & 0.3 & 0.4 & 0.9 & 172. & 80. & 85. \\
\hline 24 & 20 & 0147:04.9 & 3.63 & 9.46 & 3.31 & 1.98 & 0.10 & 0.3 & 0.3 & 0.7 & 131. & 40. & -122 \\
\hline 25 & 20 & $0235: 52.7$ & 6.69 & 9.76 & 6.03 & 1.65 & 0.08 & 0.4 & 0.3 & 0.6 & 358. & 70. & -33 \\
\hline 26 & 20 & 0466:06.1 & 6.99 & 9.47 & 5.90 & 1.64 & 0.08 & 0.5 & 0.5 & 0.7 & 206. & 60. & -42. \\
\hline 27 & 20 & $0542: 32.6$ & 4.33 & 6.71 & 6.91 & 2.35 & 0.15 & 0.5 & 0.6 & 1.0 & 290. & 70. & 0. \\
\hline 28 & 20 & $0602: 59.0$ & 6.82 & 9.70 & 6.58 & 2.21 & 0.08 & 0.2 & 0.3 & 0.7 & 200. & 65. & -67 \\
\hline 29 & 20 & $0621: 15.0$ & 6.29 & 9.74 & 8.23 & 3.00 & 0.05 & 0.3 & 0.7 & 1.1 & 200. & 65. & -67 \\
\hline 30 & 20 & 0717:33.0 & 6.94 & 9.95 & 6.97 & 2.11 & 0.07 & 0.2 & 0.4 & 0.9 & 200. & 65. & -90 \\
\hline 31 & 20 & $1058: 01.8$ & 5.45 & 6.24 & 10.53 & 0.61 & 0.05 & 0.5 & 0.6 & 0.7 & 193. & 60. & -78 \\
\hline 32 & 20 & $1443: 27.0$ & 0.98 & 12.24 & 4.42 & 1.04 & 0.06 & 0.2 & 0.2 & 0.4 & 340. & 90. & 180. \\
\hline 33 & 20 & 1508:13.6 & 7.29 & 9.50 & 5.46 & 1.29 & 0.07 & 0.2 & 0.3 & 0.7 & 170. & 25. & -87 \\
\hline 34 & 20 & $1633: 29.2$ & 1.79 & 8.06 & 7.33 & 1.03 & 0.15 & 0.5 & 0.4 & 0.9 & 157. & 65. & -163 \\
\hline 35 & 20 & $1636: 28.0$ & 4.80 & 7.39 & 6.37 & 1.45 & 0.15 & 0.4 & 0.4 & 1.1 & 185. & 65. & -90 \\
\hline 36 & 20 & $1823: 44.6$ & 7.07 & 9.48 & 5.80 & 0.55 & 0.07 & 0.3 & 0.3 & 0.7 & 220. & 70. & -59 \\
\hline 37 & 20 & $1826: 14.3$ & 6.26 & 5.98 & 9.65 & 1.09 & 0.08 & 0.3 & 0.4 & 0.6 & 192. & 48. & -80 \\
\hline 38 & 20 & 1837:68.2 & 7.64 & 9.75 & 7.15 & 2.04 & 0.06 & 0.2 & 0.3 & 0.5 & 220. & 80. & -73 \\
\hline 39 & 20 & $1900: 44.1$ & 7.49 & 9.41 & 6.00 & 1.31 & 0.09 & 0.2 & 0.3 & 0.6 & 220. & 65. & -51 \\
\hline 40 & 20 & 1924:58.1 & 6.45 & 8.61 & 7.52 & 1.70 & 0.10 & 0.3 & 0.3 & 0.6 & 150. & 80. & 153. \\
\hline 41 & 20 & 2021:25.6 & 6.89 & 8.38 & 6.11 & 1.20 & 0.11 & 0.3 & 0.3 & 0.6 & 218. & 65. & -35 \\
\hline 42 & 20 & 2058:22.1 & 7.50 & 9.04 & 7.26 & 1.28 & 0.07 & 0.3 & 0.4 & 0.6 & 220. & 65. & -51 \\
\hline 43 & 20 & 2234:16.2 & 7.68 & 7.90 & 7.09 & 1.15 & 0.06 & 0.2 & 0.3 & 0.5 & 203. & 35 . & -67 \\
\hline 44 & 20 & $2346: 14.4$ & 4.47 & 7.41 & 6.86 & 1.53 & 0.13 & 0.4 & 0.4 & 1.1 & 200. & 60. & -75 \\
\hline 45 & 21 & $0015: 15.8$ & 3.19 & 7.22 & 6.29 & 1.01 & 0.12 & 0.4 & 0.4 & 0.9 & 158. & 60. & -114 \\
\hline 46 & 21 & 0042:35.9 & 6.66 & 8.37 & 7.38 & 1.70 & 0.12 & 0.4 & 0.5 & 1.1 & 160. & 60. & -99 \\
\hline 47 & 21 & 0048:45.3 & 7.37 & 8.13 & 8.12 & 1.79 & 0.09 & 0.3 & 0.4 & 0.7 & 200. & 60. & -82 \\
\hline 48 & 21 & $0121: 30.8$ & 7.29 & 8.73 & 6.75 & 1.25 & 0.10 & 0.4 & 0.7 & 1.1 & 175. & 55. & -93 \\
\hline 49 & 21 & $0549: 22.6$ & 6.05 & 9.30 & 6.14 & 1.88 & 0.12 & 0.4 & 0.3 & 0.8 & 260. & 60. & -59 \\
\hline 50 & 21 & $0615: 54.9$ & 3.99 & 7.79 & 5.55 & 1.48 & 0.13 & 0.4 & 0.3 & 0.7 & 197. & 60. & -90 \\
\hline 51 & 21 & $1157: 06.8$ & 5.18 & 6.39 & 8.37 & 1.29 & 0.10 & 0.3 & 0.3 & 0.7 & 180. & 65. & -89 \\
\hline 52 & 21 & $1220: 33.6$ & 7.64 & 7.85 & 6.10 & 1.50 & 0.07 & 0.2 & 0.3 & 0.7 & 345. & 60. & -71. \\
\hline 53 & 21 & 1519:58.3 & 3.71 & 10.93 & 6.13 & 0.96 & 0.07 & 0.3 & 0.2 & 0.6 & 162. & 45. & 87. \\
\hline 54 & 21 & $1824: 32.0$ & 7.63 & 7.78 & 6.85 & 1.10 & 0.10 & 0.3 & 0.4 & 0.7 & 200 & 35. & -57 \\
\hline 55 & 21 & $1955: 25.1$ & 6.26 & 8.58 & 4.91 & 1.76 & 0.12 & 0.2 & 0.3 & 0.5 & 167. & 70. & -88 \\
\hline 56 & 21 & 2321:11.5 & 2.10 & 11.74 & 4.68 & 1.17 & 0.06 & 0.2 & 0.2 & 0.3 & 210. & 40. & 98. \\
\hline 57 & 22 & 0021:29.7 & 3.61 & 7.51 & 6.56 & 1.57 & 0.07 & 0.3 & 0.2 & 0.7 & 150. & 60. & -131 \\
\hline 58 & 22 & $0419: 10.6$ & 1.30 & 8.62 & 8.43 & 1.30 & 0.06 & 0.3 & 0.2 & 0.8 & 205. & 60. & -108 \\
\hline 59 & 22 & $0548: 23.1$ & 8.04 & 8.33 & 10.19 & 1.99 & 0.04 & 0.3 & 0.2 & 0.5 & 159. & 50. & -127 \\
\hline 60 & 22 & 0603:05.6 & 6.63 & 7.66 & 6.63 & 1.36 & 0.14 & 0.4 & 0.5 & 1.0 & 295. & 60. & -85 \\
\hline 61 & 22 & $1009: 05.4$ & 7.45 & 7.93 & 7.31 & 2.12 & 0.11 & 0.4 & 0.6 & 1.0 & 355. & 60. & -79 \\
\hline 62 & 22 & $1033: 52.0$ & 6.45 & 5.65 & 9.13 & 1.37 & 0.06 & 0.3 & 0.3 & 0.3 & 192. & 63. & -84 \\
\hline 63 & 22 & $1043: 27.8$ & 6.74 & 8.71 & 4.91 & 1.16 & 0.07 & 0.2 & 0.3 & 0.6 & 199. & 50. & -62 \\
\hline 64 & 22 & $1111: 47.2$ & 4.60 & 7.62 & 5.84 & 1.39 & 0.13 & 0.5 & 0.5 & 1.0 & 187. & 55. & -90 \\
\hline 65 & 22 & $1112: 35.5$ & 6.66 & 8.27 & 6.12 & 1.60 & 0.07 & 0.2 & 0.3 & 0.7 & 220. & 65. & -54 \\
\hline 66 & 22 & 1138:07.0 & 6.36 & 6.15 & 9.07 & 1.62 & 0.10 & 0.4 & 0.4 & 0.6 & 220. & 70. & -74 \\
\hline 67 & 22 & $1215: 46.0$ & 5.41 & 9.29 & 7.50 & 1.94 & 0.08 & 0.3 & 0.2 & 0.6 & 205. & 80. & 95. \\
\hline 68 & 22 & $1226: 30.6$ & 5.76 & 6.36 & 10.65 & 1.42 & 0.09 & 0.4 & 0.3 & 0.5 & 145. & 70. & -102 \\
\hline
\end{tabular}


TABLE 3. (continued)

\begin{tabular}{|c|c|c|c|c|c|c|c|c|c|c|c|c|c|}
\hline Event & $\begin{array}{c}\text { Day } \\
\text { Sep.1986 }\end{array}$ & $\begin{array}{l}\text { Time } \\
\text { GMT }\end{array}$ & $\begin{array}{l}\text { Latitude } \\
\mathbf{3 7}^{\mathbf{0}}\end{array}$ & $\begin{array}{c}\text { Longitude } \\
22^{\circ}\end{array}$ & $\begin{array}{c}\text { Depth, } \\
\text { km }\end{array}$ & $\begin{array}{l}\text { Mag- } \\
\text { nitude }\end{array}$ & rms, & $\begin{array}{c}\text { ERX, } \\
\text { km }\end{array}$ & $\begin{array}{c}\text { ERY, } \\
\mathbf{k m}\end{array}$ & $\begin{array}{c}\text { ERZ, } \\
\text { km }\end{array}$ & $\begin{array}{c}\text { Strike, } \\
\text { deg }\end{array}$ & $\begin{array}{l}\text { Dip, } \\
\text { deg }\end{array}$ & $\begin{array}{c}\text { Rake, } \\
\text { deg }\end{array}$ \\
\hline 69 & 22 & 1304:17.2 & 1.24 & 11.54 & 4.71 & 1.50 & 0.06 & 0.2 & 0.1 & 0.3 & 216. & 35. & 107. \\
\hline 70 & 22 & 1354:12.5 & 3.86 & 11.47 & 6.08 & 1.24 & 0.08 & 0.3 & 0.2 & 0.4 & 210. & 65. & -126 \\
\hline 71 & 22 & $1611: 30.9$ & 4.25 & 7.28 & 6.11 & 1.88 & 0.15 & 0.6 & 0.5 & 1.2 & 210. & 53. & -90 \\
\hline 72 & 22 & $1732: 10.9$ & 6.83 & 8.47 & 6.05 & 1.19 & 0.07 & 0.3 & 0.3 & 0.7 & 170. & 45. & -113 \\
\hline 73 & 22 & $1737: 29.1$ & 0.08 & 12.31 & 4.33 & 1.69 & 0.13 & 0.3 & 0.2 & 0.8 & 185. & 60. & 54. \\
\hline 74 & 22 & $1855: 17.4$ & 3.47 & 7.90 & 6.40 & 1.74 & 0.09 & 0.3 & 0.2 & 0.6 & 195. & 60. & -103 \\
\hline 75 & 22 & 1908:48.7 & 4.80 & 6.49 & 8.38 & 1.71 & 0.09 & 0.3 & 0.3 & 0.5 & 205. & 75. & -83 \\
\hline 76 & 22 & 2202:32.0 & 4.89 & 4.63 & 10.41 & 1.30 & 0.15 & 0.8 & 0.7 & 1.1 & 195. & 50. & -80 \\
\hline 77 & 22 & $2244: 50.9$ & 7.89 & 7.76 & 8.20 & 1.09 & 0.08 & 0.4 & 0.4 & 0.7 & 335 . & 75. & -86 \\
\hline 78 & 22 & 2333:25.0 & 7.13 & 8.28 & 7.04 & 1.52 & 0.10 & 0.3 & 0.3 & 0.6 & 355. & 70. & -77 \\
\hline 79 & 23 & $0010: 12.9$ & 7.47 & 9.27 & 4.67 & 1.15 & 0.11 & 0.3 & 0.3 & 0.6 & 195. & 60. & -54 \\
\hline 80 & 23 & $0036: 09.6$ & 4.84 & 6.78 & 7.84 & 1.38 & 0.08 & 0.3 & 0.3 & 0.6 & 175. & 60. & -90 \\
\hline 81 & 23 & $0115: 41.5$ & 6.99 & 7.81 & 6.41 & 2.16 & 0.08 & 0.2 & 0.2 & 0.7 & 345. & 60. & -67 \\
\hline 82 & 23 & 0219:54.4 & 6.92 & 6.52 & 9.20 & 1.50 & 0.10 & 0.3 & 0.3 & 0.6 & 225. & 70. & 121. \\
\hline 83 & 23 & $0516: 42.7$ & 4.42 & 7.28 & 6.31 & 0.84 & 0.05 & 0.3 & 0.2 & 0.5 & 190. & 60. & -90 . \\
\hline 84 & 23 & 0608:23.3 & 1.60 & 8.90 & 3.79 & 1.33 & 0.11 & 0.5 & 0.2 & 0.8 & 193. & 65. & -90 \\
\hline 85 & 23 & 0913:10.1 & 6.91 & 6.94 & 8.84 & 1.17 & 0.08 & 0.3 & 0.3 & 0.5 & 103. & 25. & -90 \\
\hline 86 & 23 & $0914: 13.8$ & 7.19 & 7.13 & 8.45 & 1.17 & 0.05 & 0.3 & 0.3 & 0.5 & 103. & 25. & -90. \\
\hline 87 & 23 & $1122: 10.9$ & 1.15 & 10.78 & 5.26 & 1.74 & 0.09 & 0.3 & 0.2 & 0.7 & 70. & 61. & 43. \\
\hline 88 & 23 & $1136: 22.4$ & 1.11 & 12.77 & 6.70 & 1.21 & 0.09 & 0.3 & 0.1 & 0.5 & 39. & 40. & 116. \\
\hline 89 & 23 & $1352: 05.5$ & 7.30 & 8.57 & 7.83 & 1.42 & 0.07 & 0.2 & 0.2 & 0.5 & 350. & 60. & -74 \\
\hline 90 & 23 & 1412:16.7 & 7.26 & 8.10 & 7.91 & 1.59 & 0.13 & 0.4 & 0.4 & 0.7 & 355. & 60. & -71 \\
\hline 91 & 23 & $1449: 29.9$ & 1.73 & 10.60 & 6.54 & 1.72 & 0.13 & 0.5 & 0.3 & 1.1 & 185. & 5. & 90. \\
\hline 92 & 23 & $1510: 43.2$ & 7.13 & 8.26 & 7.18 & 1.84 & 0.06 & 0.2 & 0.2 & 0.3 & 340. & 60. & -79 \\
\hline 93 & 23 & 1613:33.1 & 7.82 & 8.28 & 7.92 & 1.11 & 0.04 & 0.1 & 0.2 & 0.3 & 180. & 60. & -77 \\
\hline 94 & 23 & $1655: 24.8$ & 8.44 & 8.43 & 8.02 & 0.99 & 0.06 & 0.3 & 0.4 & 0.6 & 335. & 40. & -90. \\
\hline 95 & 23 & $1727: 06.6$ & 7.29 & 7.44 & 7.12 & 1.37 & 0.11 & 0.3 & 0.4 & 0.6 & 155. & 60. & -93. \\
\hline 96 & 23 & 1731:40.4 & 7.87 & 8.01 & 9.64 & 1.49 & 0.07 & 0.3 & 0.4 & 0.6 & 155. & 65. & -92. \\
\hline 97 & 23 & $1750: 13.4$ & 7.94 & 7.76 & 7.63 & 1.20 & 0.09 & 0.3 & 0.5 & 0.7 & 155. & 60. & .93 \\
\hline 98 & 23 & $1753: 39.2$ & 7.65 & 7.53 & 7.72 & 1.36 & 0.10 & 0.3 & 0.4 & 0.6 & 155. & 40. & -110 \\
\hline 99 & 23 & $1829: 30.2$ & 8.16 & 8.11 & 7.70 & 1.55 & 0.05 & 0.3 & 0.3 & 0.7 & 155. & 60. & -93. \\
\hline 100 & 23 & 1928:55.5 & 7.73 & 7.12 & 8.72 & 1.12 & 0.10 & 0.3 & 0.5 & 0.7 & 155. & 60. & -93 . \\
\hline 101 & 23 & $1931: 22.2$ & 7.99 & 7.75 & 7.73 & 1.23 & 0.11 & 0.3 & 0.5 & 0.7 & 155. & 60. & -93. \\
\hline 102 & 23 & $1935: 17.3$ & 7.68 & 7.22 & 9.04 & 1.38 & 0.17 & 0.5 & 0.7 & 1.1 & 155. & 60. & -93. \\
\hline 103 & 23 & 2009:25.4 & 8.03 & 7.60 & 8.61 & 1.17 & 0.05 & 0.2 & 0.2 & 0.3 & 155. & 60. & -93. \\
\hline 104 & 23 & $2325: 33.5$ & 3.81 & 8.17 & 6.77 & 0.98 & 0.07 & 0.2 & 0.2 & 0.4 & 185. & 60. & -90 . \\
\hline 105 & 24 & $0036: 46.0$ & 8.15 & 9.21 & 3.84 & 1.11 & 0.13 & 0.3 & 0.4 & 1.1 & 200. & 62. & -77 \\
\hline 106 & 24 & $0037: 51.7$ & 7.87 & 9.12 & 3.59 & 1.17 & 0.06 & 0.2 & 0.3 & 0.7 & 200. & 52. & -77 \\
\hline 107 & 24 & $0208: 21.7$ & 8.15 & 7.91 & 11.20 & 1.86 & 0.07 & 0.3 & 0.3 & 0.5 & 195. & 35. & -50. \\
\hline 108 & 24 & 0228:45.8 & 7.86 & 8.32 & 8.63 & 1.14 & 0.08 & 0.2 & 0.3 & 0.4 & 325. & 60. & -87 \\
\hline 109 & 24 & $0232: 24.0$ & 7.62 & 8.96 & 2.92 & 1.16 & 0.06 & 0.1 & 0.2 & 0.6 & 200. & 52. & -77 \\
\hline 110 & 24 & $0256: 21.0$ & 2.61 & 11.25 & 5.00 & 0.82 & 0.09 & 0.3 & 0.2 & 0.5 & 245. & 80. & 97. \\
\hline 111 & 24 & $0345: 54.2$ & 7.27 & 7.97 & 6.85 & 1.13 & 0.10 & 0.3 & 0.4 & 0.7 & 325. & 60. & -87 \\
\hline 112 & 24 & $0444: 42.6$ & 7.17 & 7.31 & 8.85 & 0.93 & 0.14 & 0.5 & 0.5 & 1.0 & 103. & 25. & -90 . \\
\hline 113 & 24 & $0448: 49.3$ & 7.10 & 6.81 & 10.20 & 1.22 & 0.08 & 0.4 & 0.4 & 0.6 & 103. & 25. & -90. \\
\hline 114 & 24 & 0449:56.4 & 7.44 & 7.28 & 8.85 & 1.18 & 0.10 & 0.4 & 0.5 & 0.8 & 103. & 25. & -90. \\
\hline 115 & 24 & 9715:07.6 & 7.70 & 7.53 & 7.93 & 1.52 & 0.11 & 0.3 & 0.4 & 0.7 & 180. & 40. & -90 \\
\hline 116 & 24 & $1856: 33.9$ & 7.32 & 7.65 & 9.22 & 1.88 & 0.07 & 0.3 & 0.3 & 0.6 & 234. & 30. & -50 \\
\hline 117 & 24 & 2024:50.2 & 1.95 & 7.37 & 8.04 & 2.11 & 0.09 & 0.4 & 0.3 & 1.1 & 155. & 56. & -68. \\
\hline 118 & 25 & $0037: 49.2$ & 4.38 & 7.75 & 6.69 & 1.67 & 0.12 & 0.4 & 0.4 & 1.1 & 200. & 40. & -106 \\
\hline 119 & 25 & 0332:22.2 & 4.72 & 6.91 & 8.69 & 1.73 & 0.11 & 0.4 & 0.5 & 0.9 & 185. & 60. & -90. \\
\hline 120 & 25 & $0552: 30.2$ & 4.42 & 6.76 & 6.97 & 2.07 & 0.08 & 0.4 & 0.4 & 1.0 & 190. & 60. & -90 \\
\hline 121 & 26 & 1108:14.3 & 4.41 & 6.53 & 7.94 & 1.50 & 0.08 & 0.3 & 0.3 & 0.4 & 185. & 60. & -90. \\
\hline 122 & 26 & 1238:06.4 & 4.85 & 6.78 & 8.10 & 1.26 & 0.11 & 0.4 & 0.4 & 0.6 & 180. & 60. & -90. \\
\hline 123 & 26 & $1307: 45.9$ & 8.27 & 7.95 & 9.30 & 1.45 & 0.12 & 0.7 & 0.5 & 0.9 & 103. & 38. & -90 \\
\hline 124 & 26 & $1409: 53.9$ & 7.68 & 7.34 & 7.31 & 1.11 & 0.10 & 0.5 & 0.6 & 1.1 & 140. & 58. & -114 \\
\hline 125 & 26 & 1528:08.1 & 8.46 & 7.47 & 7.40 & 1.36 & 0.15 & 0.5 & 0.6 & 1.0 & 285. & 40. & -90 \\
\hline 126 & 26 & 1937:21.1 & 1.72 & 10.10 & 3.20 & 1.31 & 0.15 & 0.5 & 0.3 & 1.1 & 305. & 80. & 88. \\
\hline 127 & 26 & $2142: 45.8$ & 6.83 & 8.43 & 4.87 & 0.97 & 0.11 & 0.3 & 0.3 & 0.7 & 185 & 50. & -90. \\
\hline 128 & 26 & 2236:26.1 & 6.42 & 7.07 & 9.04 & 1.86 & 0.09 & 0.3 & 0.3 & 0.7 & 90. & 2. & -23 \\
\hline 129 & 27 & 0105:03.8 & 3.48 & 7.74 & 6.55 & 1.14 & 0.14 & 0.4 & 0.3 & 0.8 & 205. & 60. & -67. \\
\hline 130 & 27 & 0132:20.3 & 5.52 & 5.76 & 9.11 & 1.30 & 0.09 & 0.3 & 0.3 & 0.4 & 180. & Б0. & -90 \\
\hline 131 & 27 & 0149:19.0 & 0.54 & 7.52 & 7.15 & 1.38 & 0.15 & 0.6 & 0.3 & 1.1 & 195. & 67. & -107. \\
\hline 132 & 27 & 0328:33.6 & 0.35 & 7.08 & 7.02 & 0.96 & 0.15 & 0.6 & 0.4 & 1.0 & 195. & 67. & -107. \\
\hline 133 & 27 & $0635: 32.9$ & 2.88 & 8.40 & 5.18 & 1.81 & 0.10 & 0.2 & 0.2 & 0.5 & 195. & 67. & -110 \\
\hline
\end{tabular}




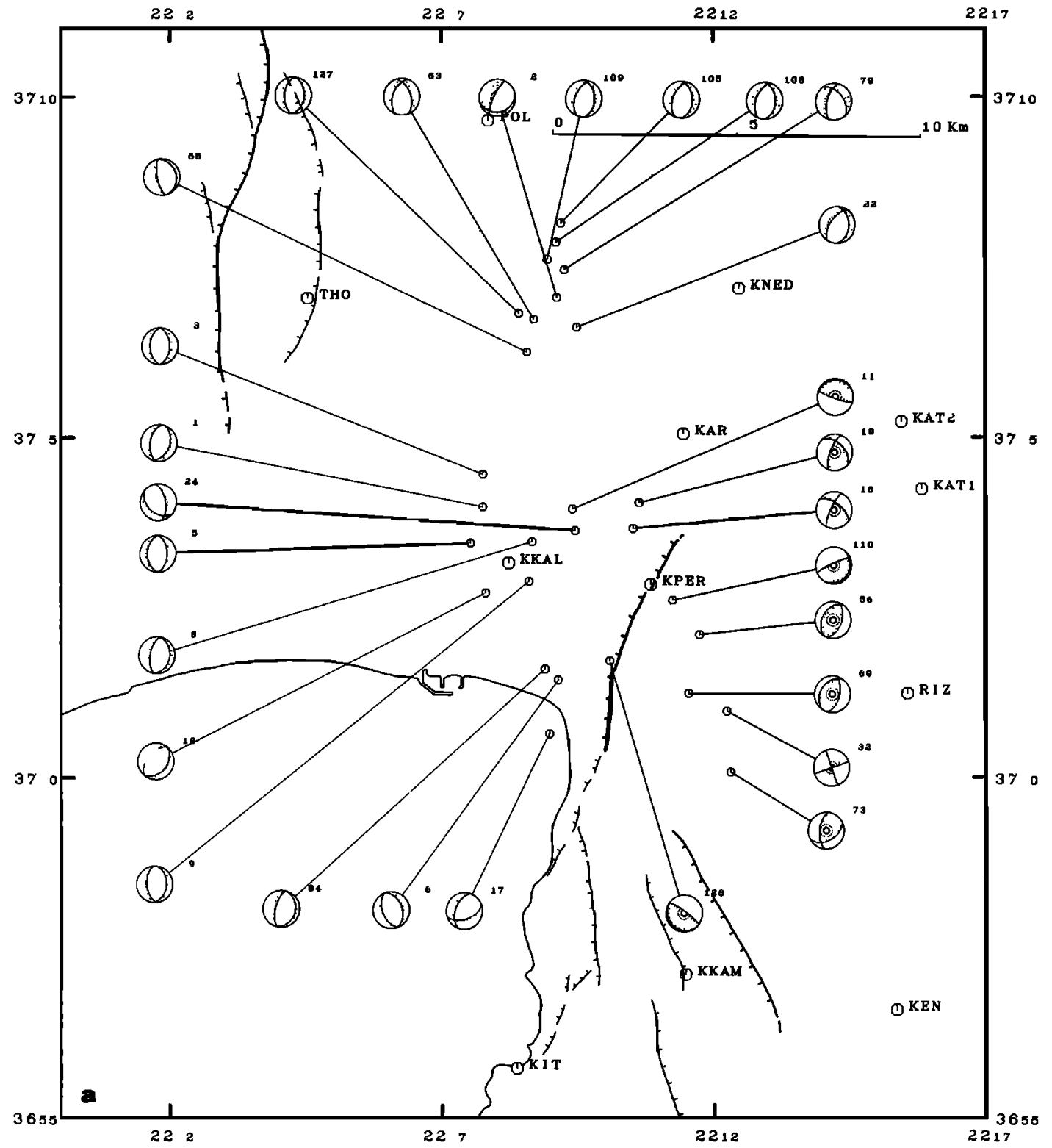

Fig. 12. Map views of 133 focal mechanisms plotted on the lower hemisphere (solid quadrants are compressional ones) by depth range: (a) 0-5 km, (b) 5-7 km, (c) 7-9 km, (d) 9-12 km. Earthquake and focal solution parameters are listed in Table 3. Individual focal solutions are shown in Figure 11 with polarity readings.

1970; Granier, 1985]. The difference in angle between minor en échelon fault planes and the main fault plane is also well known in laboratory experiments [e.g., Jaeger and Cook, 1979]. These en échelon planes represent initial shear failure under frictional regime. Then the $60^{\circ}$ dipping fault planes of aftershocks reported here may also represent deformation on such an en échelon feature, implying that the aftershocks broke patches nearly on the main fault plane. Alternatively, those aftershocks mechanisms could represent slip on antithetic planes dipping to the east, which would balance the internal rotation in the vicinity of the main fault plane.

All focal mechanisme of events in zone $F$ in the northern part of the cluster are consistent with an horizontal $T$ axis oriented $\mathrm{N} 105^{\circ} \pm 15^{\circ}$ and an almost vertical $P$ axis and are compatible both with the main shock and surface observations.

Only in the footwall do the focal mechanisms differ si- gnificantly from that of the main shock, with even some pure thrust faulting mechanisms with $P$ axis oriented about $\mathrm{N} 110^{\circ} \pm 20^{\circ}$ (events $16,19,53,69,73$, and 88). This thrust faulting is represented by a small number of events but accounts for most of the postseismic deformation in the footwall. Thrust faulting in the footwall of a normal fault has already been observed in the Wasatch fault area in Utah [Arabasz et al., 1980]. Zandt and Owens [1980] developed an elastic flexural plate model to explain such observations. However, postseismic stress release in the compressed upper part of the footwall appears here as a more straightforward interpretation.

\section{Northern Cluster}

This cluster appears to be more localized in map view (Figure 8) as well as in crose section (Figure 14a) than the one to the south. Although no surface fault trace 


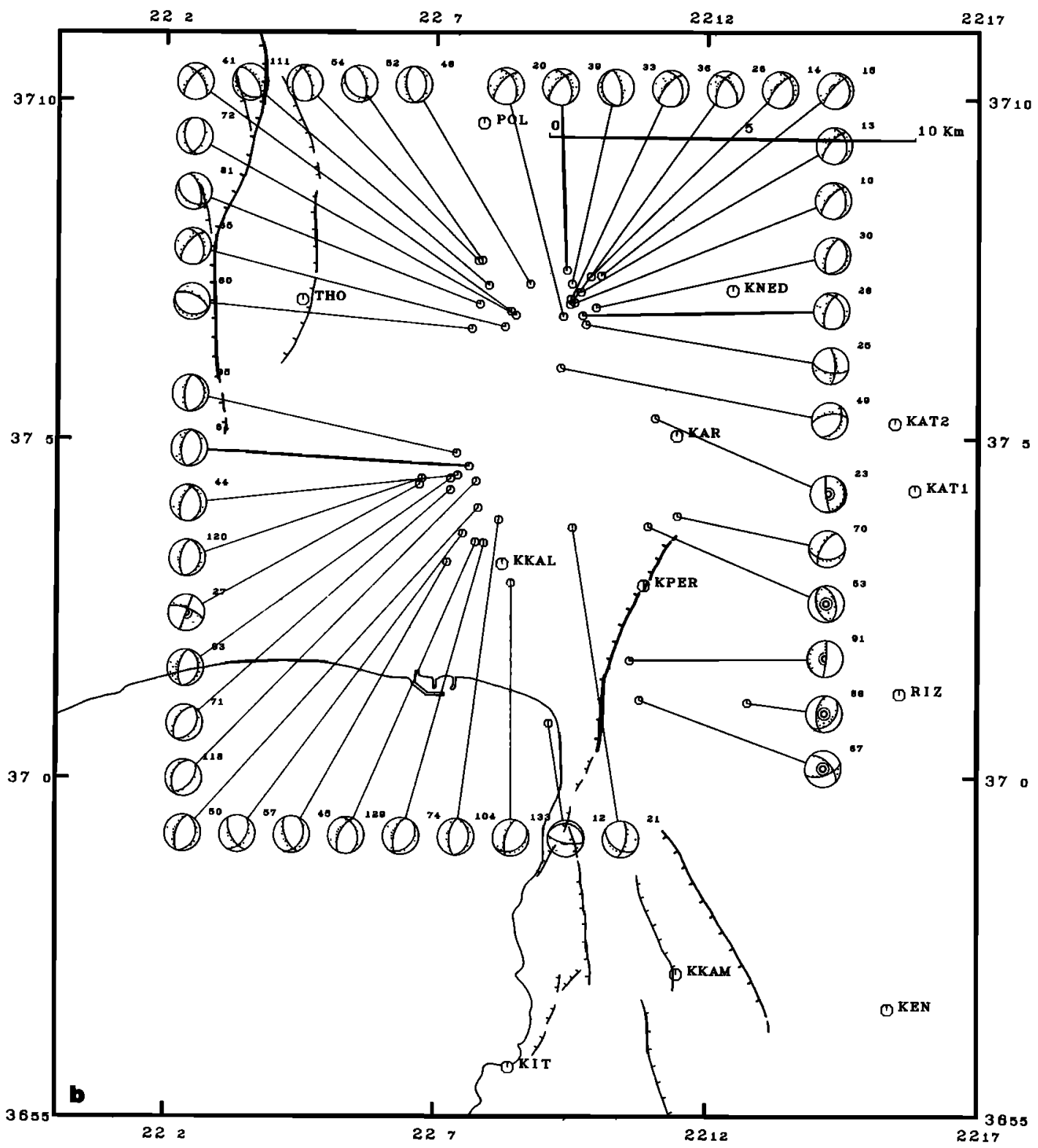

Fig. 12. (continued)

is associated with this cluster, one can project, at depth, zone $F$ into this area (Figures $14 a$ and $3 a$ ). Between depths of 10 and $4 \mathrm{~km}$, although the seismicity seems to be shifted, the projection of zone $F$ could possibly represent the northern extension of the master fault plane. However, at shallower depth zone $F$ cannot be defined because of the lack of seismicity. There is a concentration of large aftershocks $\left(M_{L}>3.0\right)$ at the top of this seismic zone at a depth of $4-6 \mathrm{~km}$, the largest aftershock recorded during the field experiment (September 20 at $0621 \mathrm{GMT}, 37^{\circ} 6.91^{\prime} \mathrm{N}$, $22^{\circ}$ 9.95' $\mathrm{E}, M_{L}=3.4$ ) also took place here (Figure 14a). The absence of shallow seismicity is real and is not an artifact of the network geometry because one of our stations (KNED) lies very close to this zone and thug constrains shallow events nearby. In any case, upward propagation of the hypothetical fault plane $F$ could be somehow hindered by the nappe etructure at a depth of 4-6 km, which may be similar to that depicted in Figure $3 a$ at a depth of 1-2 $\mathrm{km}$. Focal mechanisms in the northern cluster are more varied than in the southern one, and some are less well constrained, but they still can be classified into three sets.

A first set contains mechanisms for which the $T$ axis aximuth is consistent with that of the main shock $\left(\mathrm{N}_{115}{ }^{\circ}\right)$. It includes events (e.g., 10, 13, 14, 15, 20, 26, 28, 30, 36, 38, 39 , and 42) occurring near the largest aftershock recorded by the temporary array on September 20 (29). They are characterized by normal faulting on a steep plane $(\simeq$ $70^{\circ}$ ) oriented approximately $\mathrm{N} 220^{\circ}$. This set also includes shallower events occurring within or above zone F (e.g. 22, $55,63,79,105,106,109$, and 127). For all these events the $T$ axis is close to the horizontal and oriented $\mathrm{N}_{105^{\circ}} \pm 15^{\circ}$.

The second set contains mechanisms for which the $T$ axis azimuth is rotated about $45^{\circ}$ (about $N 70^{\circ}$ ) on the average with respect to that of the main shock. It includes events that have been drawn as almost pure normal fault with a $T$ axis oriented $N 70^{\circ} \pm 10^{\circ}$ (e.g., 52, 61, 77, 78, 81, 89, 90, $92,96,98,102,107$, and 124). Aside the better constrained mechanisms (96, 98, 102, and 124 and probably also events 


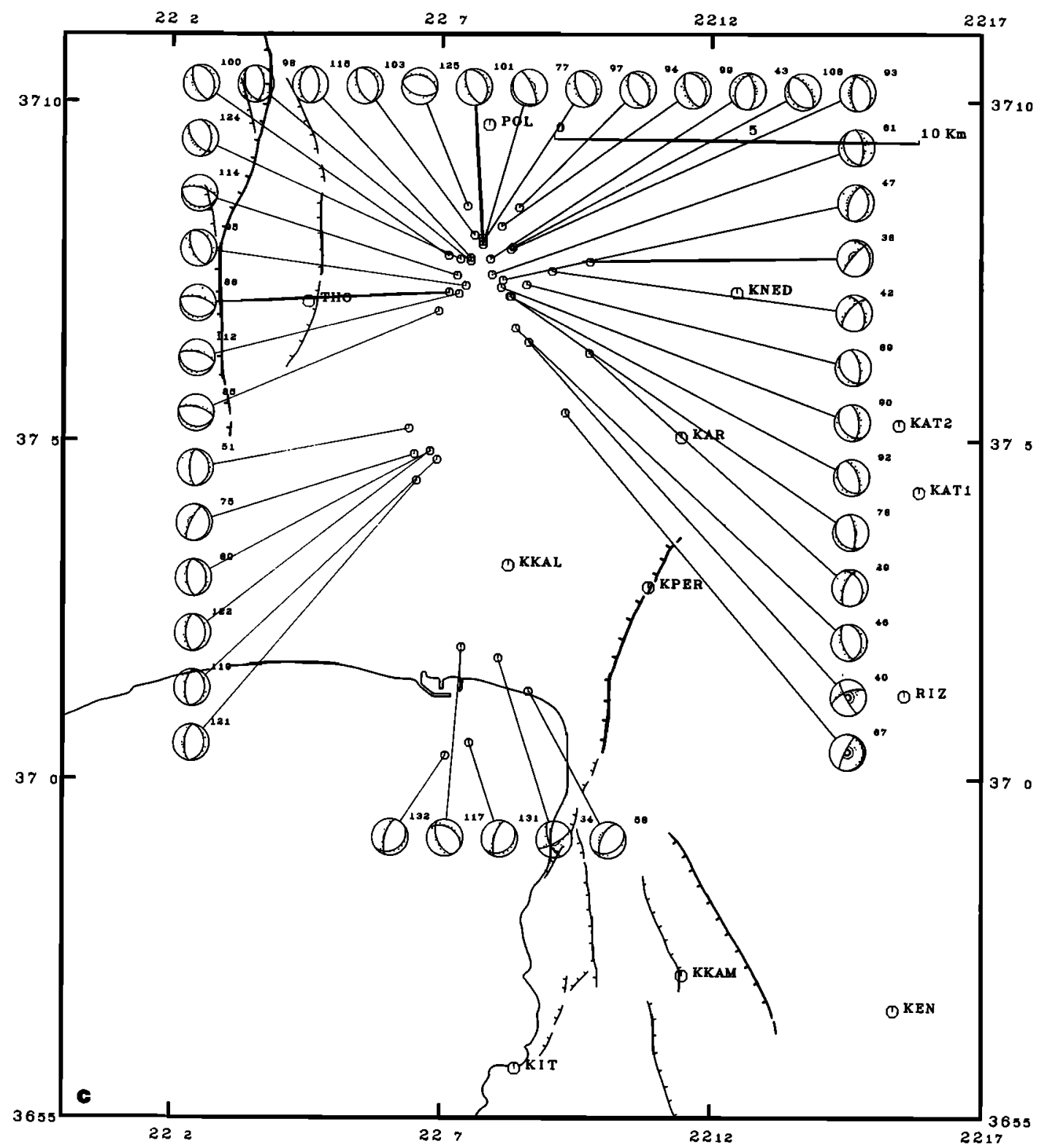

Fig. 12. (continued)

$94,97,99,100,101$, and 103), the other mechanisms could also represent almost pure strike-slip solutions with rightlateral slip on a steep plane oriented more or less east-west and thus perpendicular to the Kalamata fault (see focal solutione in Figure 11). In fact, almost any intermediate solution from a pure strike slip to a pure normal fault solution would be consistent with the data, in all cases the strike of the $T$ axie would remain about $N 70^{\circ} \pm 15^{\circ}$.

The third set contains mechanisms for which the $T$ axis azimuth is rotated about $90^{\circ}$ with respect to that of the main shock. It includes only small events located near the southern edge of the northern cluster (except event 125 located farther north). These events generally have one well-constrained nodal plane oriented $\mathrm{N}^{\circ} 00^{\circ}$ and dipping north about $80^{\circ}(60,85,86,112,114,125,113$, and 123). The other plane is not well constrained, and we represent here the mechanisms without any strike-slip component. In any case the mechanisms have a $T$ axis oriented $N 20^{\circ} \pm 10^{\circ}$.

\section{Discussion}

\section{Rupture Dimensions and Displacement}

The observed coseismic displacement on the fault trace is between 6 and $18 \mathrm{~cm}$ on the average. Taking a mean dieplacement of $15 \mathrm{~cm}, 8 \mathrm{~km}$ for the average fault length (2 km more than the ourface break), $14 \mathrm{~km}$ for the fault width (along dip) and an elastic modulus $\mu=3.3 \times 10^{10}$ $\mathrm{N} / \mathrm{m}^{2}$, we obtain a seismic moment of $5.5 \times 10^{17} \mathrm{~N} \mathrm{~m}$ which is within the error bound of the value of $7.0 \pm 2.5 \times 10^{17} \mathrm{~N}$ m obtained from waveform modeling. A seismic moment of $7.0 \times 10^{17} \mathrm{~N}$ in yields a mean displacement of $18.5 \mathrm{~cm}$ for the fault dimensions listed above. This may indicate that the observed displacement at the surface is smaller than the mean displacement on the fault due to stress relaxation near the surface. Alternatively, if the whole surface of the aftershock zone, including that of the "gap", is also taken into account to evaluate the area ruptured by the 


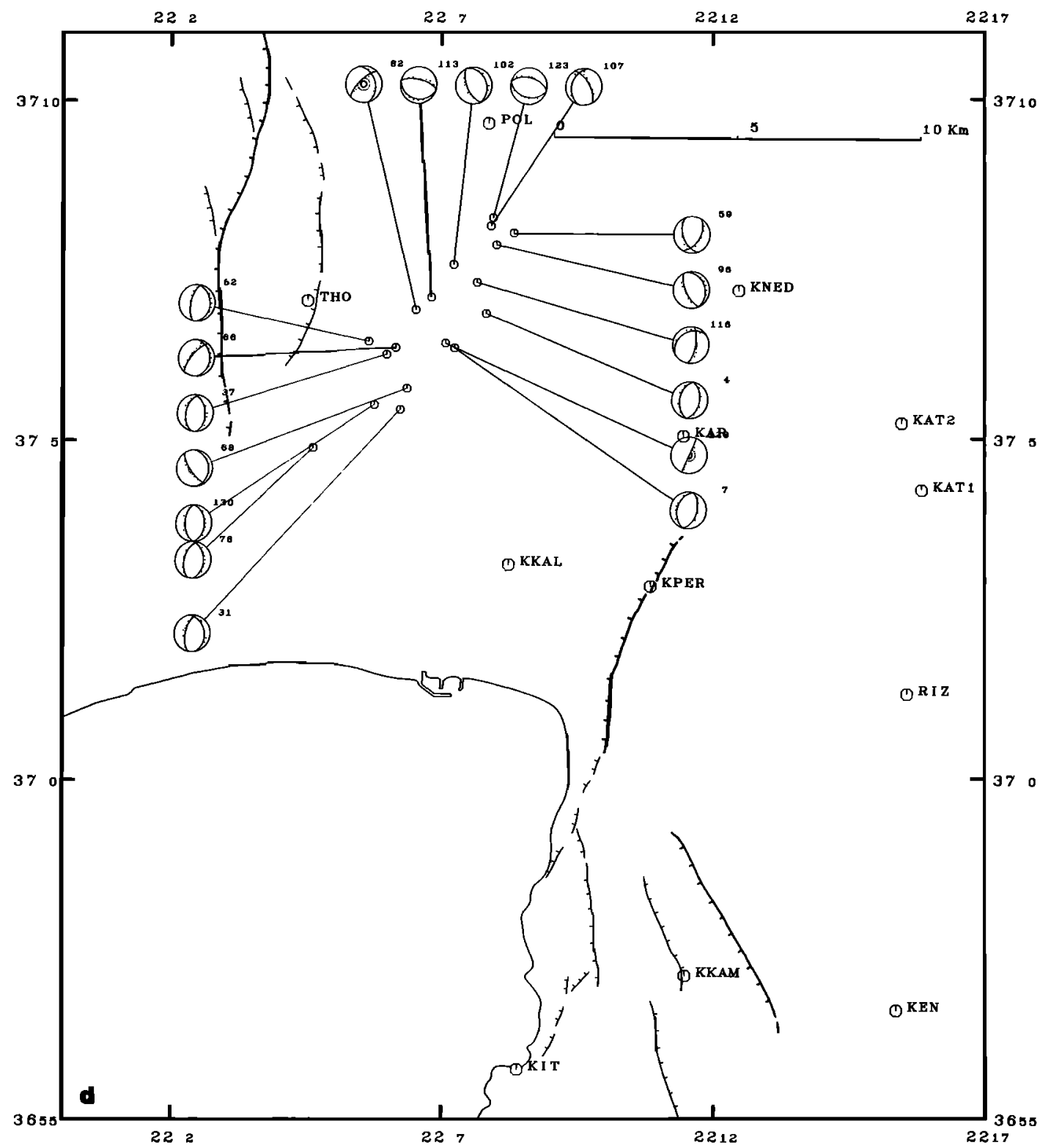

Fig. 12. (continued)

main shock, the estimate of the seismic moment would be increased by about $30 \%$. In any case, the resolution on the value of the seismic moment does not allow to differentiate between these two hypotheses concerning the extent of the ruptured area.

\section{Kalamata Fault}

The most striking result obtained in this study is the very good consistency between surface data (i.e., geometry and kinematics of both coseismic surface faulting and long term quaternary faulting) and seismological data at depth (i.e., aftershock distribution, main shock focal mechanism and individual aftershocks mechanisms). They all point to a simple normal fault geometry with a fault plane striking about $\mathrm{N}^{\circ}$ and dipping about $45^{\circ}$ northwestward. The observed surface faulting length is $6 \mathrm{~km}$, but the fault plane is continuous over a length of about $8 \mathrm{~km}$ from the subsurface to about $10 \mathrm{~km}$ as shown by the aftershock distribution of the Kalamata fault cluster. Within this cluster most of the aftershocks occurred either on the fault plane or in the footwall of the fault. Events on the fault plane have focal mechanisms showing northwest-southeast extension in agreement with the main shock.

Such a consistency is unusual in well-documented dipslip earthquake sequences, even those with clear surface faulting. Often aftershocks do not define a fault plane (e.g., Thessaloniki [Soufleris et al., 1982], Corinth [King et al., 1985], and El Asnam [Ouyed et al., 1983]). In addition, aftershock mechanisms cannot generally be easily integrated in a single faulting model (e.g., Irpinia [Deschamps and King, 1984]) even when aftershock locations define a main fault plane as for the Borah Peak earthquake [Richins et al., 1987|. All the studies cited above concern earthquakes with magnitude 6.4 or more, with aftershock zone at least 3 or 4 times larger than that of Kalamata but covered by about the same number of stations. The minimum distance between 


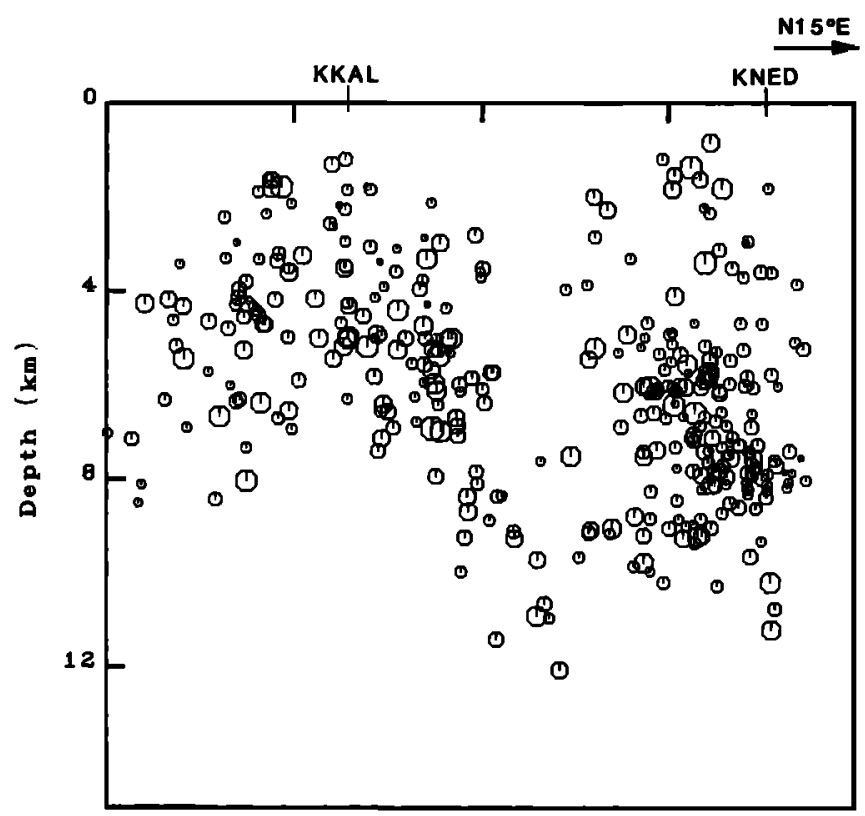

Fig. 13. Hypocenters projected on cross section oriented $\mathrm{N} 15^{\circ} \mathrm{E}$, parallel to the average strike of the Kalamata fault (d in Figure 8c).

stations is very rarely less than $10 \mathrm{~km}$ as opposed to this study where, within the aftershock zone, stations are $5 \mathrm{~km}$ or less apart. Thus the resolution on aftershock locations for this study is probably better than in most of the studies mentioned. This may contribute to the fairly simple picture given by the aftershocks. However, for the 1980 earthquake in Norcia (Central Apennines, Italy) which was similar to that of Kalamata both in size and aftershock zone coverage but which did not ruptured the surface, there was no simple relationship between the aftershock geometry and the main shock focal mechanism [Deschamps et al., 1984].

Although scaling laws relate earthquake seismic moments (or magnitudes) to their rupture dimensions [e.g., Kanamori and Anderson, 1975], small and large earthquakes must be distinguished because one rupture dimension is fixed by the thickness of the seismogenic layer [Scholz, 1982] which ranges from about 10 to $20 \mathrm{~km}$ (for crustal events) depending on the regional context [Chen and Molnar, 1983; Meissner and Strehlau, 1982]. Small earthquakes, with magnitude lese than about 5.5, usually correspond to rupture dimensions less than about $10 \times 10 \mathrm{~km}^{2}$ with a mean displacement less than $10 \mathrm{~cm}$ and may hardly ever reach the surface (Figure 15). At the other extreme, earthquakes with magnitude larger than about 7 correspond to rupture areas greater than about $500 \mathrm{~km}^{2}$ and to mean displacements greater than about $1 \mathrm{~m}$. Those earthquakes often produce surface breaks, probably because the vertical dimension of their rupture plane exceeds the thickness of the seimogenic layer. For those events, except possibly for low-angle thrusting, the rupture plane must therefore extend horizontally in length: the shape of the rupture plane is elongated (aspect ratio $>1$ ) and the large slip per unit length to be absorbed implies a wide perturbed zone where strain energy is released, on the two sides of the fault and around the edges (Figure 15). Thus aftershocks will spread on both sides of the fault and will not outline its geometry. In addition, the stress field around edges may also be perturbed, leading to the presence of a large number of aftershocks and to a complicated pattern of focal mechaniems. For moderatesize earthquakes, with magnitude between about 5.5 and 7, any intermediate situation may exist. The dimensions of the rupture plane along strike and dip are comparable (aspect ratio $\simeq 1$ ) and the rupture may or may not reach the surface depending upon local conditions (Figure 15). For instance, in Irpinia $\left(M_{0}=6.9\right)$, the rupture reached the surface only in few places, representing less than $20 \%$ of its total length [Westaway and Jackson, 1987; Bernard and Zollo, 1988] and the focal mechanisms of aftershocks were highly varied [Deschamps and King, 1984]. In contrast, in Kalamata $\left(M_{0}=5.8\right)$, the surface rupture was clear and covered about $2 / 3$ of the aftershock zone length. In both instances, normal faults cut across a nappe structure made of platform sedimentary rocks, but in Irpinia the presence of a thick pile of flysh under a massive rigid layer of limestones may hinder rupture propagation to the surface.

Finally, an important and rather unique observation (to our knowledge) is the nature of focal mechanisms of events on the fault plane versus those of events in the footwall. Events on the fault plane all have focal mechanisms indicating northwest-southeast extension like the main shock. In contrast in the footwall focal mechanisms usually show clear northwest-8outheast compression. This compression can be understood qualitatively as the result of postseismic stress release in the compressed upper part of the footwall The comparable observation made by A rabasz et al. [1980] in the Wasatch fault footwall was not directly linked to the occurrence of a large earthquake like here. It could nevertheless well represent the same kind of residual deformation rather than being associated with elastic flexure as proposed by Zandt and Owens [1980].

\section{Main Shock Location and Rupture Process}

On the basis of a rough interpretation of strong motion records, we concluded before that the distance between $\mathrm{Ka}$ lamata city and the main shock epicenter was at least about $10 \mathrm{~km}$ unless a low-velocity sedimentary layer exists beneath the city, in which case the distance could be smaller (but larger than about $7.5 \mathrm{~km}$ ). Thus the main shock epicenter is probably within the northern cluster (corresponding to a 8.5- to 12-km distance). This case is illustrated by scenario I on Figure 16 where the rupture is assumed to have been initiated in the northern cluster. Then the northern cluster would be the northernmost extension of the Kalamata fault plane and the "gap" of aftershock activity might represent an unbroken barrier on this plane. The other possibility is that the main shock lies a few kilometere to the south of the northern cluster (corresponding to a distance of 7.5-8.5 km for the strong motion record), within this "gap" of aftershocks. The Borah Peak earthquake [Richins et al., 1987] is a well-documented example of such a situation where no aftershock activity has been recorded in the surroundings of the main shock hypocenter. The main shock being located within the gap, two possibilities atill remain. The first one, scenario Ila (Figure 16) assumes as scenario I that the northern cluster is the northernmost extension of the fault plane and that the earthquake ruptured the entire aftershock zone. Scenario Ilb (Figure 16) assumes instead that the rupture propagated only to the south and that the northern cluster is a diffuse zone of deformation.

The complexity in the first 3-4 a of the rupture inferred from a preliminary analysis of short-period records suggests 

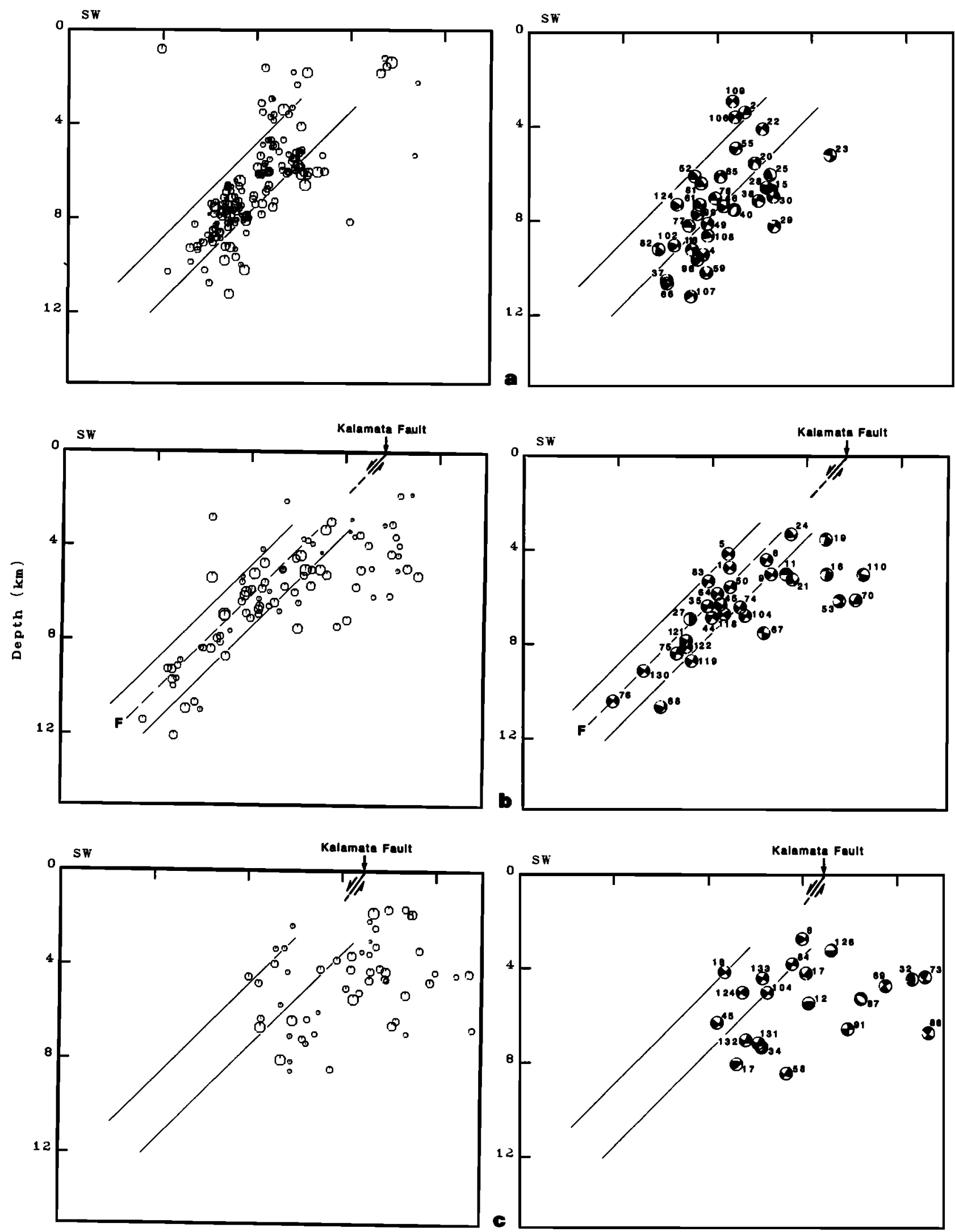

Fig. 14. Hypocenters (left) and focal mechanisms (right) projected on cross sections oriented $\mathrm{N} 105^{\circ} \mathrm{E}$, perpendicular to the average strike of the Kalamata fault ( $a, b$ and $c$ in Figure $8 c$ ). The front hemisphere projections of focal spheres are plotted. Because of space problems, only a representative sample of the focal mechanisms in Figure 12 have been projected. Numbers refer to Table 3 and to Figure 12. (a) The northern cluster on Figure 8. (b) and (c) The Kalamata fault cluster. On Figure $14 b$ the Kalamata fault is represented to dip $50^{\circ}$ near the surface and $45^{\circ}$ at depth (dashed line). The two parallel dashed lines deflne zone $\mathrm{F}$ which encloses all epicenters that can be considered to lie on the fault plane, within location uncertainties (see text). On Figures $14 a$ and $14 c$ the projection of zone $F$ is represented although there is no fault trace at the surface in Figure $14 a$ (see also Figure $3 b$ ). 
TABLE 4. Fault Plane Solution Parameters Obtained From Inversion of $P$ and $S H$ Waveforms for the Kalamata (Figure 9a) and the Northwestern Crete (Figure A1) Earthquake

\begin{tabular}{|c|c|c|c|c|c|c|c|}
\hline Date & Latitude & Longitude & $\begin{array}{c}\text { Depth, } \\
\text { km }\end{array}$ & $\begin{array}{c}\text { Strike, } \\
\text { deg }\end{array}$ & $\begin{array}{l}\text { Dip, } \\
\text { deg }\end{array}$ & $\begin{array}{c}\text { Rake, } \\
\text { deg }\end{array}$ & $\begin{array}{l}\text { Moment, } \\
\text { N m }\end{array}$ \\
\hline $\begin{array}{l}\text { Apr. 27, } 1966 \\
\text { Sep. 13, } 1986\end{array}$ & $\begin{array}{l}35^{\circ} 42.0^{\prime} \\
37^{\circ} 06.0^{\prime}\end{array}$ & $\begin{array}{l}23^{\circ} 30.0^{\prime} \\
22^{\circ} 11.4^{\prime}\end{array}$ & $\begin{array}{r}14.0 \\
5.0\end{array}$ & $\begin{array}{l}191.0 \\
204.0\end{array}$ & $\begin{array}{l}64.0 \\
45.0\end{array}$ & $\begin{array}{l}-79.0 \\
-77.0\end{array}$ & $\begin{array}{l}2.0 \times 10^{17} \\
7.9 \times 10^{17}\end{array}$ \\
\hline
\end{tabular}

to $u$ that scenarii IIa and IIb are not very likely because the absence of aftershocks around the epicentral area would rather indicate a clean initiation of the rupture than a complex one. Thus the main shock may have been initiated in the northern cluser by a small energy release (equivalent
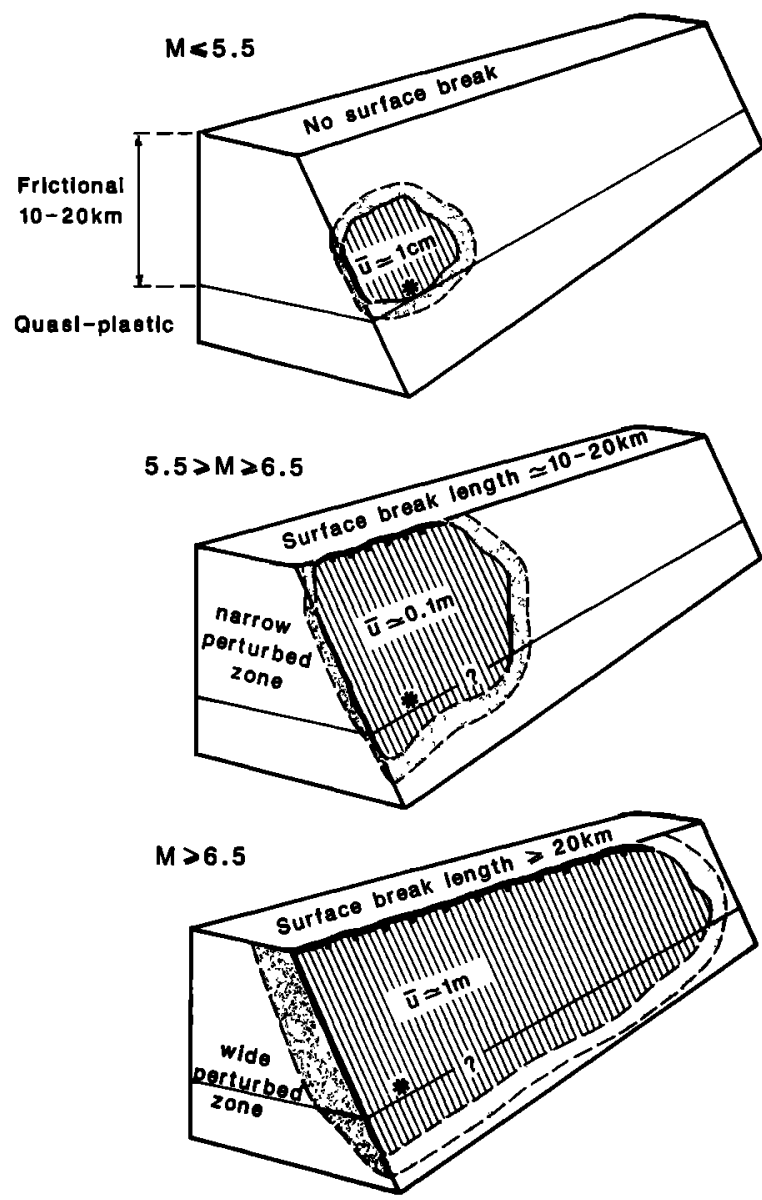

Fig. 15. Relationship between earthquake magnitude, rupture dimensions, and width of perturbed zone surrounding a normal fault plane. The star indicates location of hypocenter, the hatched area is the ruptured plane, the perturbed zone is shown dotted. For small earthquake (top) the width of the ruptured plane is smaller than the size of the seismogenic layer (frictional) and the rupture does not reach the surface. For large earthquake (bottom) the ruptured plane reaches the surface and its width is limited by the size of the seimogenic layer. Surface breaks length, amount of olip, and width of perturbed zone increase with magnitude. For the Kalamata earthquake the aspect ratio of the rupture is about 1 (middle), and aftershocks are concentrated in a very narrow zone surrounding the fault plane. to a magnitude 4.5 or 5 event). Whether this event is part of the main shock (i.e., occurred on the edge of the fault plane) or triggered it (and occurred outside the main fault plane, within the relay zone) cannot be answered. In either case, the main shock initiated within the zone offeeting the Kalamata and Thouria en ćhelon normal faults which is subjected to complex deformation. But once the rupture front met with the main fault plane, slip could occur easily, releasing most of the energy there. The observation of the decreasing coseismic surface displacement toward the south from site 4 to site 1 (Figures $2 b$ and 4 ) is additional evidence in favor of the southward propagation of the rupture. The gentle way in which the surface rupture attenuated and finaly stopped before the southernmost extremity of the fault system (Figure 2) may be related to the low level of aftershock activity there (Figure $8 b$ ).

\section{Deformation in the Relay Zone Between the Kalamata and the Thouria Faults}

Focal mechanisms in the northern cluster show that in this area deformation is complex, including focal mechanisms with $T$ axis azimuths oriented about $\mathrm{N} 110^{\circ}, \mathrm{N} 70^{\circ}$, and $\mathrm{N} 20^{\circ}$ and with horizontal projection of slip vectors lying at high angles to that of the Kalamata fault (Figure 16). Only a few of these mechanisms (e.g., 89, 90, 108, and 111) could be interpreted as pure east-west right-lateral strike-slip, with horizontal projection of slip vector parallel to that of the Kalamata fault. Those mechanisms may correspond to motion on strike-slip segments between the Kalamata and Thouria faults. Nevertheless, a large number of observed mechanisms in this area cannot be explained by such rigid kinematics. They, however, are all consistent with a uniform state of stress where $\sigma_{1}$ is vertical, $\sigma_{3}$ is horizontal and roughly perpendicular to the trace of the Kalamata fault, and $\sigma_{2}$ is roughly parallel to it. Preexisting planes of weakness parallel to $\sigma_{3}$ and dipping to the north or to the south could then be reactivated as pure normal faults. Such planes of weakness may exist within the relay zone at depth, along an older zone of transverse fractures, as discussed in the tectonic section.

\section{Implications for Regional Active Tectonics}

The pattern of Quaternary and active faulting in the Aegean region has recently been compiled from various data sources (i.e. geology, morphology, bathymetry, Landsat images, etc.) and summarized by Armijo et al. [1986]. The following discussion combines regional tectonic observation from Armijo et al. [1986] and new detailed observations presented in this paper (Figures 1 and 17).

Our new observations clearly indicate that the present style of deformation in Kalamata (Figure 2), and probably in the entire southern Peloponnesus (Figure 1), is dominated by normal faulting and extension oriented approximatively 


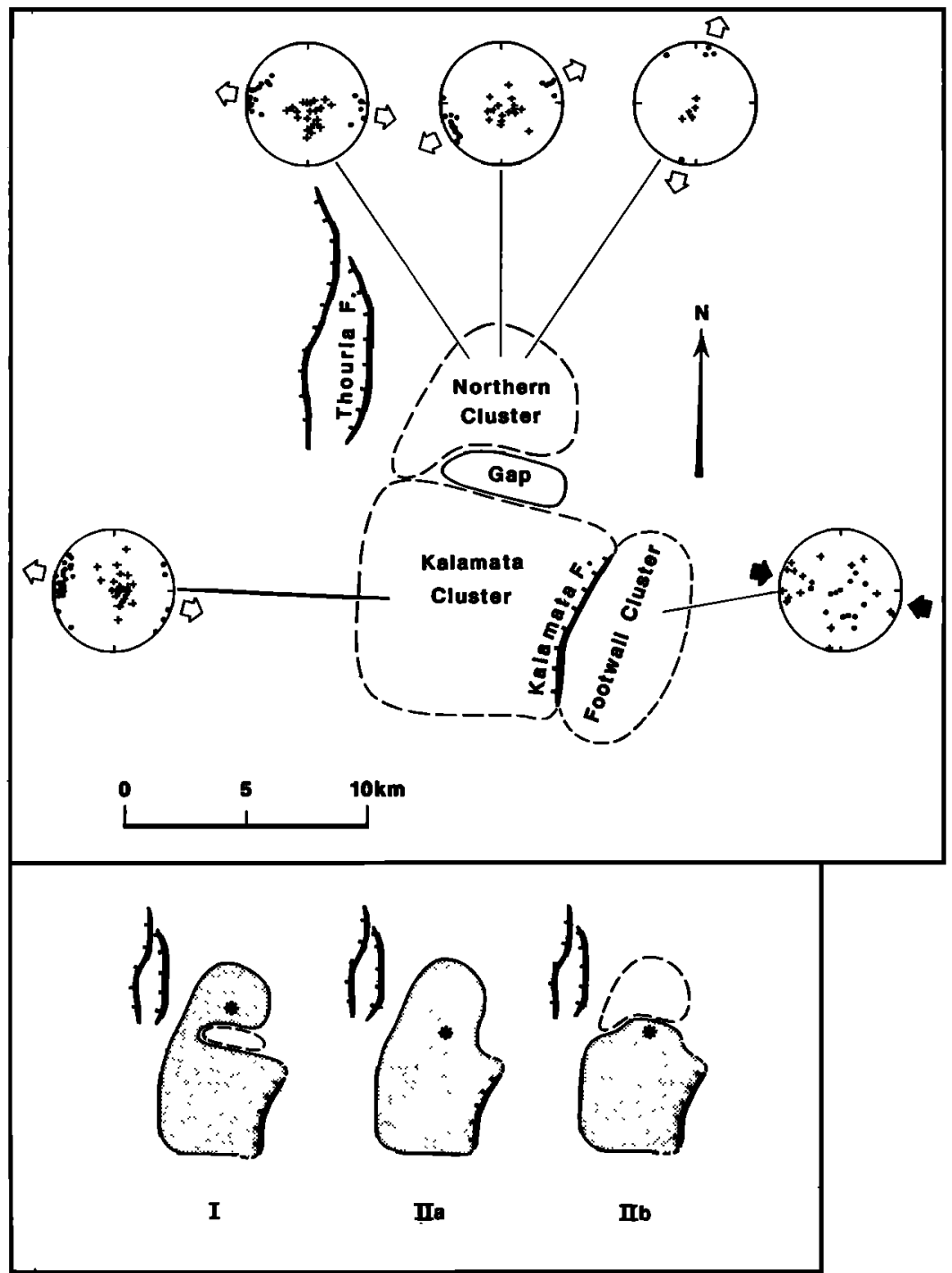

Fig. 16. Aftershock distribution with respect to fault geometry. (Top) The Kalamata cluster is related to the downward extension of the Kalamata fault. The northern cluster and the gap of aftershocks are within the relay zone between the Kalamata and Thouria faults. $P$ (pluses) and $T$ (dots) axes for all focal mechanisms determined in this study are plotted for each cluster. In the northern cluster, aftershock mechanisms are separated into three groups according to differences in $T$ axes azimuth. The open arrows indicate mean direction of extension; the solid arrows indicate mean direction of compression in the footwall cluster. (Bottom) Earthquake rupture propagation. Sketches illustrate three possible scenarii discussed in the text. The location of the main shock is shown with a star, within the northern cluster for $\mathrm{I}$, within the gap for $\mathrm{\Pi l}$ and IIb. The ruptured area is in gray in each case.

$\mathrm{N} 90^{\circ}-110^{\circ} \mathrm{E}$. We have recalculated the focal mechanism and the depth of the April 27, 1965 earthquake ( $m_{b}=5.7$ ) northwest of Crete using waveform modeling of long-period $P$ and $S H$ waves (see the appendix). The earthquake occurred within the crust at a depth of $14 \pm 5 \mathrm{~km}$ and corresponds to almost pure normal faulting along a N$S$ striking plane. This plane may be associated with the normal faults that appear to control the large northsouth bathymetric escarpments on the western edge of Crete (Figure 1). Thus the combined observation of a normal fault earthquake mechanism and of active normal faulting indicates E-W extension there. Some of these faults are also observed on land, particularly at the edges of the two N-S peninsulas in western Crete (Figure 1). Between southern Peloponnesus and Crete, the bathymetry indicates that large N-S normal faults exist [Lyberis et al., 1982] and that $\mathrm{E}-\mathrm{W}$ extension may also be the dominant active regime.

The N-S normal faults, from southern Peloponnesus to Crete, represent a rather uniform tectonic regime $\left(\sigma_{3} \simeq\right.$ E-W, $\sigma_{2} \simeq \mathrm{N}-\mathrm{S}, \sigma_{1}$ vertical) (Figure 1). They cut the folds and nappe structure of Miocene age of the Hellenic belt and thus are mostly newly formed faults. In places where $\sigma_{3}$ forms a relatively large angle $\left(>45^{\circ}\right)$ with the Hellenic structures, those structures may be largely reactivated by quaternary faulting (Sparte fault east of the Taygetos range, Figure 1). In contrast, where $\sigma_{3}$ is almost parallel to the Hellenic structures, the normal faults cut at high angle the old structures and are thus independent of them (Crete). 

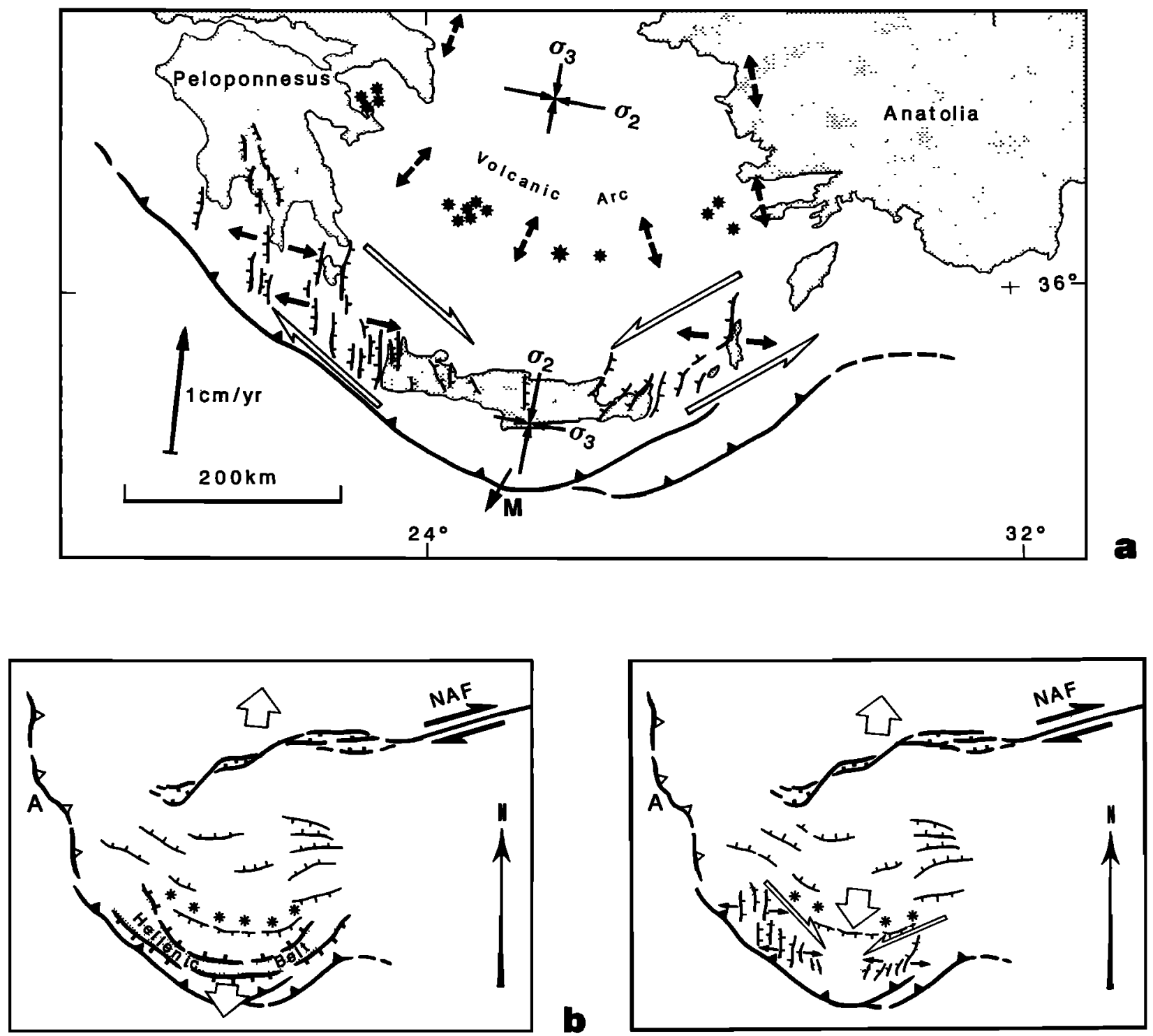

Fig. 17. (a) Sketch map of fault kinematics in the Hellenic arc. Faults are simplified from Figure 1 and Armijo et al. [1986]. Small solid arrows show direction of local extension. En échelon N-S normal faulting imply right-lateral motion between Peloponnesus and western Crete and left-lateral motion between Anatolia and eastern Crete (open arrows). Average direction of active extension $\left(\sigma_{3}\right)$ is about N-S at and north of the volcanic arc and about $\mathrm{E}-\mathrm{W}$ in the Hellenic arc, near the subduction zone. The arrow $\mathrm{M}$ indicates the average azimuth of slip vector of subduction earthquakes (N31 $\left.{ }^{\circ} \mathrm{E}\right)[\mathrm{McKenzie}, 1978]$. The relative Africa/Europe convergence $(\simeq 1 \mathrm{~cm} / \mathrm{yr})$ is from Chase [1978]. (b) Outline of the evolution of normal faulting in the Aegean region from late Miocene-Pliocene (?) (left) to Pliocene-Quaternary (right). Large open arrows represent the bulk Aegean extension. NAF is the North Anatolian fault, A is the collisional boundary with Apulia, other symbols as in Figure 17 a.

Because the Hellenic structure follows the trench (and forms the Hellenic arc), any intermediate situation between these two extreme cases may be found.

The observations that the $\mathrm{E}-\mathrm{W}$ active extension is of regional importance (Figure 1) calls for a discussion of its relationship with the active $\mathrm{N}-\mathrm{S}$ extension occurring in most of the Aegean. This N-S extension, which can be observed now in the Gulf of Corinth only about $100 \mathrm{~km}$ from the Taygetos faults (Figure 1), is roughly perpendicular to the Hellenic arc and to the active volcanic arc and has often been linked to large-scale boundary forces [e.g. Tapponnier,
1977] or to forces acting at the base of the lithosphere [e.g. McKenzie, 1978]. In Crete, normal faults parallel to the arc are observed but microtectonic measurements suggest that the direction of extension changed from N-S to $\mathrm{E}-\mathrm{W}$ [Angelier, 1979]. Our results imply that the extension perpendicular to the Hellenic arc is no longer dominant and that older (Late Miocene-Pliocene?) normal faulting parallel to the arc probably formed prior to the onset of recent (Pliocene-Quaternary?) N-S normal faulting which overprints it.

The geometry of N-S normal faulting is characterized by 
large échelons. A clear example is the fault oystem along the western edge of the Taygetos (and eastern edge of the gulf of Messenia) (Figure 1) where at least three and probably four main segments (Thouria, Kalamata, and Kardhamili (Figure $2 a$ ) and possibly another one offshore (Figure 1)) can be distinguished. Those segments probably correspond to a more continuous, mostly reactivated structure at depth. The kinematics of surface faulting requires the average displacement on this structure to be oblique, with a right-lateral component of slip. The small right-lateral component of slip observed in slickensides along the Kalamata fault is consistent with this average oblique displacement (Figure $5 d$ ). Rotation of blocks within the large rightlateral en échelon system would require, however, small components of left-lateral motion on the individual normal fault segments [e.g., Jackson and McKenzie, 1988]. The leftlateral component implied by the main shock mechanism of the Kalamata earthquake would thus be in better agreement with such rotational movements.

At a larger scale, between southern Peloponnesus and Crete, the overall pattern of faulting is also en échelon and oblique to the Hellenic subduction zone (Figures 1 and 17a). This also requires an overall right-lateral component of slip to be absorbed within a wide zone parallel to the trench (Figure 17a). The observations discussed in this paper suggest that this en échelon structure is formed of almost purely normal faults which reflect $\mathrm{E}-\mathrm{W}$ stretching oblique to the arc. That the Hellenic belt is segmented by those faults and that a large part of it is now below sea level between Peloponnesus and Crete corroborate this inference and require a significant amount of $\mathrm{E}-\mathrm{W}$ extension across the belt [Lyberis et al., 1982], probably of the order of several kilometers across an $\mathrm{E}-\mathrm{W}$ section of the en échelon zone.

On the eastern side of the Hellenic arc, between eastern Crete and Anatolia, Quaternary faults observed on satellite images and inferred from bathymetric charts as well as microtectonic measurements [Angelier, 1979] suggest the existence of another large scale échelon array of approximately N-S striking normal faults (Figure 17a). This structure would require, as on the western side of the arc, a significant amount of $\mathrm{E}-\mathrm{W}$ extension across the mountain belt and a "conjugate" left-lateral component of slip within a zone parallel to the trench. All these observations suggest that both the eastern and western échelons are not formed by strikeslip fault segments associated with the southward displacement of Crete with respect to Peloponnesus and Anatolia, as proposed by Angelier et al. [1982].

The change in the tectonic regime (from an extension perpendicular to the arc, mostly $\mathrm{N}-\mathrm{S}$, to an $\mathrm{E}-\mathrm{W}$ extension across the belt) suggests a change of unprecised Pliocene age in the boundary conditions. Because this change is observed only in the southern Aegean area, close to the subduction zone (less than $200 \mathrm{~km}$, Figure 17a), boundary conditions have most probably changed there. This could be one effect of the incipient collision of the Hellenic arc with the African margin to the south. North-south shortening in the Mediterranean ridge [e.g., Ryan et al., 1982] is probably an other effect of such a collision. The increasingly buoyant crust of the African margin being subducted would hold the southern part of the arc. Then, the Hellenic arc and the adjacent Aegean crust would have to spread toward places where less buoyant crust is being consumed as, for instance, the Ionian basin to the west.
This change does not require a large modification of the regional tectonic stress (Figure 17). The whole Aegean region being dominated by extension ( $\sigma_{1}$ vertical), slight differences between the values of horizontal principal stresses may lead to different faulting patterns. Probably, the amount of $\mathrm{E}-\mathrm{W}$ extension near the subduction zone $(\simeq$ $10 \%$ ?) is small compared to the bulk of N-S extension in the rest of the Aegean region $(\simeq 100 \%)$ [e.g. McKenzie, 1978; Le Pichon and Angelier, 1979]. Nevertheless, the pattern of active N-S normal faulting may be viewed as the response of the overriding plate to the horizontal force transmitted by the incoming African margin across the Hellenic subduction zone. Then the average strike of the newly formed normal faults $\left(\simeq \mathrm{N} 10^{\circ} \mathrm{E}\right)$ is an estimate of the direction of this force (along $\sigma_{2}$ in Figure 17a). The average azimuth of slip vectors of thrust earthquakes along the entire arc (N31 ${ }^{\circ} \mathrm{E}$ [McKenzie, 1978; Jackson and McKenzie, 1988], M in Figure 17a) is slightly deviated from this direction but is based on a limited number of tightly constrained fault plane solutions. The average direction of Africa-stable Europe convergence ( $\simeq \mathrm{N} 6^{\circ} \mathrm{E}$ [Chase, 1978]) is roughly parallel to the average strike of normal faulting near the subduction boundary. This suggests a quite simple pattern for the late Neogene kinematics of the Aegean region (Figure 17b) where lateral movements, originated at distant collisional boundaries, are apparently balanced with, on one side, the westward displacement of Anatolia, and on the other side, the east or southeastward push exerted by Apulia [Tapponnier, 1977]. The force transmitted by the African margin impeeds further N-S stretching and creates a new fault pattern only near the subduction zone and not in the rest of the Aegean. This corroborates the earlier inference that the Aegean lithosphere is particularly weak [e.g., Tapponnier, 1977; McKenzie, 1978; Le Pichon and Angelier, 1979].

\section{ApPendix: Depth and Focal Mechanism OF THE APRIL 27, 1965, EVENT NORTHWEST OF CRETE $\left(35.7^{\circ} \mathrm{N}, 23.5^{\circ} \mathrm{E}, m_{b}=5.7\right)$}

McKenzie [1972] published for this event a focal solution computed by placing the event in the mantle at a depth of $50 \mathrm{~km}$ and based on first motion readings (strike $=214^{\circ}$, $\operatorname{dip}=50^{\circ}$, rake $=-80^{\circ}$ ). Here we present the results of the inversion of the $P$ and $S H$ available WWSSN long-period waveforms of this earthquake. These data clearly show that this event is shallow and its mechanism, although not very well constrained, differs somewhat from that proposed by McKenzie [1972] (Figure A1). One plane is moderately well constrained (strike $=191 \pm 15^{\circ}, \operatorname{dip}=65 \pm 10^{\circ}$, Figure A2), and $S H$ waveforms at $C H G$ and QUE in particular are useful in constraining the value of the rake $\left(-79 \pm 20^{\circ}\right.$, Figure A2). Using a crustal $P$ velocity of $6.2 \mathrm{~km} / \mathrm{s}$, the depth is found to be $13 \pm 5 \mathrm{~km}$. The crust in the area is a thinned continental crust and its thickness, based on refraction profiles [Makris, 1978], is believed to be about 30 $\mathrm{km}$ in Crete and $20 \mathrm{~km}$ farther north in the sea. Although the refraction profiles run north and east of the area of interest here, the crust is probably not much thinner and thus the earthquake occurred within the crust. The focal mechanism found here is in agreement with the polarity readings presented by McKenzie [1972]; however, the two nodal planes have been rotated about $30^{\circ}$ to the north. 


\section{CRETE 1965.04.27}

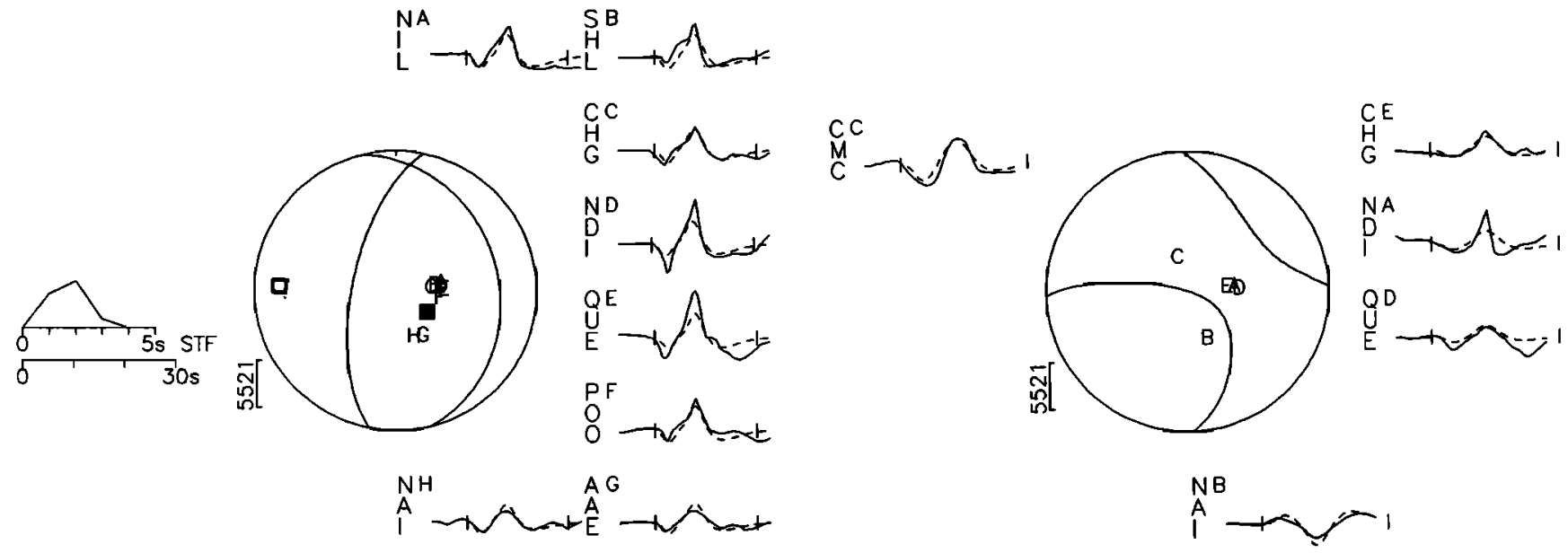

Fig. A1. Focal mechanism of the April 27, 1965 Crete earthquake obtained by simultaneous inversion of $\boldsymbol{P}$ and $S H$ WWSSN long-period waveforms. Observed (solid curve) and synthetic (dashed curve) seismograms are plotted, scaled to the seismic moment. Earthquake parameters used for the computation of synthetic seismograms are listed in Table 4. STF is the source time function. The amplitude scale is in microns. Open square is the $T$ axis, solid square is $P$ axis.

NIL P NAI P CHG SH QUE SH NAI SH CMC SH

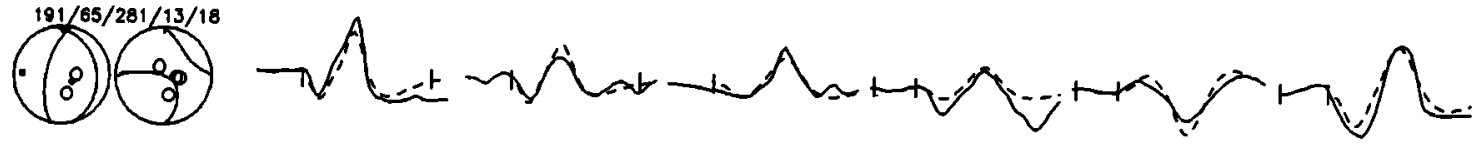

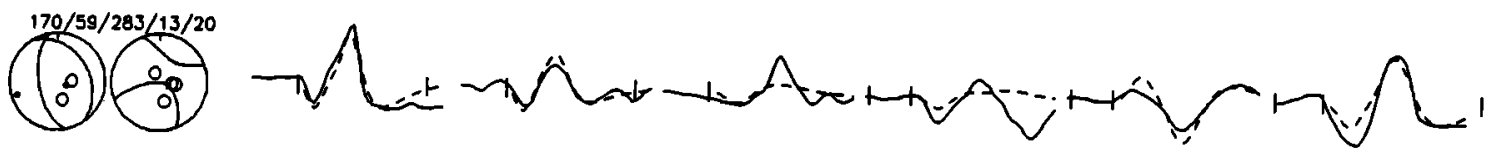

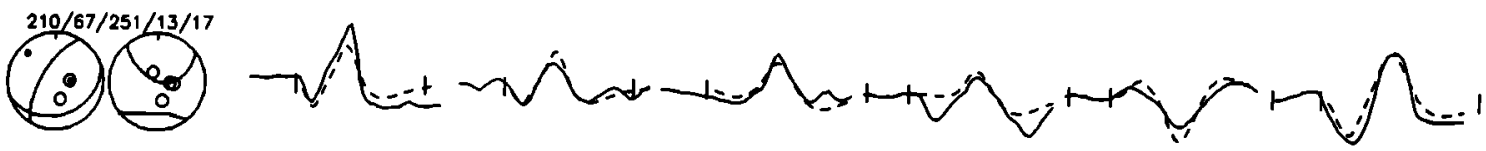

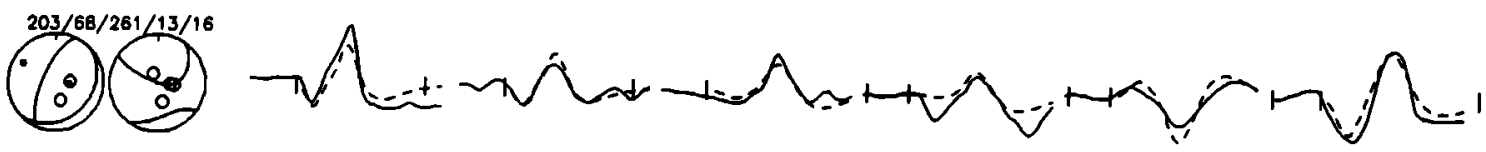

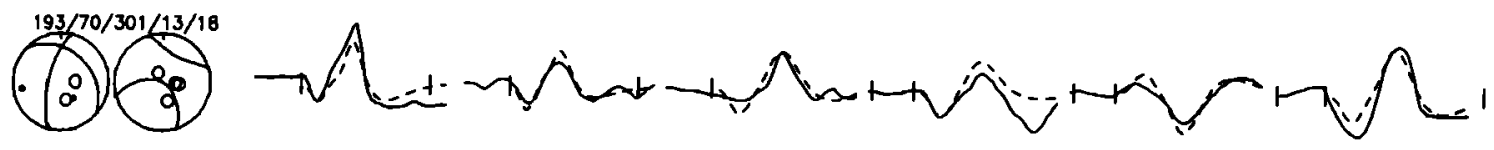

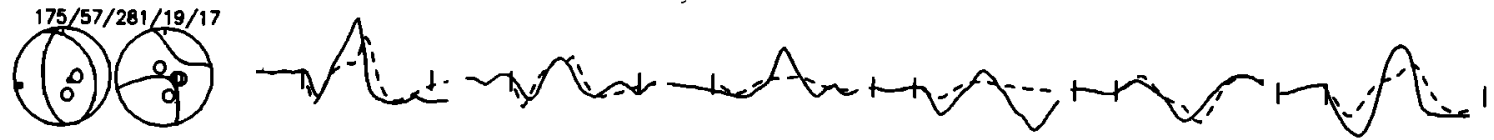

Fig. A2. Sensitivity of waveforms to variations in strike and rake at six selected stations. Row 1 is the solution shown on Figure A1. Rows 2-5: one parameter was fixed (rows 2-3: strike, rows 4-5: rake) and waveforms were inverted for the remaining ones. Numbers on top of the focal spheres are strike/dip/rake/depth/moment $\times 10^{16}$. 
Acknoudedoments. We thank the Earthquake Planning and Protection Organisation (OAII) of Greece and the Greek Army for their efficient help during fleld work and P. Bernard, A. Deschamps, and D. Hatzfeld for fruitful discussions. R. Madariaga and $P$. Tapponnier critically read the manuscript and suggested improvements. Drafting was done by G. Aveline. This work was funded by the Institut National des Sciences de l'Univers and we thank G. Aubert and J.C. Rossignol for its prompt organisation. This is contribution IPGP ${ }^{\circ} 1041$.

\section{REFERENCES}

Angelier, J., Néotectonique de l'arc égéen, thèse d'état, 405 pp., Univ. Paris VI, 1979

Angelier, J., N. Lyberis, X. Le Pichon, E. Barrier, and P. Huchon, The tectonic development of the hellenic arc and the sea of Crete: A synthesis, Tectonophysics, 86 159-196, 1982.

Arabasz, W.J., R.B. Smith, and W.D. Richins, Earthquake studies along the Wasatch front, Utah: Network monitoring, seismicity and seismic hazards, Bull. Seiomol. Soc. Am, 70, 14791499, 1980.

Armijo, R., A. Deschamps, and J.P. Poirier, Carte sismotectonique de l'Europe et Bassin méditerranéen, Inst. de Phys. du Globe, Paris, 1986.

Bernard, P., and A. Zollo, The Irpinia, Italy, 1980 earthquake: Detailed analysis of a complex normal faulting, J. Geophys. Res., in press, 1988.

Bounif, A., H. Haessler, and M. Meghraoui, The Constantine (northeast Algeria) earthquake of October, 27 1985: Surface ruptures and aftershocks study, Earth Planet. Sci. Lett., 85, 451$460,1987$.

Chase, C. G., Plate kinematics: The Americas, East Africa and the rest of the world, Earth Planet. Sci. Lett., S7, 355-368, 1978.

Chen, W.P., and P. Molnar, Focal depths of intracontinental and intraplate earthquakes and their implications for the thermal and mechanical properties of the lithosphere, J. Geophys. Res., 82, 2945-2969, 1983.

Delibassis, N., J. Makris, and J. Drakopoulos, Crustal and upper mantle structure of westem Greece, Ann. Ged. Pays Hell, 39 (2), 47-61, 1988.

Deschamps, A., and G.C. King, Aftershocks of the CampaniaLuciana (Italy) earthquake of 23 November 1980, Bull. Seiomol. Soc. Am, 74, 2483-2516, 1984.

Deschamps, A., G. Iannaccone, and R. Scarpa, The Umbrian earthquake (Italy) of 19 September 1979, Anm. Geophys., 2 (1), 29-36, 1984.

Driewonski, A.M., and D.L. Anderson, Preliminary reference Earth model, Phys. Earth Planet. Inter., 25, 297-356, 1981.

Dziewonski, A.M., and J.H. Woodhouse, An experiment in systematic study of global seiemicity: Centroid-moment tensor nolutions for 201 moderate and large earthquakes of 1981, J. Geophys. Res., 88, 3247-3271, 1983.

Dziewonski, A.M., G. Ekström, J.E. Franzen, and J.H. Woodhouse, Centroid moment tensor solutions for July-September 1986, Phys. Earth Planet. Inter., 46, 305-315, 1987.

Granier, T., Origin, damping, and pattern of development of faults in granite, Tectonics, 4, 721-738, 1985.

Hatzfeld, D., A. Christodoulou, E. Scordilis, D. Panagiotopoulos, and P. Hatzidimitriou, A microearthquake study of the Mygdonian graben (northern Greece), Earth Planet. Sci. Lett., $81,379-396,1987$.

Institute of Geology and Mineral Exploration, Geological map of Greece, Kalamata sheet, scale 1:50 000, Athens, 1986.

Jackeon, J.A., and D. McKenzie, The geometrical evolution of normal fault systems, $J$. Struct. Geol, 5, 471-482, 1983.

Jackson, J.A., and D. McKenvie, The relationship between plate motions and seismic tensors, and the rate of active deformation in the Mediterranean and Middle East, Geophys. J., 99, 45-73, 1988.

Jackeon, J.A., J. Gagnepain, G. Houseman, G.C. King, P. Papadimitriou, C. Soufleris, and J. Virieux, Seismicity, normal faulting and the geomorphological development of the gulf of Corinth (Greece): The Corinth earthquakes of February and March 1981, Earth Planet. Sei. Lett., 57, 377-397, 1982.

Jaeger J.C., and N.G. Cook, Fundamentals of Rock Mechanics, 593 pp., Chapman and Hall, London, 1979.

Kanamori, H., and D.L. Anderson, Theoretical basis for come empirical relations in seismology, Bull. Seiomol. Soc. Am, 65, 1073-1095, 1975.

King, G., Z. Ouyang, P. Papadimitriou, A. Deachamps, J. Gagnepain, G. Houseman, J. Jackson, C. Soufleris, and J. Virieux, The evolution of the gulf of Corinth (Greece): An aftershock study of the 1981 earthquakes, Geophys. J. R. Astron. Soc., 80, 677-693, 1985.

Lee, W.H.K., and J.C. Lahr, HYPO71: A computer program for determining hypocenter, magnitude and first motion pattern of local earthquakes, U.S.Geol.Surv. Open File Rep.,pp. 75-311, 1975.

Le Pichon, X., and J. Angelier, The Hellenic arc and trench system: A key to the neotectonic evolution of the eastern Mediterranean area, Tectonophysics, 60, 1-42, 1979.

Lyberis, N., Géodynamique du domaine égéen depuis le Miocène supérieur, thèse d'état, Univ. Paris VI, 1984.

Lyberis, N., J. Angelier, E. Barrier, and S. Lallemant, Active deformation of a segment of arc: The strait of Kythira, Hellenic arc, Greece, J. Struct. Geol., A, 299-311, 1982.

Makris, J., The crust and upper mantle of the Aegean region from deep seismic sounding, Tectonophysics, 46, 269-284, 1978.

McCaffrey, R., and J. Nabxlek, Earthquakes, gravity and the origin of the Bali Basin: An exemple of a nascent continental fold and thrust belt, J. Geophys. Res., 98, 441-460, 1987.

McKenzie, D., Active tectonics of the Mediterranean region, Geophys. J. R. Astron. Soc., SO, 109-185, 1972.

McKenzie, D., Active tectonics of the Alpine-Himalayan belt: the Aegean Sea and surrounding regions, Geophys. J. R. Astron. Soc., $55,217-254,1978$.

Meisener, R., and J. Strehlau, Limits of etresses in continental crust and their relation to the depth-frequency distribution of shallow earthquakes, Tectonics, 1, 73-89, 1982.

Mercier, J.L., N. Delibassis, A. Gauthier, J.J. Jarrige, F. Lemeille, H. Philip, M. Sébrier, and M. Sorel, La néotectonique de l'arc égéen, Rev. Geol. Dym. Geogr. Phys., 21, 67-92, 1979a.

Mercier, J.L., N. Mouryaris, C. Simeakis, T. Roundoyannis, and C. Angelidhis, Intraplate deformation: A quantitative study of the faults activated by the 1978 Thessaloniki earthquakes, Nature, 278, 45-48, 1979b.

Nábělek, J., Determination of earthquake source parameters from inversion of body waves, Ph.D. thesis, 361 pp., Mass. Inst. of Technol., Cambridge, 1984.

Ouyed, M., G. Yielding, D. Hatzfeld, and G.C. King, An aftershock study of the El Asnam (Algeria) earthquake of $1980 \mathrm{Oc}$ tober 10, Geophys. J. R. Astron. Soc., 79, 605-639, 1983.

Papazachos, B., A. Kiratzi, B. Karacostas, D. Panagiotopoulos, E. Scordilis, and D.M. Mountrakis, Surface fault traces, fault plane solution and spatial distribution of the aftershocks of the September 13, 1986 earthquake of Kalamata (southern Greece), Pure Appl. Geophys., 126, 55-68, 1988.

Richins, W.D., J.C. Pechmann, R.B. Smith, C.J. Langer, S.K Goter, J.E. Zollweg, and J.J. King: The 1983 Borah Peak, Idaho, earthquake and its aftershocks, Bull. Seismol. Soc. Am., $77,694-723,1987$.

Ryan, W.B.F., K.A. Kastens and M.B. Cita, Geological evidence conceming compressional tectonics in the eastern Mediterranean, Tectonophysics, 86, 213-242, 1982.

Scholz, C.H., Scaling laws for large earthquakes. Consequence on 'physical models, Bull. Seismol. Soc. Am., 7R, 1-14, 1982.

Sébrier, M., Tectonique récente d'une transversale à l'arc égéen, (le golfe de Corinthe et ses régions périphériques), thèse de 3ème cycle, Univ. d'Orsay, France, 1977.

Soufleris, C., and G.S. Stewart, A source study of the Thessaloniki (N. Greece) 1978 earthquake sequence, Geophys. J. R. Astron. Soc., 67, 343-358, 1981.

Soufleris, C., J.A. Jackson, G.C.P. King, C.P. Spencer, and C.H. Scholz, The 1978 earthquake sequence near Thessaloniki (northern Greece), Geophys. J. R. Astron. Soc., 68, 429-458, 1982.

Tapponnier, P., Evolution tectonique du systeme alpin en Méditerranée: Poinçonnement et écrasement rigide-plastique, Bull. Soc. gél. Fr., 7, 437-460, 1977.

Tchalenko, J.S., Similarities between shear zones of different magnitudea, Geol. Soc. Am. Bull., 81, 1625-1640, 1970.

UNESCO, International Bathymetry Chart of the Mediterranean, scale 1:1,000, 000, 1981. 
Westaway, R.W.C., and J. Jackson, The earthquake of 1980 November 23 in Campania-Basilica, Geophys. J. R. Astron. Soc., 90, 375-443, 1987.

Zandt, G., and T.J. Owens, Crustal flexure associated with normal faulting and implications for seismicity along the Wasatch fault, Utah, Bull. Seiomol. Soc. Am, 70, 1501-1520, 1980.

R. Armijo, Laboratoire de Tectonique, Institut de Physique du Globe de Paris, 4 Place Jussieu, 75252 Paris Cedex 05, France.

J. Baskoutass, J. Drakopoulos, J. Latoussakis, and D. Papanastassiou, Seismological Institute, National Observatory of Athens, Athens, Greece.
N. Delibassis, V. Kouskouna and K. Makropoulos, Division of Geothermy, University of Athens, 15784 Ilissia, Athens, Greece.

R. Gaulon, H. Lyon-Caen, and P. Papadimitriou, Laboratoire de Sismologie, Institut de Physique du Globe de Paris, 4 place Jussieu, 75252 Paris Cedex 05, France.

G. Pedotti, Observatoire de Grenoble, IRIGM, B.P. 63X, 38041 Grenoble Cedex, France.

(Received December 4, 1987; revised July 26, 1988; accepted August 17, 1988.) 


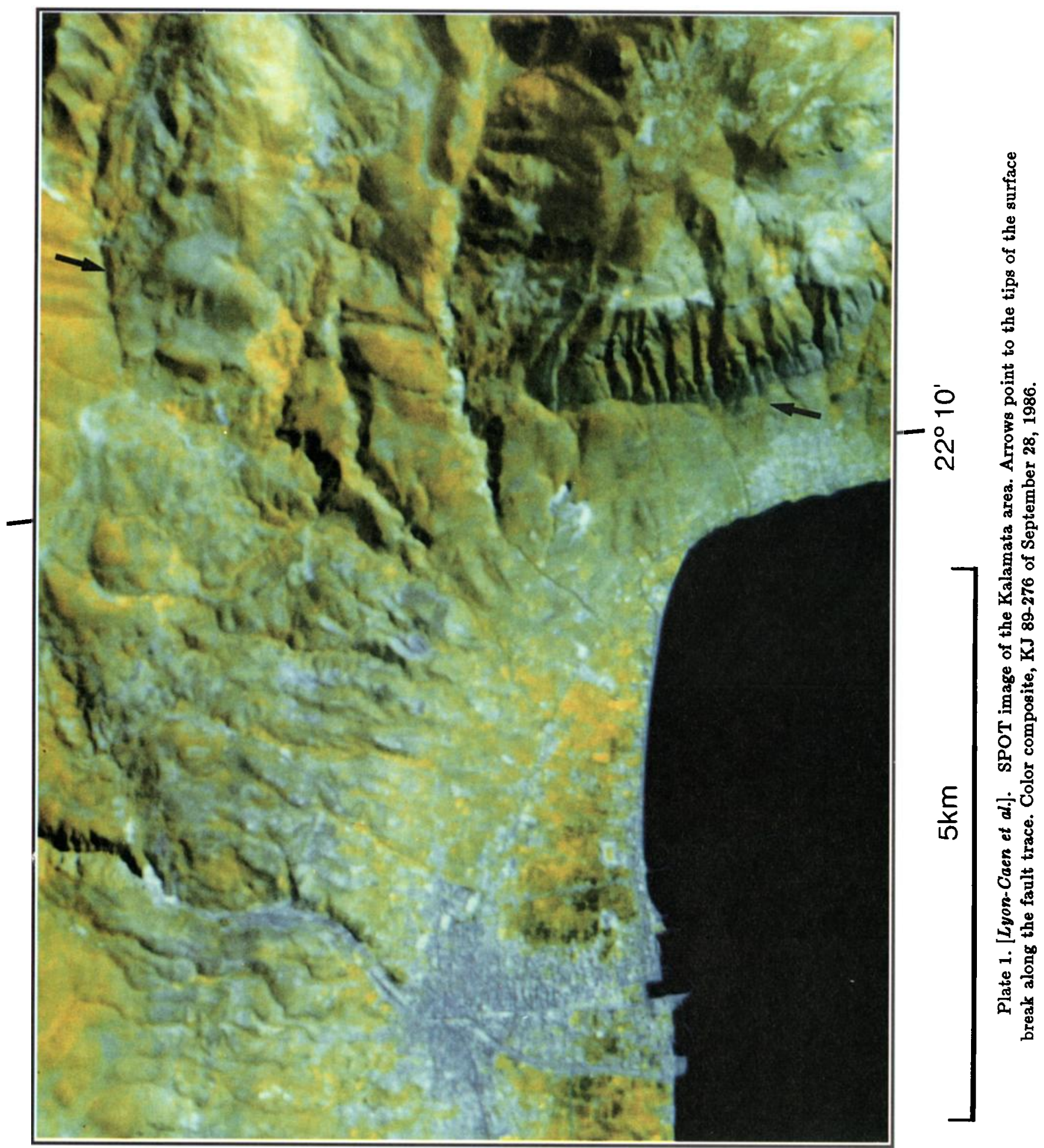

